Georgia State University

ScholarWorks @ Georgia State University

Spring 5-10-2014

\title{
Biocultural Consequences of Spanish Contact in the Lambayeque Valley Region of Northern Peru: Internal Enamel Micro-defects as Indicators of Early Life Stress
}

Carey James Garland

Georgia State University

Follow this and additional works at: https://scholarworks.gsu.edu/anthro_theses

\section{Recommended Citation}

Garland, Carey James, "Biocultural Consequences of Spanish Contact in the Lambayeque Valley Region of Northern Peru: Internal Enamel Micro-defects as Indicators of Early Life Stress." Thesis, Georgia State University, 2014.

doi: https://doi.org/10.57709/5519791

This Thesis is brought to you for free and open access by the Department of Anthropology at ScholarWorks @ Georgia State University. It has been accepted for inclusion in Anthropology Theses by an authorized administrator of ScholarWorks @ Georgia State University. For more information, please contact scholarworks@gsu.edu. 


\title{
BIOCULTURAL CONSEQUENCES OF SPANISH CONTACT IN THE LAMBAYEQUE \\ VALLEY REGION OF NORTHERN PERU: INTERNAL ENAMEL MICRO-DEFECTS AS \\ INDICATORS OF EARLY LIFE STRESS
}

by

\author{
CAREY JAMES GARLAND
}

Under the Direction of Bethany L. Turner-Livermore

\begin{abstract}
This study utilizes dental histological methods to analyze enamel micro-defects (Wilson bands) as indicators of early life stress in indigenous Muchik individuals interred at two sites: La Capilla Santa María Magdalena De Eten (CSMME) (n=15) and La Capilla Del Niño Serranito (CNS) $(\mathrm{n}=15)$, both located in the Lambayeque region of northern Peru. Individuals interred at CNS date to the Early Colonial Period (A.D. 1533-1620) and individuals interred at CSMME date to the Middle/Late Colonial Period (A.D. 1620-1760). Results reveal a fairly high prevalence of Wilson bands at both sites, with a lower prevalence at CSMME. This indicates that, over time, Muchik individuals may have been able to acclimate to life under Spanish oppression. Stress chronologies suggest that early life stress possibly resulted from inadequate and less than desirable food and/or water available for supplemental feeding during early infancy, especially around the ages of 4 and 5 months.
\end{abstract}

INDEX WORDS: Spanish Contact, Bioarchaeology, Dental histology, Stress, Lambayeque 


\section{BIOCULTURAL CONSEQUENCES OF SPANISH CONTACT IN THE LAMBAYEQUE VALLEY REGION OF NORTHERN PERU: INTERNAL ENAMEL MICRO-DEFECTS AS INDICATORS OF EARLY LIFE STRESS}

by

CAREY JAMES GARLAND

A Thesis Submitted in Partial Fulfillment of the Requirements for the Degree of

$$
\text { Master of Arts }
$$

in the College of Arts and Sciences

Georgia State University 
Copyright by

Carey James Garland 2014 


\section{BIOCULTURAL CONSEQUENCES OF SPANISH CONTACT IN THE LAMBAYEQUE VALLEY REGION OF NORTHERN PERU: INTERNAL ENAMEL MICRO-DEFECTS AS INDICATORS OF EARLY LIFE STRESS}

by

CAREY JAMES GARLAND

Committee Chair: Bethany L. Turner-Livermore

Committee:

Jeffrey B. Glover

Frank L. Williams

Electronic Version Approved: April 10, 2014

Office of Graduate Studies

College of Arts and Sciences

Georgia State University

May 2014 


\section{ACKNOWLEDGEMENTS}

First, I would like to gratefully acknowledge and thank Dr. Bethany Turner-Livermore and Dr. Haagen Klaus for allowing me to take part in this project and to conduct my research on samples from and CNS and CSMME; it was an honor to have been able to take part in reconstructing the life histories and providing a voice to indigenous individuals that lived in Eten, Peru during the Spanish Contact periods. I would also like to thank the continued support and encouragement of my awesome thesis committee members, Dr. Bethany Turner-Livermore, Dr. Frank L. Williams, and Dr. Jeffrey Glover; their ongoing support provided me with enough confidence to feel as if I could conquer anything! Furthermore, my thesis project, and graduate school in general, would not have been the same without support and entertainment from cohort Keegan T. Brooks and Daniel S. Jones, especially for the countless amount of times they were unwillingly forced to proof read my thesis and term papers. I must also acknowledge and thank my wife, Amber Carpenter, and daughter, Luna Wren, for being extremely patient with me over the last few months as I dedicated so much, if not too much, of my time to my thesis work. You guys can have me back now....at least for a little while! Last but not least, Thank You to the rest of my graduate cohort for making the last two years of my life a truly amazing experience. 


\section{TABLE OF CONTENT}

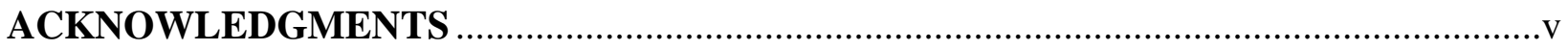

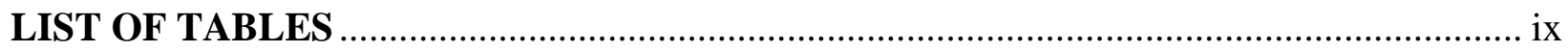

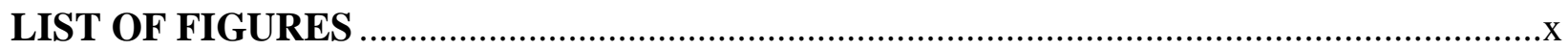

CHAPTER 1: INTRODUCTION

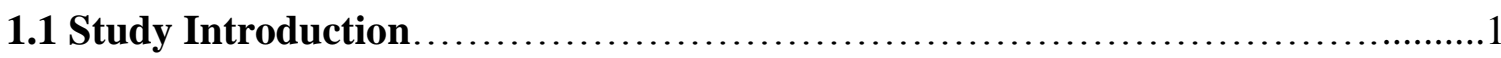

1.2 Reconstructing Life in the Andes: Balancing Conflicting

Accounts of Life in Pre-Hispanic and Colonial Peru with

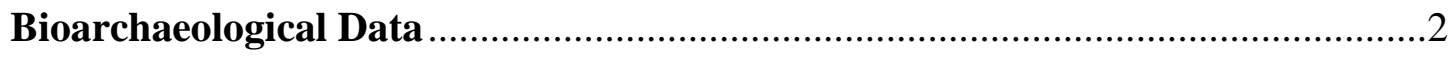

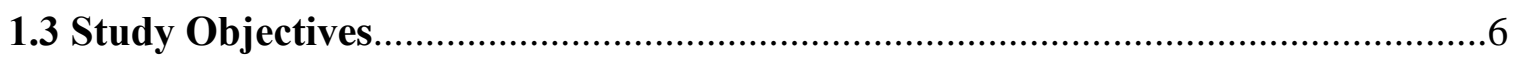

1.3.1 Research Questions and Hypotheses .......................................................8

\section{CHAPTER 2: THEORIES AND METHODS IN BIOARCHAEOLOGY}

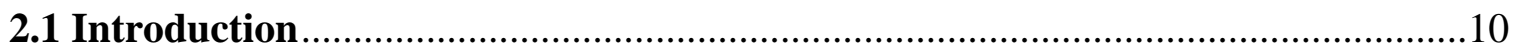

2.1.1 Physiological Stress: Dental Indicators of Disruptions in

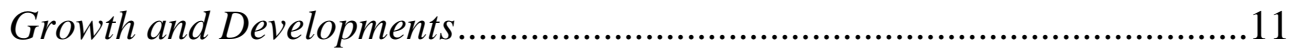

2.1.2 Skeletal Indicators of Physiological Stress and Disease ...........................18

2.1.3 Stable Isotopic Analysis and Dietary Reconstruction: The Link

Between Diet and Disease ..................................................................20

2.2 The Bioarchaeology Stress and Health: Theoretical Perspectives .....................21

2.2.1 Theoretical Perspectives on Health in Archaeological Populations ............22

2.2.2 Major Stressors across Different Life Periods ........................................24

2.3 The Bioarchaeology of Spanish Contact in the Americas ..............................25 
CHAPTER 3: ANDEAN GEORGRAPHY AND CULTURAL ECOLOGY

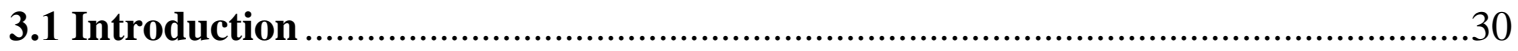

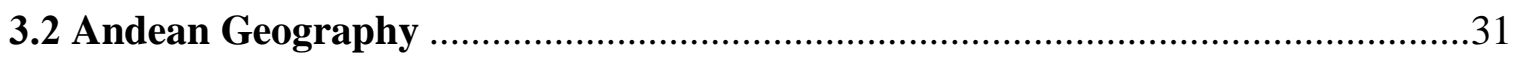

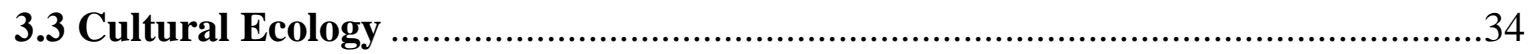

3.4 Lambayeque Valley Complex Ecology and Subsistence Strategies......................36

\section{CHAPTER 4: CULTURAL DEVELOPMENTS IN PERU}

4.1 Introduction: Culture Developments in Pre-Hispanic Peru ................................39

4.2 Early Sociopolitical Structures and Subsistence Economies of Northern Peru ....39

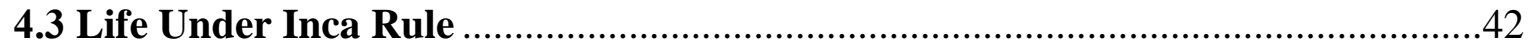

4.4 The Spanish Colonization of Peru ...........................................................45

4.4.1 Spanish Arrival and the Early Contact Period .........................................47

4.4.2 Political, Social, Economic and Ecological Transformations in the

Lambayeque Valley Region .............................................................50

\section{CHAPTER 5: REASEARCH DESIGN}

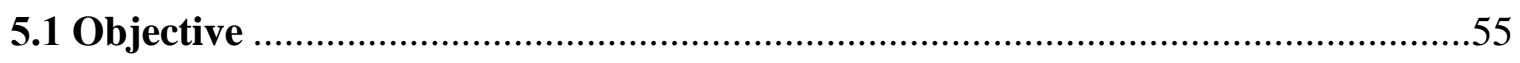

5.2 Site History and Excavations of CSMME and CSMME-CNS ........................55

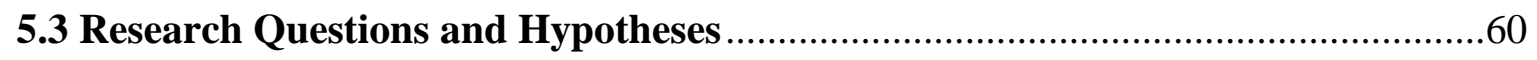

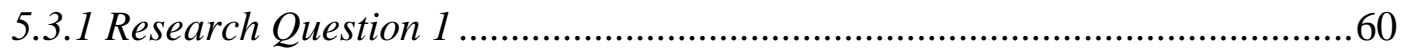

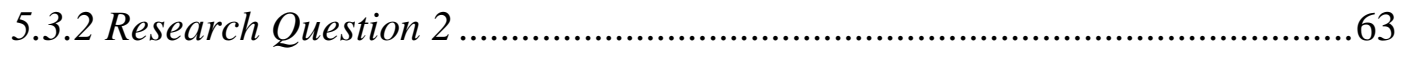

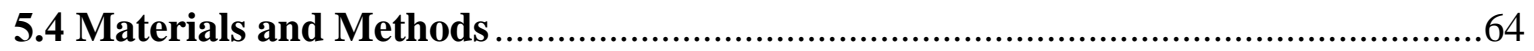




\section{CHAPTER 6: RESULTS AND DISCUSSION}

6.1 Thin Sectioning Results: Prevalence and Chronology of Wilson Bands

6.1.1 Prevalence of Wilson bands and Number of Wilson Bands per

Individual .68

6.1.2 Chronology of Wilson Bands

6.2 Testing the Barker Hypothesis: Wilson Bands as Indicators of

Early Mortality

6.3 Testing the Barker Hypothesis: Enamel Hypoplasias as Indicators of

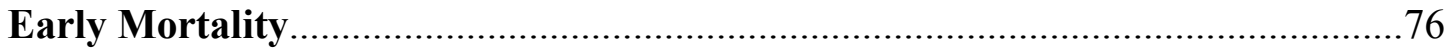

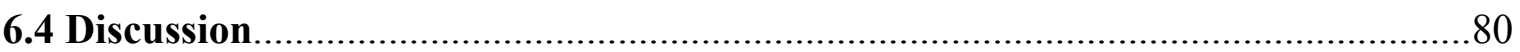

6.4.1 Early Life Stress in the Lambayeque Valley Region of Northern Peru .........80

6.4.2 Barker Hypothesis: Enamel Defects as Indicators of Early Mortality ..........87

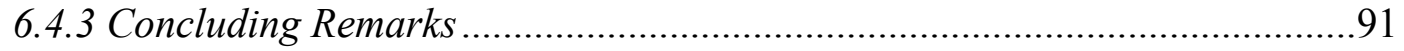

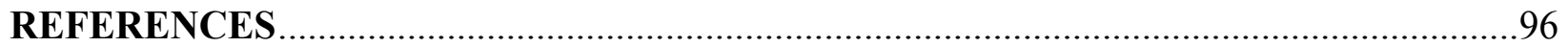

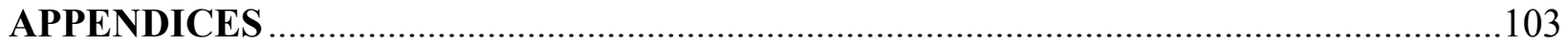




\section{LIST OF TABLES}

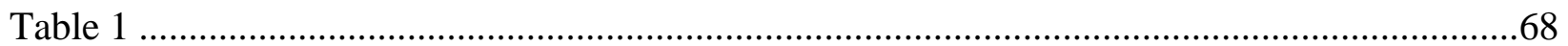

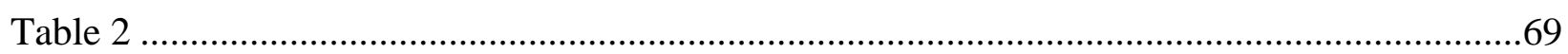

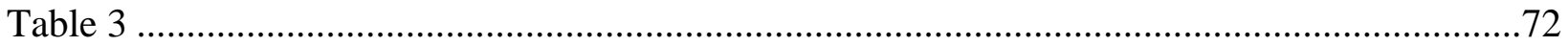

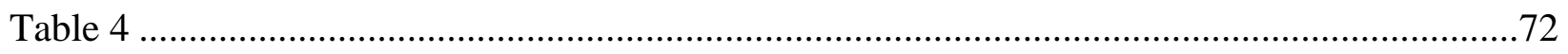

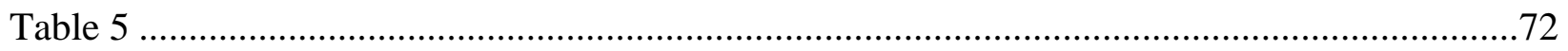

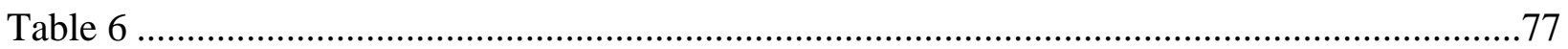

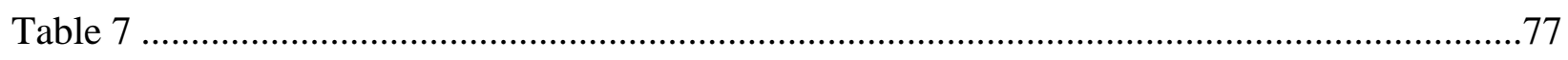

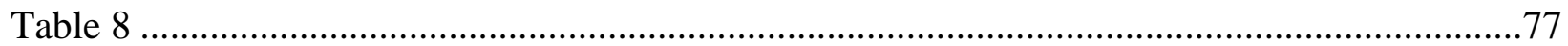

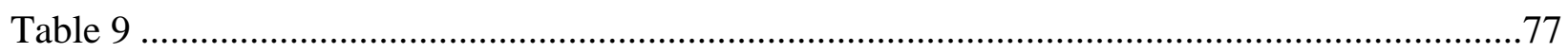

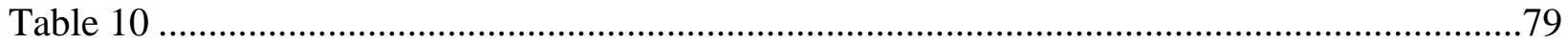




\section{LIST OF FIGURES}

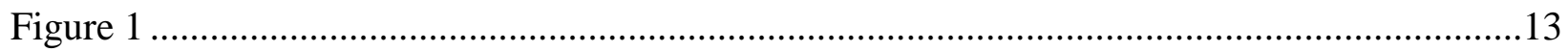

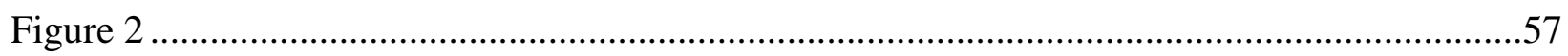

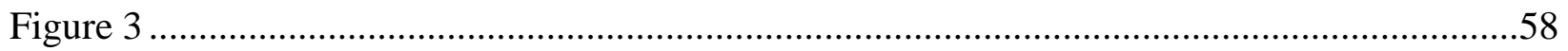

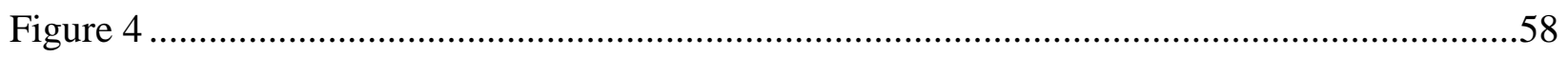

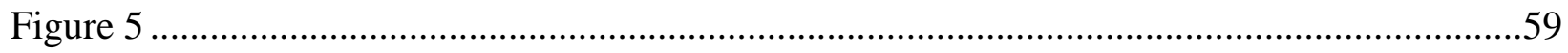

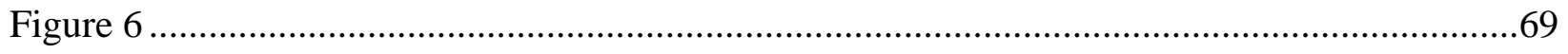

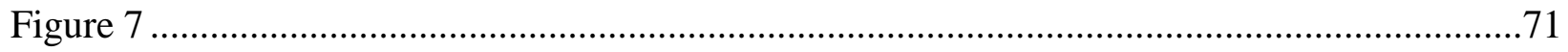

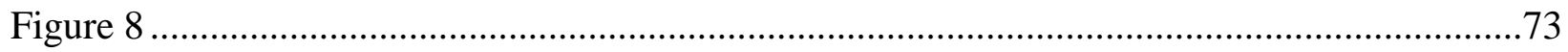

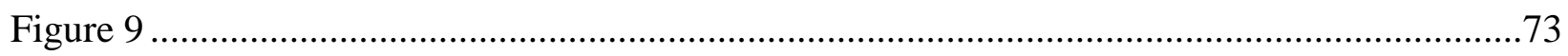

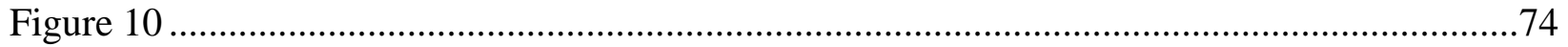

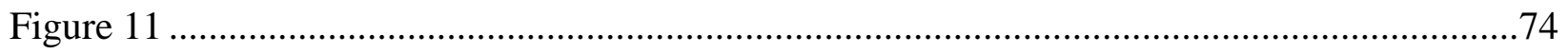

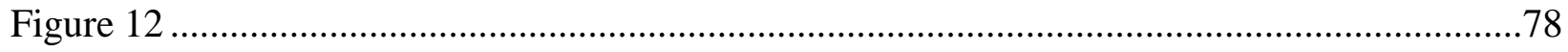

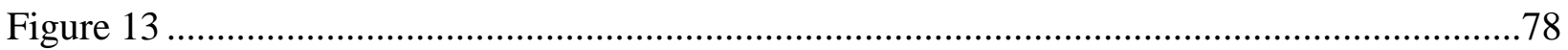




\section{CHAPTER 1: INTRODUCTION}

\subsection{Study Introduction}

The Central Andes of pre-Hispanic Peru were home to a number of distinct cultures that developed "complex and sophisticated" ways of life to overcome the environmental constraints of Peru's disparate and complex geographical landscapes (Hagen and Morris 1998:14). Among this diverse array of Andean cultures were the Muchik, a population inhabiting the Lambayeque Valley region of northern Peru. In September of 1532, the Spanish conquistador Francisco Pizarro and his Castilian mercenaries entered the Lambayeque region of Peru for the first time, most likely making contact with a Muchik fishing village, Atim (Klaus and Alvarez-Calderón in press). Thirteen months later, the Inca city of Cusco had fallen under the control of the Spanish, which subsequently led to the permanent Spanish colonization of Peru (Klaus 2008:283). The European colonization of Peru, and the Americas in general, is often described as a "total biocultural phenomenon," representing one of the most influential historical processes that shaped the world as we know it (Deagan 2003:3; Klaus and Tam 2009:356). This process was fast and unexpected, bringing together two groups of people who had no idea of each other's existence prior to Pizarro landing on the western coast of South America in 1530 (Deagan 2003:3). During this time, a series of biocultural transformations began to unfold, forever altering the established lifeways of indigenous Andean populations (Klaus and Tam 2009:356). In many instances, these transformations included the altering of Andean modes of production, technology, commerce, religion, social hierarchies and patterns of diet and disease (Andrien 2001:2). These alterations subsequently led to not only environmental degradation in the Lambayeque region, but also the socioeconomic disarticulation and political destabilization 
of many Andean cultures, often pushing them on a downward slope into resource-restricted poverty (Andrien 2001:2; Ramirez 1996).

The premise of this study is to employ a bioarchaeological method to infer correlations between socioeconomic inequality, early life stress, and negative health outcomes of Muchik individuals that lived in post-contact Peru. More specifically, this study utilizes dental histological methods to analyze internal enamel micro-defects known as Wilson Bands in Muchik individuals interred at two sites: La Capilla Santa María Magdalena De Eten (CSMME) and La Capilla Del Niño Serranito (CNS), both located in the coastal town of Eten in the Lambayeque Valley region of northern Peru (see Figure 2, page 57). Furthermore, utilizing the Barker hypothesis, this study investigates whether or not enamel defects are associated with early mortality. It is hypothesized that the Muchik population at Eten suffered negative health outcomes and higher morbidity rates as a result of economic, social, and political transformations that unfolded during the Early to Late Colonial Periods. This should be revealed by comparing the prevalence of dental stress markers between the Early and Late Colonial Periods. As will be discussed in Chapter 4, these transformations ultimately lead to inequality amongst indigenous populations and the Spanish colonizers and thus alterations in indigenous subsistence patterns and access to natural resources.

\subsection{Reconstructing Life in the Andes: Balancing Conflicting Accounts of Life in Pre- Hispanic and Colonial Peru with Bioarchaeological Data}

Like all other ancient Andean civilizations, the Muchik never developed a formal system of writing and therefore left no written record to narrate human life experiences in pre-contact and post-contact Peru. However, according to Hagen and Morris (1998:201), three principal tools are widely used to help reconstruct and interpret life in the ancient Andes: ethnohistorical 
accounts recorded by sixteenth-century Spanish chroniclers, the ethnographic observation of modern analogs, and archaeological techniques and analyses. Spanish chronicles of the Americas, primarily written by priests, bureaucrats and soldiers such as Father Bernabé Cobo (1653 [1990]) and Pedro De Cieza de León (1537 [1999]), provide valuable historical details of life in pre-contact Peru, especially indigenous accounts of Inca politics, economy, ideology (Andrien 2001:5; Hagen and Morris 1998:201; Turner 2008:1). These historical chronicles, supplemented by administrative documents, census data, ecclesiastical sources, treasury accounts, wills and testimonies, also reveal "transformations, conflicts and challenges" in postcontact Peru (Hagen and Morris 1998:201; Klaus 2008:282). That said, these ethnohistorical accounts of European colonialism in Peru are, for the most part, dominated by Spanish chronicles and documents that frequently neglect the Native Americans' points of view (Ramirez 1996:1; Turner 2008). Thus, historical narratives based on the etic perspectives of the Spanish most likely provide ethnocentric, limited, and/or misrepresented portrayals of indigenous life and beliefs in pre-Hispanic and Colonial Peru.

Archaeological and bioarchaeological analyses of material and human remains have proved to be effective tools to balance limited and often biased accounts of pre- and post-contact Peru (Deagan 2003; Ramirez 1996). These investigations provide insight into the indigenous perception of Spanish domination and colonization by allowing for a perspective that does not interpret the Andean way of life within a "Christian European framework" (Ramirez 1996:4). In other words, archaeological and bioarchaeological analyses provide an alternative portrayal of how Andean life was transformed during European colonization by not only reconstructing and interpreting life in pre-Hispanic Peru, but also by emphasizing how indigenous life was disassembled and turned upside down by Spanish social, political, environmental and ecological 
transformations. For instance, hundreds of indigenous communities in Colonial Peru were forcefully moved and relocated into dense colonial towns in order to provide labor for the extraction of natural resources (Andrien 2001; Klaus 2008; Klaus and Tam 2009; Ramirez 1996). The Lambayeque region, specifically, was transformed into "colonial ranches," or “colossal haciendas," with labor being allocated towards the extraction and/or production of resources such as sugar cane and alfalfa, along with the herding of cattle and raising of swine (Klaus and Tam 2009:357). As will be discussed in subsequent chapters, Spanish policies, such as the resettlement of indigenous communities into colonial towns known as reducciónes, resulted in the breakdown of political structures and cultural traditions, environmental degradation, and to the spread of epidemic diseases (Deagan 2003:5; Klaus 2008:325).

An overarching negative consequence of the Spanish colonization of Peru, and the European colonization of the Americas in general, is the increase in indigenous biological stress due to these social, political, and environmental/ecological transformations (Klaus 2008:4; Klaus and Tam 2009:356-357). However, biocultural responses, such as increases in stress and declines in health, did not occur uniformly (Baker and Kealhofer 1996:1; Klaus and Tam 2009:356). According to Klaus and Tam (2009:356), health was shaped by the duration and intensity of Spanish contact and associated socioeconomic transformations. This is apparent in the high variability of biological and cultural responses to European contact as revealed through bioarchaeological investigations. Some populations experienced a rapid "cultural and demographic collapse" while other populations were more resilient (Baker and Kealhofer 1996:1). Given this variation, an important question is, how can bioarchaeological studies be used to investigate possible correlations between indigenous biological stress and social, political and ecological transformation brought about by Spanish colonization? 
Bioarchaeological methods, including the examination of internal and surface enamel growth defects, stable isotopic analysis, and the analysis of skeletal markers of deprivation and disease, have become central in the study of disease, levels of stress, and the nutritional status of past populations. These methods considered together emphasize a need for an interdisciplinary approach that examines multiple independent, but complementary, indicators of diet, stress and disease in order to reconstruct past life histories, and, as Simpson (1991:241) states, provide a model to understand patterns of adaptation in past populations. Dental histology, specifically, has proved to be a useful tool in the field of bioarchaeology to determine levels of nonspecific physiological stress in archaeological populations, thus providing a building block for the reconstruction of past life histories (Blakely and Armelagos 1985; FitzGerald and Saunders 2005; FitzGerald 1998; Marks and Rose 1996). Dental remains from bioarchaeological populations can provide almost "imperishable" records of past human behaviors (Clement 1968:245; Larsen and Kelly 1991:1). The excellent preservation of teeth relative to other parts of the body is due to chemical, biological and physical factors that have led to a hard, dense, and calcified dentition (Kelly and Larsen 1991:1). However, during dental development, human teeth are sensitive to internal and external factors that often leave markers reflecting early life stressors embedded in enamel (Goodman and Rose 1991:279; Reid and Ferrell 2006:195).

Generally, researchers have classified dental enamel defects as either internal microdefects or external surface hypoplasias (FitzGerald and Saunders 2005:277). Irregular striae of Retzius, also known as Wilson bands, are internal defects of enamel growth that have been used as indicators of a broad range of infant, juvenile and maternal stresses that are often due to infection or nutritional deficiencies, especially in regards to infant feeding practices (Fitzgerald et al 2006:185; Marks and Rose 1996:493). Studying internal enamel defects has several 
advantages over other indicators of stress. The primary advantages are that enamel does not remodel after injury, the defects can provide data on the duration of the stress, and, due to the rhythmical apposition of enamel layers revealed by incremental markers, one can record the developmental age at which a stress occurred (Armelagos and Blakely 1985:371; Larsen 1997:48; Larsen and Kelly 1991:1; Simpson 1991:241).

\subsection{Study Objective}

The objective of this thesis is to employ a bioarchaeological method to examine indicators of early life stress in skeletal remains from an Andean population that lived during the Spanish colonization of Peru. More specifically, this study utilizes dental histological methods to analyze internal enamel micro-defects (Wilson Bands) in Muchik individuals interred at two sites: the La Capilla Santa María Magdalena De Eten (CSMME) and the La Capilla Del Niño Serranito (CNS), both located in the coastal town of Eten in the Lambayeque Valley region of northern Peru (see Figure 2, page 57). Stratigraphic and archaeological evidence indicates that individuals interred at CNS date to the Early Colonial Period (A.D. 1533-1620) and individuals interred at the CSMME site date to the Middle/Late Colonial Period (A.D. 1620-1760) (Klaus and Alvarez-Calderón - in press). The CNS burial sample includes 253 burials representing 450 individuals from the Early Colonial Period and the CSSME burial sample includes 256 burials representing 308 individuals from the Middle/Late Colonial Period (Klaus and Alvarez-Calderón - in press). Of these 509 burial samples, 15 subsamples from each site have been selected for this research project. In sum, these two sites represent the same ethnic group yet different occupational phases, therefore providing a diachronic perspective to compare patterns of stress during the Early and into the Middle/Late Colonial Periods. 
The examination of internal micro-defects in Muchik individuals interred at these two sites permits a comparative analysis to shed more light on challenges faced by indigenous populations as political, social, and ecological transformations unfolded during the Spanish contact, conquest and colonization of Peru. Furthermore, this comparative analysis provides a diachronic perspective to investigate how the indigenous Muchik population at Eten adapted to this transition. Based on the previous assertion that biocultural responses to European colonization were not uniform, the central question investigated here is, how did Muchik individuals adjust to life under Spanish domination? Were they negatively affected by Spanish transformations or were they resilient? This study is of particular importance because there have been few archaeological and bioarchaeological studies of Colonial Peru. As Klaus (2008:2) asserts, far more attention has been given to historical archaeology in North and Central America. Conversely, most of South American archaeologists have devoted their attention to pre-Columbian archaeology and, therefore, have not investigated the biocultural impacts of European contact in Peru. Adding a bioarchaeological perspective from South America through multiple lines of evidence will help create a "hemispheric-level understanding" of the biological consequences of European contact in the New World (Klaus and Alvarez-Calderón - in press). This study is also of importance because the Lambayeque Valley did not have a Spanish chronicler, and most of what is known about Colonial Eten is based on local oral history and lore. Therefore, adding a bioarchaeological perspective will help lend a voice to the Muchik individuals that inhabited the Lambayeque Valley region during the Spanish colonization of Peru. 


\subsubsection{Research Questions and Hypotheses}

1. Did early life biological stress (i.e. malnutrition and/or disease) increase from the Early to Middle/Late Colonial periods as a result of social, political, economic and ecological transformations that ensued after the Spanish colonization of Peru? It is hypothesized that early life biological stress increased as a result of the Spanish colonization of Peru. This should be revealed by not only a high prevalence of Wilson bands at both sites compared to published research elsewhere, but also by an increased prevalence of Wilson bands at CSMME in comparison to CNS.

2. Based on the constant periodicity of enamel apposition was there a common age at which stress occurred and what specific stressors could be causing the enamel defects? If common ages at stress events exist, can these stress events be correlated to any particular stressor?

3. If physiological stress did increase in subadults, how did it impact adult health and longevity? Consistent with the Barker hypothesis, it is hypothesized that individuals with observed enamel hypoplasias and Wilson bands are associated with a younger age at death.

In sum, it is hypothesized that the Muchik population at Eten suffered increases in early life stress and thus negative health outcomes as a result of economic, social, and political transformations that ensued after the Spanish colonization of Peru. As stated, an increase in biological stress, possibly due to poverty and indigenous malnutrition in the Lambayeque region, should be revealed by a higher prevalence of Wilson bands in individuals interred at the CSMME site in comparison to individuals interred at the CNS site. The subsequent chapter 
provides an introduction to bioarchaeology and the theoretical position and methodological approach of this study. Chapter 3 elucidates Andean geography and pre-contact cultural ecology, while Chapter 4 provides the cultural contexts that drive the previously discussed research questions. Chapter 5 lays out the research design and specific methodologies used in this study and Chapter 6 provides the statistical results, concluding with a discussion of the results and original hypotheses. 


\section{CHAPTER 2: THEORIES AND METHODS IN BIOARCHAEOLOGY}

\subsection{Introduction}

Bioarchaeology is an emergent subfield within the discipline of anthropology that combines archaeological and biological anthropological methods to draw inferences about past human behavior based on skeletal remains. As Larsen (2001:72) states, the human skeleton is a "highly sensitive indicator of life experiences," providing records of growth and development and insight into diet, nutrition, disease, lifestyle and stress. Stress, defined as any physiological perturbation resulting from an array of environmental factors, is central to the study of health in archaeological populations (Larsen 2001:86). The growth and development of dental and skeletal tissues are easily disrupted if a negative environmental factor arises during the formation of a given tissue (Larsen 2002:126). Disruptions in dental enamel development, specifically, represent physiological perturbations during maternal and early childhood when the tooth crowns are in the process of forming. Methodological approaches to examine past human lifeways, and reconstruct patterns of stress specifically, include the examination of internal and surface enamel growth defects, stable isotopic analysis, and the analysis of skeletal markers of deprivation and disease. These methods considered together emphasize a need for a multi-methodological approach that examines independent, but complementary, indicators of diet, stress and disease in order to reconstruct past life health histories, and, as Simpson (1991:241) states, provide a model to understand patterns of adaptation in past populations. This chapter provides an overview of methodological approaches in bioarchaeology, elucidating how they can be used to infer stress and overall health in relation to ecological, social, and economic factors. As more directly related to the research at hand, this chapter primarily focuses on dental indicators of disruptions in growth and development, more specifically, enamel micro-defects and surface hypoplasias. 


\subsubsection{Physiological Stress: Dental Indicators of Disruptions in Growth and Development}

Dental anthropology provides a unique perspective to study the lifeways of past populations. This is due to the fact that dental remains from archaeological populations provide almost "imperishable" records of past human behaviors (Clement 1968:245; Hillson 1979:147; Larsen and Kelly 1991:1). As Baron Georges Cuvier once stated, "show me your teeth and I will tell you who you are" (Hillson 1996:1). Excellent preservation is attributed to chemical, biological and physical factors that have led to a hard, dense, and calcified dentition (Hillson 1979:147; Kelly and Larsen 1991:1). For this reason, dental remains from archaeological excavations are generally well preserved, even under conditions in which other parts of the skeleton do not survive (Hillson 1979:147). However, during dental development, human teeth are sensitive to internal and external factors that often leave markers of early life stressors embedded in enamel (Goodman and Rose 1991:279; Reid and Ferrell 2006:195). Enamel growth disruptions are used to determine levels of nonspecific physiological stress in archaeological populations, thus providing a building block for the reconstruction of past life histories (Blakely and Armelagos 1985; FitzGerald 1998; FitzGerald and Saunders 2005; Marks and Rose 1996).

Generally, researchers have classified dental enamel defects as either internal microdefects or external surface hypoplasias (FitzGerald and Saunders 2005:277). Irregular striae of Retzius, also known as Wilson bands, are internal defects of enamel growth that have been used as indicators of a broad range of infant, juvenile and maternal stresses that are often linked to infection or nutritional deficiencies (Marks and Rose 1996:493). Hypoplasias, also linked to disease and malnutrition, are surface defects in enamel growth that result in a reduction in enamel thickness. Studying enamel defects has several advantages over other indicators of 
stress. The primary advantages are that (1) enamel does not remodel after injury, (2) the defects can provide data on the duration of the stress, and, (3) due to the rhythmical apposition of enamel layers revealed by incremental markers, one can record the developmental age at which a stress occurred (Armelagos and Blakely 1985:371; Larsen 1997:48; Larsen and Kelly 1991:1; Simpson 1991:241).

Enamel crowns begin to form around four months in utero and are complete at 12-13 years of age when the crown of the permanent third molar is fully formed (Larsen 1997:48). Enamel production, which is controlled by epithelial cells known as ameloblasts, can be described as a rhythmical apposition of proteinaceous matrix from enamel crystals (Goodman and Rose 1991:280; Larsen 1997:43). This layering begins at the dentin-enamel junction (DEJ) and continues in a circadian rhythm to the surface of the tooth (Goodman and Rose 1991:280; Larsen 1997:47; Reid and Ferrell 2006:195). First, a tiny dome-like structure forms at the core of the future cusp around the dentine horns (Hillson 1992:119). Subsequent layers are added on top until the crown cusps are formed. Once the occlusal surface is complete, enamel layering proceeds in the imbricational area down towards the cervical margin until enamel formation ceases (Hillson 1992:121).

The primary enamel microstructures include enamel prism rods, cross striations, and regular striae of Retzius. Prism rods, as seen under a polarized light microscope, are alternating light and dark bands that run at a 120 degree angle from the DEJ to the grown surface. Hunter Schreger bands, representing undulations in groups of prisms, are seen as larger alternating dark and light bands radiating from the DEJ to the crown surface (Hillson 192:153) (see Figure 1 below). Cross striations, running perpendicular across prism rods, are incremental growth lines representing daily apposition of enamel matrix. Striae of Retzius are incremental bands that are 
marked by discontinuity in enamel matrix, causing light to be scattered when viewed under a light microscope (Hillson 1992:157) (see Figure 1 below). Typically, striae of Retzius are more sharply defined near the crown surface and are more poorly defined in deeper enamel closer to the DEJ. Furthermore, cross striations and striae of Retzius are closer together near the DEJ and get further apart as they approach the crown surface (Hillson 1992:155). A neonatal line and external perikymata are structures associated with striae of Retzius (Goodman and Rose 1991:280; Hillson 1979:148). A neonatal line is essentially the first accentuated stria of Retzius, or Wilson band, and represents the stress endured at the time of parturition. Perikymata are external grooves that represent the location where striae of Retzius terminate at the crown surface. Cross striations and regular striae of Retzius are both rhythmically formed and suggest constant periodicity of enamel matrix secretion (Hillson 1979:148; Reid and Ferrell 2006:196; Goodman and Rose 199:280). Cross striations are formed at a daily periodicity, while the formation of regular striae of Retzius is longer and varies between eight and ten days (Hillson 1979:148).

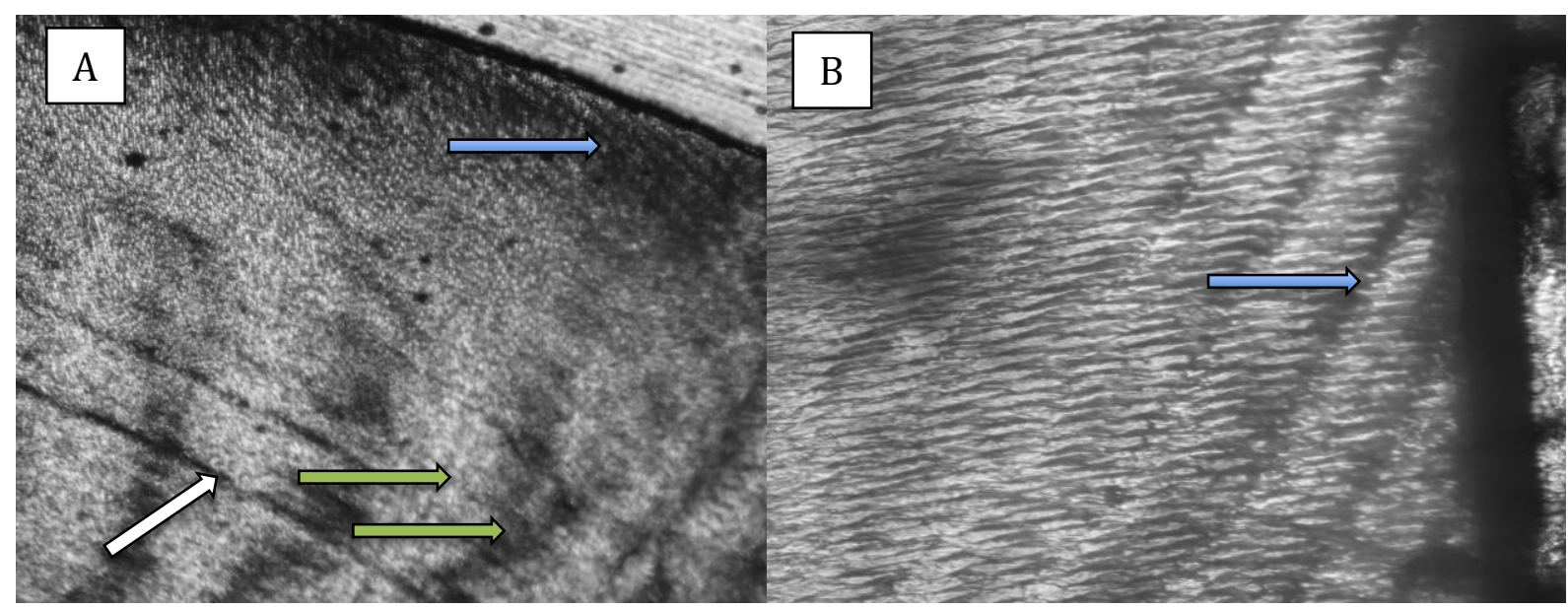

Figure 1: A-Enamel features including Wilson Band (White arrow at lower left), Hunter-Schreger bands (green arrows pointing to alternating dark and light bands), and striae of Retzius at the crown surface (blue arrow). B-Well defined striae of Retzius at the crown surface (blue arrow) (Photo credit: Garland 2014). 
Surface hypoplasias and Wilson bands are both developmental defects that result from disruptions in amelogenesis and thus enamel matrix formation (Goodman and Rose 1991:281). Enamel defects occur with the highest prevalence on the canine and are associated with external nonspecific stress. Wilson bands are layers of abnormal enamel development "marking the position of the active ameloblasts at the time of stress" (Larsen 1997:47). They are defined by their differences in relation to regular striae of Retzius and are typically broader in width, longer, and consist of an atypical prism structure (Fitzgerald and Saunders 2005:278). Regular striae of Retzius are incremental markers resulting from a cessation of enamel apposition. Wilson bands, therefore, can be characterized as regular striae of Retzius in which enamel cessation was increased due to external factors. As FitzGerald and Saunders (2005:278) articulate, the only difference between Wilson bands and regular striae of Retzius is the "nature of the systemic trigger that produced them."

Hypoplasias are described as decreases in enamel thickness that can be characterized as "small furrows" to "deep and wide troughs" on the enamel surface (Larsen 1997:45; Goodman and Rose 1991:281). Generally, hypoplasias run across the tooth surface as horizontal grooves and occur on the cervical and middle thirds of anterior teeth. Larsen (1997:46) argues that this suggests that specific teeth and specific regions on those teeth are more or less susceptible to growth disruptions. In contrast to hypocalcification, which results in color change, hypoplasias remain the same color as the surrounding enamel (Larsen 1997:45). Hypoplasias have been linked to hereditary anomalies, local traumas to the tooth, or systemic metabolic stressors (Goodman and Rose 1991:280). 
FitzGerald and Saunders (2005:278) discuss a number of studies over the past few decades that have hypothesized correlations between surface hypoplasias and Wilson bands. These studies have varied in their hypotheses and results. Some studies have proposed that enamel defects are proportional to their severity; this would suggest that Wilson bands result from short periods of "metabolic disturbances," while hypoplasias result from long term “systemic disturbances" (Larsen 1997:47; FitzGerald and Saunders 2005:278). Larsen (1997:47) argues that there is a lack of consistent evidence for associating macro- and micro-defects, thus suggesting that they have different etiologies. Other studies have observed Wilson bands being found on the cuspal edge of hypoplasias; therefore suggesting a correlation. Hillson and Bond (1997) argue that the appearance and size of enamel defects have more to do with the placement and position of the defect in the crown than the severity of the stressor. They continue by stating that microscopic defects are not different phenomenon from macroscopic defects. Instead, enamel defects usually exist on a continuum from a microscopic size to a macroscopic size (Hillson and Bond 1997). FitzGerald and Saunders (2005:278) argue that Wilson bands can be seen "holistically within the context of enamel development" as one example of a range of "histological microstructures that share a common etiology." This range of histological microstructures refers to enamel microstructures including regular striae of Retzius, cross striations, the neonatal line and the external perikymata. Perikymata are external manifestations of regular striae of Retzius. As posited by FitzGerald and Saunders (2005:278), Wilson bands are internal manifestations of "malformed perikymata" that are due to interruptions in normal enamel growth. However, multiple subsequent studies do not reveal a correlation between micro- and macro-defects, suggesting that they result from different etiologies. Taking all of this into consideration, for this study, Wilson bands are defined as resulting from short-term 
metabolic disturbances, whereas surface hypoplasias arise from different etiologies resulting from long-term chronic stress.

Enamel defects, especially surface hypoplasias, have been linked to an array of conditions including, but not limited to, negative effects of supplementation and weaning (Larsen 1997:48), nutritional status and poor living conditions (Goodman and Rose 1991:281), traumatic parturition (Larsen 1997:47), infantile diarrhea and dehydration (Simpson 1999), neonatal asphyxia, hypocalcemia, intrauterine malnutrition, hypothyroidism, and maternal diabetes (FitzGerald and Saunders 2005:278). This is due to enamel being extremely sensitive to metabolic "insults" from diseases, stress, or dietary deficiencies (Larsen 1997:44). Epidemiological and experimental studies of living human populations have supported the assertion that surface hypoplasias are due to nonspecific stress, such as poor living conditions, traumatic births and malnutrition (Goodman and Rose 1991:282; Larsen 1997:50). According to Larsen (1997:50), less than 10 percent of individuals from contemporary developed nations have hypoplasias; however, hypoplasias are quite common in underdeveloped countries with poor nutrition and higher levels of life stressors. Goodman and Rose (1991:282) expand on this even further, stating that a study in the 1930s shows that ninety percent of Chinese children had hypoplasias or some other form of enamel defect.

Extensive research supports the growing emphasis of dental histology in bioarchaeology; however, the method is not entirely without criticism. Before concluding, it is necessary to address some of the limitations of dental histology, along with responses by researchers who have attempted to account for and overcome these limitations. Two primary critiques of dental histology include the rejection of regular time periodicity of enamel formation and a lack of "satisfactory proof" of the relationship between enamel micro-defects and life stressors 
(FitzGerald 1998:371; FitzGerald and Saunders 2005:277, respectively). FitzGerald and Saunders (2005:288) point out that different types of stress will leave different types of markers in dental enamel, and that it is difficult to "recognize all such events throughout a whole dentition." For the purpose of this study, I focus on FitzGerald (1998), who provides a thorough response to the rejection of the regular periodicity of enamel microstructure development, and FitzGerald and Saunders (2005), who discuss limitations in regards to interpreting Wilson bands. A growing body of research supports constant periodicity of enamel formation; however, FitzGerald (1999:277) notes that some researchers reject the constant periodicity of enamel formation and some go as far as to claim that it is an anthropological hoax in equal proportion to the Piltdown Man. That is quite an assertion! FitzGerald (1999) elucidates lines of evidence that support the regular time dependency of enamel formation, including direct experimental evidence, credible functional explanations, regularity of circaseptan intervals, and tooth development tested against known standards. He goes even further and tests the hypothesis of regularity of circaseptan intervals. FitzGerald (1998) notes that the most convincing direct experimental evidence involves in vivo experimentally induced stress markers. A few experiments have been conducted by injecting infants suffering from inoperable hydrocephalus with sodium fluoride. Sodium fluoride administered at known intervals produces visible markers in the teeth, allowing researchers to calculate enamel growth rates at the time of death (note - the infants do not die from the injections). These experiments have verified that cross-striations develop at a constant daily rate (FitzGerald 1998:372). Researchers have also provided functional explanations for the rhythmical apposition of dental matrix (FitzGerald 1998:373). These studies have revealed that degree of enamel apposition is influenced by shifting acid base balances in the body, which fluctuate between day and night (FitzGerald 
1998:373). The last evidence that FitzGerald (199:375) discusses is the regularity of circaseptan intervals. This line of evidence was primarily derived from a study by Fukuhara, which calculated an average circaseptan of eight for humans by counting the number of cross-striations a between striae of Retzius (FitzGerald 1998:375). This count was repeated in three to five different areas of each tooth. In sum, FitzGerald (1998:383) argues that enamel apposition occurs at uniform intervals and that all anterior teeth in a given individual develop at a similar interval. However, other studies, such as Reid and Beynon (1998) reveal that enamel apposition is not uniform. Reid and Beynon (1998:475) argue that histological studies on dental development are relatively precise; however, they note that enamel production slows down toward the end of the crown formation.

FitzGerald and Saunders (2005) discuss of few limitations that must be considered when interpreting Wilson Bands. The first limitation is that the extent of enamel disruption has more to do with the timing and placement of the Wilson band than the severity of a stress. FitzGerald and Saunders (2005:288) also note that prevalence rates calculated in dental histological investigations are only minimum rates. In conclusion, the examination of enamel micro-defects and surface defects provide a valuable method to reconstruct patterns of stress in archaeological populations, especially in regards to intrauterine (and by inference maternal) and early childhood stress.

\subsubsection{Skeletal Indicators of Physiological Stress and Disease}

In addition to assessing physiological stress through disruptions in enamel growth, bioarchaeologists also reconstruct patterns of stress based on multiple skeletal indicators (Larsen 2001; Larsen 1997). Similar to dental growth disruptions, certain skeletal indicators also reflect 
non-specific stressors during childhood when the bones are in the process of forming (Larsen 2002:128). For instance, growth rates are recognized as "highly sensitive indicators" of stress and health in archaeological populations. Growth rates are influenced by an interplay between genetic, epigenetic and environmental factors. Furthermore, growth rates can be determined by comparing skeletal development to chronological age (Molnar 2005:209). A growing body of research suggests that malnourished children raised in impoverished environments are generally small for their age, thus revealing that the early years of life are the most sensitive to environmental stress (Larsen 1997:9). Additionally, the bowing of long bones and pelvic deformations related to nutritional deficiencies, especially vitamin $\mathrm{D}$, have been observed in the archaeological record (Larsen 1997:20; 2002:128).

Analyses of skeletal remains also reveal pathological indicators of deprivation, specific and nonspecific infectious diseases, and degenerative disorders resulting from heavy workloads and physical activity (Larsen 1997:29; 2002:128). Porotic hyperostosis, cribra orbitalia, and Harris lines are primary of examples of pathological markers of deprivation that generally result during early childhood. Porotic hyperostosis is a morphological conditions characterized by “spongy" lesions on the orbital roofs and/or the cranial vault (Larson 1997:29). It is often linked to chronic anemia or vitamin B deficiency during childhood that results from a synergism between malnutrition, poor iron absorption and infection (Klaus and Tam 2009:360). Nonspecific infectious diseases, resulting from malnutrition, poor sanitation and exposure to pathogens, are characterized by periosteal lesions most commonly found on the tibia (Klaus and Tam 2009:360). These lesions provide a baseline to measure adult systemic stress. Some infectious diseases, such as syphilis, tuberculosis and leprosy, on the other hand, leave specific lesions on skeletal tissue (Larsen 202:124). 


\subsubsection{Stable Isotopic Analysis and Dietary Reconstructions: The Link between Diet and Stress}

Dietary behaviors are fundamental to a person's health in that poor nutrition is often linked to elevated levels of stress and infectious disease (Larsen 2001:79). Chemical analysis of bone and tooth enamel has proved to be an effective tool to reconstruct subsistence patterns (Larsen 1997:270; Price 2012; Reitsema 2013:445). In regards to stress and health, reconstructing past subsistence patterns provides a context for investigating the impacts of malnutrition on growth and development and assessing paleopathological indicators of physiological perturbations and disease (Larsen 1997:270). Isotopes are described as intransmutable chemical elements that have the same number of electrons and protons, but differ in the number of neutrons (Larsen 1997:271). Chemical analysis of skeletal remains involves the measurement of stable isotope ratios present in mineralized tissue. These measurements represent the ratio of heavier isotopes to lighter isotopes relative to an international standard. As Reitsema (2013:445) states, "you are what you eat." This is derived from the fact that the chemical signatures of foods are passed down to the consumer, allowing bioarchaeologists to characterize past dietary behaviors (Larsen 1997:270; Reitsema 2013:445). The primary isotopes used in the reconstruction of subsistence patterns are carbon and nitrogen. Isotopic data can be collected from both tooth enamel and bone; these tissues respectively reflect early life and late life subsistence, allowing bioarchaeologists to infer changes in diet during an individual's lifetime. Furthermore, isotopic data can be collected from both bone collagen and carbonate. In order to better understand how dietary reconstructions can provide contexts for interpreting the impacts of malnutrition on growth and development, it is necessary to elucidate what can be inferred from bone chemistry. 
Carbon has two stable isotopes, a lighter ${ }^{12} \mathrm{C}$ isotope and a heavier ${ }^{13} \mathrm{C}$ isotope. Carbon isotopic ratios (expressed as $\delta^{13} \mathrm{C}$ ) in animal tissues have been demonstrated to reflect the ratios in foods consumed and, therefore, can be used to track dietary shifts and infer nutritional status (Larsen 1997:271; 2001:79). These ratios depend on the photosynthetic pathway of a particular plant, more specifically, how the plant extracts carbon from atmospheric carbon dioxide. These pathways are characterized as $\mathrm{C}_{3}, \mathrm{C}_{4}$ and Crassculian Acid Metabolism (CAM). $\mathrm{C}_{4}$ plants discriminate less against ${ }^{13} \mathrm{C}$ isotope when using carbon dioxide and thus have less negative $\delta^{13} \mathrm{C}$ values than $\mathrm{C}_{3}$ plants (Larsen 1997:271). $\mathrm{C}_{3}$ plants are generally found in tropical and temperate areas and have $\delta^{13} \mathrm{C}$ values averaging -26 parts/mil, whereas $\mathrm{C}_{4}$ plants are generally found in tropical areas and have $\delta^{13} \mathrm{C}$ values averaging -12.5 parts/mil (Larsen 1997:271). According to Larsen (1997:272), collagen requires essential amino acids for its formation, thus reflecting the protein component of diet, whereas the carbonate signature represents the whole diet, including carbohydrates, fats and protein.

Nitrogen, similar to carbon, also has two isotopes, the heavier ${ }^{15} \mathrm{~N}$ isotope and the lighter ${ }^{14} \mathrm{~N}$ isotope. In contrast to carbon isotopic analysis, nitrogen isotopic analysis provides a method to distinguish terrestrial from marine food consumption (Larsen 2001:80). Furthermore, nitrogen isotopes provide a way to distinguish between herbivores, omnivores and carnivores, ultimately revealing one's trophic position (Reitsema et al. 2010:1413). This distinction is due to the way in which nitrogen enters the ecosystem; plants either fix nitrogen directly from their air or acquire nitrogen from the soil through bacterial degradation (Larsen 1997:282). Marine organisms generally have more positive nitrogen isotope ratios (expressed as $\delta^{15} \mathrm{~N}$ ) due to the way it is utilized in the aquatic ecosystem. Given this broad array of multi-methodological 
approaches to reconstruct patterns of health, what are major stressors and how are they used to infer overall health related to ecological and socioeconomic factors?

\subsection{The Bioarchaeology of Stress and Health: Theoretical Perspectives}

\subsubsection{Theoretical Perspectives on Health in Archaeological Populations}

Various theoretical approaches have been developed to explain how aspects of health correlate to the synergistic relationship of ecological, social, political and economic factors (Agarwal and Glencross 2011:1). As Agarwal and Glencross (2001:1) succinctly state, "the duality of the skeleton as both a biological and cultural entity has formed the basis of bioarchaeological theoretical inquiry." Due to the development of the processual school of thought in archaeology, early investigations into the health status of bioarchaeological populations were almost always embarked upon from an ecological perspective (Goodman 1998:152). Goodman et al. (1984) provide a biocultural model to explain the cause and consequences of biological stress. This model begins with environmental constraints that can impact disease and stress, such as the availability of food and water and climatic conditions (Goodman 1984). In this sense, the environment can be viewed as both a source of natural resources and a stressor. Cultural systems and practices, however, can creatively buffer populations against environmental stressors. If these constraints are insufficiently buffered, stress can have population-level consequences, such as reductions in work capacity, mobility, and fertility (Klaus 2008:43). According to Klaus (2008:43), these consequences often lead to socioeconomic and political destabilization in past populations. Conversely, cultural systems can also be a "paradoxical" source of stress (Klaus 2008:43). These stressors include malnutrition and infectious disease due to changes in subsistence strategies, social inequality, poverty, violence and environmental degradation. Subsequent to this biocultural model put forth 
in 1984, Goodman (1998:152) argues for the integration of social, political and economic perspectives into human biology. More specifically, he calls for bioarchaeologists to consider the relationship between health and sociopolitical factors that create inequalities in access to and control of resources (Goodman 1998:152).

It has been well established that socioeconomic inequality is highly correlated with developmental stress and worsened health outcomes in both contemporary and past populations (Brunner 1997; Goodman 1998; Klaus 2008; Nguyen and Preschard 2003). As Nguyen and Preschard (2003:448) articulate, social inequality manifests itself in the body as a product of "psychobiological pathways" and "cumulative biosocial dynamics." In other words, the human body can be seen as a "historicized" and "socialized" object, shaped by cultural, political and historical processes (Klaus 2008:45). Bioarchaeological investigations reveal that inequality in the past often arose when one group conquered and remained dominant over another group. Furthermore, social inequalities also arose in societies with social stratification and differential access to resources. In this sense, stress and disease can be understood as the “embodiment” of social hierarchy and inequality (Nguyen and Preschard 2003:447).

Mechanisms by which social inequality and poverty cause disease and developmental stress are well understood and include decreased immunity and physiological development due to poor nutrition and, moreover, the spread of pathogens due to "insalubrious" living conditions (Nguyen and Preschard 2003:449). Additionally, environmental degradation and ecological stress may also impact health outcomes. According to Donohoe (2003:573), environmental degradation, due to factors such as overpopulation, air and water pollution, and unsustainable agriculture, has an impact on the health of individuals and populations. In sum, social inequality is highly correlated with various systemic stresses experienced at different life history stages. 


\subsubsection{Major Stressor across Different Life Periods}

As revealed, bioarchaeology provides a critical approach to study patterns of stress in past populations. Furthermore, a broader understanding of stress, especially in relation to growth and development, is important in attempting to infer the health status of archaeological populations (King and Ulijaszek 1999:161). Major stressors across various life history stages have been identified and used to infer aspects of overall health. These stressors involve the interplay between infectious disease, nutrition, environmental interactions and socioeconomic structures during both infant-childhood growth and developmental periods and adulthood (King and Ulijaszek 1999:161; Klaus 2008:43; Klaus and Tam 2009:359; Larsen 2002:128). For example, in a range of archaeological settings, population overcrowding seems to correlate with elevated levels of infectious disease and stress (Larsen 2002:128). However, the most common stressor seen in archaeological populations, especially in regards to the early childhood life stage, involves the interaction between malnutrition and infection (King and Ulijaszek 1999:161; Larsen 2002:128).

According to Larsen (1997:8), nutrition and infectious disease have a synergetic relationship. In other words, malnourished children are more susceptible to infection, and at the same time infections reduce the body's ability to absorb essential nutrients (Larsen 1997:8). Additionally, maternal and fetal stress can also impact a child's growth and development. According to the Barker hypothesis, stressors during fetal development, such as malnutrition, can result in negative adult health outcomes and reduced adult longevity (Armelagos et al. 2009:261). In conclusion, growth disruptions brought about by early childhood stress can be revealed by various dental and skeletal indicators, such as enamel microdefects and surface hypoplasias, porotic hyperostosis, reduced growth rates and/or indicators of 
infection. These physiological perturbations are linked to major stressors, primarily malnutrition and infection, which in turn can be used to draw inferences about health outcomes related to ecological, social, political and economic factors.

\subsection{The Bioarchaeology of Spanish Contact in the Americas}

The large corpus of work on European contact in the Americas has been based upon archaeological investigations and European-based ethnohistorical accounts (Andrien 2001:6). Klaus (2008:282) asserts that this presents a "fundamental dichotomy" because each avenue of research is based on completely different methodologies and data sources. Spanish chronicles of the Americas can provide valuable historical accounts of pre-contact and postcontact life; however, these sources are often biased and misleading. Due to the absence of a written language in ancient Peru, along with cultural and linguistic barriers, ethnohistorical accounts of European colonialism in Peru are, for the most part, dominated by Spanish chronicles and documents that frequently neglect the Native Americans' point of view (Ramirez 1996:1; Turner 2008). Consequently, these historical chronicles must be viewed through a "double filter" that takes into consideration the limited understandings and biases of Spanish chroniclers (Andrien 2001:5; Klaus 2008:282). Bioarchaeological analyses can provide a "filter" to help balance these limited and often biased chronicles, thus providing an alternative perspective on Spanish colonization.

As Klaus (2008:2) notes, increasing attention has been given to colonial bioarchaeology in North America. Larsen (2001a, 2001b, 2002) has conducted a twenty-plus-year project in La Florida examining the impacts of European contact from a holistic bioarchaeological perspective. Simpson (1999) and Wright (1990) have both examined enamel micro-defects in the context of 
Spanish contact in La Florida and Belize, respectively. Conversely, the majority of South American bioarchaeologists have devoted their attention to pre-Hispanic archaeology. However, the colonial bioarchaeological work that has been conducted on the north coast of Peru, primarily by Haagen Klaus $(2008,2009)$, provides important insight into how the Spanish colonization of Peru impacted the lives of indigenous populations. Klaus's $(2008,2009)$ work characterizes the life and death of indigenous individuals interred at the Chapel of San Pedro de Mórrope in the colonial town of Mórrope in the Lambayeque Valley region Peru. According to Klaus and Tam (2009:363), Mórrope was a colonial town, or reducción, created in 1536 in a marginal scrub microenvironment with limited supplies of water and natural resources. Furthermore, ecological transformation due to Spanish agricultural policies led to environmental degradation and the destruction of irrigation canals, often leaving indigenous populations without irrigation or drinking water (Klaus and Tam 2009:363). In order to examine the biological consequences of these transformations, Klaus and Tam (2009) studied multiple indicators of subadult systemic stress, including linear enamel hypoplasias, porotic hyperostosis, and femoral growth velocity, along with indicators of adult systemic stress, including non-specific periostitis and degenerative joint disorders (Klaus and Tam 2009). These indicators were compared between pre-Hispanic and post-contact subsamples and reflect the interplay between social, economic and political environments (Klaus and Tam 2009:360). Furthermore, these indicators are strongly linked to poor nutrition, disease and elevated energy expenditure, leaving inadequate nutrient supply for cells (Klaus and Tan 2009:360). Of the systemic stress variables used, four directly indicate increased biological stress as a result of European contact (Klaus and Tam 363). From this analysis, Klaus and Tam (2009) argue that Spanish socioeconomic policies that included the forced resettlement of indigenous populations into poor and resource restricted towns created 
"disease reactors" in which people experienced negative health outcomes as a result of poverty, malnutrition and increased infectious diseases.

In regards to the bioarchaeology of European contact in North America, Simpson (1999) provides an additional example to show how dental histology can be used to interpret biological consequences of European contact. Simpson (1999) examines enamel microstructure defects from populations that inhabited northern Florida between AD 1 and AD 1704; this large time span allowed for a temporal comparison of Wilson bands from samples that capture not only the transition from hunting and gathering, but also the period of European contact in the sixteenth century. The samples included mandibular canines of 143 individuals, which were collected from 14 different archaeological sites in northern Florida. The samples were divided into four different groups, each representing a different period: prehistoric pre-agriculture, prehistoric agriculture, historic non-mission and historic mission (Simpson 1999:245).

In the first two groups, Simpson (1999:248) found that the prehistoric pre-agriculture group had a greater frequency of individuals with Wilson bands in comparison to the later agriculture group (67\% and 36\%, respectively); however, individuals in the agriculture group had a greater number of Wilson bands per tooth. According to Simpson (1999:248), this suggests that fewer individuals were getting sick during the agricultural period, but the ones that were getting sick suffered from a greater number of subsequent episodes. As one may expect, the post-contact mission sample revealed the greatest frequency of Wilson bands (83\% of individuals), the greatest number of Wilson bands per individual and the greatest number of total Wilson bands (Simpson 1999:248). Based on the previously described constant periodicity of enamel growth, Simpson (1999:251) also elucidates the chronology of canine formation to understand the timing of the enamel defects. Simpson (1999:252) states that, due to different 
ecological demands placed on different population, studies vary regarding the chronology of canine crown formation, often ranging from 35 to 78 months. What accounts for these variations and how can these inconsistencies be overcome? In order to overcome the "limitations of using growth standards," Simpson (1999:252) developed an internally consistent chronology based on the constant periodicity of enamel micro-features using slightly worn or unworn canines. Duration of crown formation is calculated by counting regular striae of Retzius lines, which occur at a rate ranging from 8-10 days. In sum, the number and distribution of striae of Retzius in a longitudinal thin-section of the tooth being analyzed can determine the chronology of canine development, thus making the reliance on other developmental growth schedules unnecessary (Simpson 1999:255). This technique yielded a canine crown formation time of 60-63 months. In the final section of the article, Simpson (1999:255) draws a comparison of the distribution of surface hypoplasias and Wilson bands. The comparison reveals that the surface hypoplasias and the Wilson bands have different age distribution and microscopic structures. Simpson (1999:256) argues that this suggests different etiologies of the two enamel features. Thus, in contrast to the hypothesis put forth by Hillson and Bond (1997), which argues that micro- and macro-defects are the same phenomena, Simpson (1999:256) argues that micro- and macrodefects cannot be seen as "graded responses" to the same or similar stressor. This leads Simpson (1999:256) to question the cause of Wilson bands. He argues that water is crucial during enamel matrix formation; therefore, any event that disrupts fluid and electrolyte homeostasis, such as severe diarrhea and vomiting, may disrupt normal enamel formation (Simpson 1999:258). Possible sources of acute diarrhea in prehistoric societies include diarrhea associated with weaning and/or bacteria, such as Vibrio cholera, Salmonella spp., and Escherichia coli. In conclusion, Simpson's research reveals that the frequency of Wilson bands was the highest 
during the historic Spanish mission era (1999:258). Simpson (1999:258) notes that this is consistent with other historical data and skeletal analyses that suggest Native American populations were negatively affected by European contact. Simpson (1999:259) also suggests that Wilson bands do not correlate with surface hypoplasias, and that they are formed as a response to dehydration possibly due to severe diarrhea or vomiting with the onset of infant weaning.

Similarly, Wright (1990) examined enamel micro-defects in pre- and post-contact bioarchaeological remains from Lamanai, Belize. This Maya center was abandoned soon after European contact and eventually reoccupied as a Catholic mission. Wright (1990) notes that diet changed relatively little during this period; however, $84 \%$ of the Wilson bands observed were from the post-contact era. Furthermore, post-contact samples revealed more Wilson bands per individual in comparison to pre-contact samples (2.4 vs. 0.88, respectively). Wright (1990) argues that the increased prevalence of Wilson bands was due to European disease and not dietary shifts. The present study, taken into consideration with the previously discussed bioarchaeological case studies, provides a hemispheric perspective of the relationship between Spanish contact and early life stress by expanding the geographic scope of analysis to include colonial-period South America. 


\section{CHAPTER 3: ANDEAN GEOGRAPHY AND CULTURAL ECOLOGY}

\subsection{Introduction}

The Central Andes of pre-Hispanic Peru were home to a multitude of diverse cultures that developed sophisticated methods, such as irrigation systems and agricultural terracing, to overcome the environmental constraints of Peru's complex landscapes (von Hagen and Morris 1998:14). In the past, archaeological sites were viewed as being "self-contained" and therefore were not interpreted within the context of their surrounding landscapes (Renfrew and Bahn 2012:223). Current archaeological investigations, however, consider the environment as a dynamic and heterogeneous variable (Renfrew and Bahn 2012:223). Therefore, the environment can be seen as playing a pivotal role in influencing human experiences of economics and ideology. That being said, Peru's dynamic and diverse geography placed environmental constraints on indigenous populations, which may have subsequently influenced the formation of various political, economic and ideological systems across the Andean region (Moseley 1992; Turner 2008). This chapter explores Peru's geographical diversity and provides an environmental context for the subsequent chapters. In this chapter, I first provide a brief overview of Andean geography; second, I elucidate cultural systems created by indigenous populations that creatively buffered them against environmental constraints; finally, I provide a detailed description of the microenvironments and subsistence strategies in the Lambayeque Valley Complex.

\subsection{Andean Geography}

In order to understand how life in the Lambayeque Valley region of pre-Hispanic Peru was shaped by humans' interactions with the environment and, moreover, how the Spanish may have disrupted these interactions, it is first necessary to look at the region in its broader setting of 
the Central Andes. The Andean mountain chain spans 7,000 miles through South America from Venezuela to Argentina and is divided into three regions: the Northern Andes, the Central Andes and the Southern Andes. Unlike other alpine regions, The Central Andes of Peru is characterized by diverse and horizontally stratified ecological zones that are densely populated and heavily cultivated (Klaus 2008:72). As described by Hagen and Morris (1998:14), the Central Andes is often divided into three separate geographical regions: the coast, the highlands and the tropical forests. The ecological zones in these areas consist of fertile montane valleys, rugged and treeless foothills, temperate grasslands, hyper-arid deserts, and humid tropical rainforests, respectively. Furthermore, these zones often transition from one to another with changes in elevation as little as 30 meters and require different techniques for cultivation and farming (Klaus 2008:73; Turner 2008). Researchers posit that these environments in, and thus human populations of, northern Peru were shaped by two forces: the Humboldt Ocean current and the South American Cordillera (Moseley 1992:25).

The Humboldt ocean current, or Peruvian coastal current, is responsible for not only the rich marine ecosystem, but also the extreme aridity of Peru's harsh coastal regions (von Hagen and Morris 1998:14). This oceanic current moves warm surface water to the west of the continent, while a deep cold-water current brings cold water up to the Central Andean coast from Antarctica. The cold current cools prevailing winds and as the cold air blows inland over the coastal plains, it is heated and thus prevented from condensing as rain (von Hagen and Morris 1998:14-15; Keatinge 1988:43). As the air rises up the flanks of the Andean mountains, it is cooled and the moisture is condensed into clouds. During the winter, these clouds can become trapped under a layer of warm air, creating a temperature inversion that leads to a thick fog and mist along the coast, known as garua (von Hagen and Morris 1998:16). Lush bottomlands, or 
lomas, composed of fog-dependent plant species are formed when hills intervene with patches of fog. Due to these climatic conditions, a narrow strip of desert, traversed by approximately fifty rivers and patches of lomas, runs along the entire 2,400 kilometers of Peru's coastline (von Hagen and Morris 1998:14; Klaus 2008:78; Moseley 1992:42). The northern coast, specifically, includes 14 river valleys that run from the Andean mountains to the ocean. Unfortunately, only a third of these rivers bring water to the valleys year-round (von Hagen and Morris 1998:14). As previously mentioned, the Humboldt Current has another important ecological impact. The cold coastal current forces nutrients to stay directly below the ocean's surface, where photosynthesis is at its maximum (Keatinge 1988:43). This process, also known as the "Ekmann Spiral," increases phytoplankton and biodiversity and thus creates a coast with a rich marine ecosystem (Klaus 2008:79; Keating 1988:43). Interestingly, the Humboldt Current produces more fish than any other region in the world, explaining why $22 \%$ of all marine fish are caught along the Peruvian coast (Joyce 1999:6564). Indigenous pre-Hispanic populations exploited these rich coastal waters for fish, guano, sea mammals, algae and seaweed. Furthermore, these marine resources may have been fundamental to the development of Andean civilizations (Klaus 2008:79-80).

To the east of Peru's arid coastal desert lie the temperate western foothills of the Andes, also known as the Chaupi Yungas, or yunga zones (von Hagen and Morris 1998:14). These warm and sunny areas extend up to 2,500 meters above sea level (masl) and are ideal for growing chili peppers, maize and coca, and extracting minerals such as copper, iron and silver (von Hagen and Morris 1998:14; Klaus 2008:77). Additionally, rainfall in yunga zones provides water for the arid coastal valleys via rivers and underground aquifers (Klaus 2008:77). Further east, the mountains continue to rise and are flanked by fertile intermontane valleys that lie within 
the quechua cultivation zone (von Hagen and Morris 1998:14). This cultivation zone was extensively terraced by the Inca and was primarily used to grow maize, legumes, and grains such as kiwicha and quinoa. As one moves up to 4,000 to 5,000 (masl) above sea-level they encounter the grasslands of the altiplano, also known as the Puna zone. This zone was home to camelids, llamas, and alpacas that provided meat and fibers to weave cloths (von Hagen and Morris 1998:17-18). Travelling down the eastern slopes of the Andes, one encounters the humid tropical rainforests of Peru. Indigenous populations exploited these areas for coca leaves, honey, wood, medicinal plants, manioc, peanuts and sweet potato (von Hagen and Morris 1998:18). However, it must be noted that populations on the western slopes of the Andes had little interaction with populations on the eastern slopes. Moving from north to south along the coast of Peru also reveals variations in landscapes. The Andean foothills in northern Peru are lower and travel further inland with a more gradual slope. This geographic feature creates coastal valleys with large rivers and fertile alluvial, such as the Lambayeque Valley Region (Klaus 2008:73).

Devastating climatic conditions and environmental instability, such as earthquakes and El Niño, have also impacted life in the Central Andes. Peru sits on the highly active Nazca Plate, which is slowly subducting beneath the continent, occasionally causing violent and destructive earthquakes and volcanic eruptions (von Hagen and Morris 1998:18; Klaus 2008:84). These earthquakes and volcanic eruptions can destroy crops, irrigation canals, livestock, and human life, as well as contaminate water sources (von Hagen and Morris 1998:18). However, the El Niño phenomenon is possibly one of the most devastating climatic events in Peru (von Hagen and Morris 1998:18). El Niño events alter the Humboldt Ocean Current and thus disrupts Peru's rich marine ecosystem. Additionally, El Niño causes severe droughts in the southern Andes and 
flooding in the northern coast. Flooding can destroy irrigation canals and wash out agricultural fields (von Hagen and Morris 1998:22). For instance, archaeological investigations of the Moche sites of Huaca del Sol and Huaca de la Luna reveal that the surrounding settlements may have been buried by a flash flood around A.D. 600, followed by a multi-decadal drought (von Hagen and Morris 1998:22).

\subsection{Cultural Ecology: Buffers against Environmental Constraints}

As revealed in the previous sections, the landscapes of the Central Andes can be described as extremely harsh and volatile. However, as Klaus (2008:81) articulates, they contain abundant natural resources, that "combined with human creativity, can support a remarkable demographic and economic potential." That being said, since at least 1500 B.C., indigenous Andean populations have developed complex solutions to overcome Peru's geographical and climatic constraints. Andean agriculture in pre-Hispanic Peru, as anywhere else, depends on the domestication of plants, arable land, moisture, sunshine and temperature (Moseley 1992:30). However, as already elucidated, the Andean mountains provide little arable land and little or no water. One of the creative solutions to overcome this was the development of extensive irrigation systems. Irrigation networks connected multiple river valleys on the north coast bringing water from perennial rivers to drier valley areas (Hagen and Morris 1998:22). These irrigation networks transformed portions of deserts on the north coast into fertile and arable land, allowing people to cultivate crops on once unviable land. Another solution was the creation of agricultural terracing on the highland slopes (Moseley 1992:31). During droughts and dry seasons, there is still a considerable amount of rain in the higher altitudes of the Andean mountains. However, "topographic slopes and roughness" increases with altitude, providing little horizontal space to cultivate crops (Moseley 
1992:31). Terraces, or andenes, on highland slopes increased the amount of horizontal space and thus the amount of arable land (Hagen and Morris 1998:22). Klaus (2008:81) notes that we see creative solutions at local levels as well. During the Moche era, indigenous populations on the north coast began to create sunken gardens, also known as Pukios or cochas (Klaus 2008:81; Moseley 1992:32). These sunken gardens were created in areas with high water tables that allowed for cultivation during the dry seasons.

Andean geography can be described on two axes: vertical and horizontal. Various social and economic models have been proposed to explain how Andean populations procured resources from these two different but complementary axes. John V. Murra (1980) outlined an economic strategy known as the "vertical archipelago." This model posits that indigenous populations moved up and down the mountains exploiting, utilizing and distributing resources available in the different ecological zones along lines of kinships. In this model, communities could be self-sufficient by producing and exploiting resources without having to seasonally migrate or trade in markets (Turner 2008). A key component of this economic model is the ayllu system. An ayllu could establish colonies in different ecological zones and distribute resources throughout the Andes. Furthermore, exploiting different Andean ecological zones provided harvests year round. Shimada (1982), Rostrorowski de Diez Canseco (1999) and Moseley (1992) propose alternative "horizontal" economic models for populations living in the coastal regions of pre-Hispanic Peru. In these models, people procured their subsistence through a "horizontal strategy," emphasizing the exploitation of the abundant terrestrial and marine resources found along the coastline and the diverse microenvironments of northern Peru. According to Klaus (2008:83), coastal communities in northern Peru, such as those living in the Lambayeque Valley region, rarely exploited highland resources directly. Instead different 
ethnic groups focused on local maritime and agricultural specializations so that products could be reciprocally exchanged or traded. Both models provide important and useful frameworks to investigate variation in economic organizations of pre-Hispanic Peru.

\subsection{The Lambayeque Valley Complex}

The Lambayeque Valley Complex is located on Peru's northern coast and was the setting of a number of influential Andean cultural developments such as the Cupisnique, Moche and Sican (Klaus 2008:88). The region contains a diverse array of microenvironments, ranging from deserts to forests, plains, and pastures. Furthermore, the complex is transversed by five river valley systems: the Motupe, La Leche, Lambayeque, Reque and Zana (see Figure 1). During the Moche era, these rivers were all combined into a single irrigation network called the Lambayeque canal complex (Klaus 2008:88-90; Moseley 1992:43). According to Klaus (2008:88), the Lambayeque Valley Complex is ideal for irrigation agriculture, offering approximately 136,000 hectares of arable land. Additionally, the region was at one point home to one third of Peru's entire coastal population and contained one third of the total amount of arable land in the coastal regions of Peru (Klaus and Alvarez-Calderón - in press; Kosok 1965). The town of Eten is located in the southwest corner of the Lambayeque Valley near the mouth of the Reque River. Eten straddles an area that is geographically unique in comparison to other areas in the Lambayeque Valley Complex (Klaus and Alvarez-Calderón - in press). The area is markedly different in that it is surrounded by lagoon-marsh, ocean, riverine and desert ecologies that are biologically diverse and resource-dense (Klaus 2008:90). Furthermore, the area had year-round access to drinking water, possibly from riverine sources and/or wells tapping into underground aquifer water sources (Klaus and Alvarez-Calderón - in press). In order to 
understand subsistence strategies in the Lambayeque Valley region, it is necessary to elucidate the different microenvironments and the resources that are available for exploitation. For the purpose of this study, I focus on the diverse microenvironments that surround the coastal town of Eten, which includes a littoral zone, a desert zone, and a riverine zone.

Littoral zones, generally spanning from the shoreline to 600 feet out in the water, are typically characterized by abundant dissolved oxygen, sunlight and nutrients. The littoral zone near Eten consists of steep and rocky cliffs, heavy surf and strong riptides, and a unique and resource-dense lagoon-marsh microenvironment at the mouth of the Reque River near Puerto Eten (Klaus 2008:90). Generally, populations inhabiting littoral zones in Peru partake in maritime fishing, along with the hunting of mollusks and sea mammals (Klaus 2008:90). The indigenous inhabitants of Eten most likely consumed marine resources, such as Donax species, crabs, and a large variety of pelagic fish including anchovy, sardine and mackerel. A coastal desert lies directly to the east of Peru's littoral zone. This zone stretches some 10 to 20 kilometers inland and is characterized by active sand dunes with sparse vegetation (Klaus 2008:90). As discussed in the previous section, irrigation networks transformed portions of these desert zones into fertile and arable land, allowing for the cultivation of maize and alfalfa.

Riverine zones consist of narrow strips of alluvial floodplains and terraces formed where river flow current decreases, yet sediment transport still occurs. The amount of water that flows through the riverine zones of the Lambayeque Valley varies throughout the year; however, the area generally provided freshwater fish, mollusks and crayfish (Klaus 2008:94). Riverine microenvironments also develop along the drains of irrigation canals far away from the actual river. These drains are home to a wide range of fauna, such as ducks and foxes, and provide fertile land for the cultivation of fruit trees (Klaus 2008:95). In addition to the previously 
discussed resources, archaeological and paleobotanical remains suggest that populations in the Lambayeque Valley most likely subsisted on terrestrial mammals, such as camelid, guinea pig, and lizards, and plant resources including squash, corn, peppers, chenopods, and beans (Klaus 2008:99; Klaus and Alvarez-Calderón - in press). In regards to the town of Eten, Klaus and Alvarez-Calderón (in-press) note that most of this food was locally grown in irrigated fields to the north of town. In conclusion, this chapter provided an overview of Andean geography and how past human populations exploited the diverse microenvironments of Peru, especially in the Lambayeque Valley region. What were some of the cultures that crystallized in northern Peru across time, and how were their social, political, economic, and ecological structures disrupted by Spanish contact in the $16^{\text {th }}$ century? 


\section{CHAPTER 4: CULTURAL CONTEXT}

\subsection{Cultural Developments in Pre-Hispanic Peru}

This chapter explores pre-Hispanic cultural developments on the northern coast of Peru. As Klaus (2008:110) asserts, "biocultural patterns do not develop in a vacuum," and in order to understand any cultural development, it is necessary to investigate its "dialectical relationship with its past on local and regional levels." The northern coast of Peru witnessed the crystallization of multiple cultures over the past few thousands of years. The social, political and economic development of a culture is often shaped in part by external factors (Klaus (2008:167). Therefore, in order to develop a broader understanding of the Muchik identity, it is imperative to elucidate regional and diachronic cultural patterns that contributed to the ethnogenesis and persistence of the Muchik ethnic group. A broad understanding of social, political, and economic structures in pre-Hispanic Peru thus provides a foundation to investigate how Spanish colonialism may have dismantled and turned life upside down for Muchik individuals living in the Lambayeque Valley region. Beginning with the Moche culture some 1500 years ago and ending with life under the Inca Empire, this chapter briefly traces the development of the Muchik identity, focusing on social, political, and economic factors and subsistence strategies across this time span. This is followed by a detailed discussion on how indigenous life in the Lambayeque Valley region was turned upside down by social, political and environmental transformations that ensued from the Spanish invasion of Peru in 1532.

\subsection{Early Sociopolitical Structures and Subsistence Economies}

The development of the Moche culture is often contributed to sociopolitical changes that took place in the pre-existing Gallinazo tradition. During this time, political transformations led 
to more centralized governance and the Moche polity began to spread up and down the coast of Peru (Moseley 1992:178; Quilter 2002:159). The Moche culture (A.D. 100 -750) is considered to be one of the first indigenous states to develop on the north coast of Peru, and in the Andes in general (Klaus 2008:126). According to Klaus (2008), it was during this time that the Muchik community developed as a cultural substratum. However, as revealed by material cultural and burial patterns, Muchik practices and identity seem to have thrived and persisted under subsequent cultural developments and their respective changes in political and economic structures (Klaus 2008).

A key characteristic of Moche rule, a characteristic that persisted throughout subsequent cultural developments, was the obligation of constituents to pay taxes through labor (Moseley 1992:183). Indirect rule through local lords, or curacas, was a policy used by Moche rulers to harness substantial amounts of labor to work agricultural lands (Moseley 1992:196). However, a curaca did not govern alone; under the parcialidad system, grouped pairs of ranked lords would operate at every level of organization. As revealed below, indirect rule through the parcialidad system was a policy adopted by the Inca Empire and eventually exploited by the Spanish colonizers. The Moche culture is often divided into five chronological phases (I-V), with its early development being centered in the La Leche-Lambayeque Valley Complex. Here, special attention is paid to Moche V (A.D. 250-750). According to Klaus (2008:131), a re-organization of sociopolitical structures marked the beginning of this phase, which included the first urbanized settlements in the area. Furthermore, state-level organization developed at Pampa Grande, which included a redistributive economy, increased sociopolitical complexity, and highly specialized production systems (Klaus 2008:131). In regards to subsistence, Moche populations in northern Peru exploited the diverse microenvironments the coastal regions had to 
offer and nutrient-rich resources from the ocean (Quilter 2002:156). They also began domesticating animals, such as guinea pigs, ducks, dogs and camelids, and cultivating crops, including maize, potatoes, sweet potatoes, beans and avocados (Quilter 2002:156).

Around A.D. 700-750, the Moche polity began to dismantle at Pampa Grande (Klaus 2008:133). As Klaus (2008:133) asserts, one explanation is that declines in agricultural productivity due to El Niño weather disturbances eventually led to internal friction. Following the disintegration of the Moche culture at Pampa Grande, a small polity known as the Sicán rose to regional domination on the northern coast of Peru (Klaus 2008:136). During the Middle Sicán period (A.D. 900-1100) "state-level organization" was characterized by control over multiple forms of resource exploitation, separate social classes with differential access to natural resources and a hierarchical centralized administration (Klaus 2008:136). Furthermore, power and wealth transitioned to being held by a small group of elites that controlled overarching political, economic and religious structures (Klaus 2008:139). According to Klaus (2008:150), subsistence strategies and economic power were key features of the Middle Sicán period. The Sicán followed a horizontal subsistence strategy, which emphasized the exploitation of the abundant terrestrial and marine resources found along the coastline and the diverse microenvironments of northern Peru. Furthermore, large-scale irrigation networks developed during the Moche era in the Lambayeque Valley region allowed for the cultivation of maize, gourds, squash, and avocados (Klaus 2008:150). Long-distance trade networks that spanned nearly 1000 kilometers along the coast allowed for the expansion of Sicán hegemony and economic domination. The Chimu kingdom rose to power on the coast of Peru around A.D. 1375, incorporating pre-existing policies and governing structure into their political realm (Klaus 
2008:163). Clashes between the Chimu king Chimu Capac and the highland Inca imperial state in A.D. 1460 led to Inca domination and end of the Chimu kingdom.

\subsection{Life under Inca Rule}

\subsubsection{Social, Political and Economic Structures of the Inca Empire}

The Inca imperial state of Tawantinsuyu, though only in power for less than one hundred years, was the largest empire in the pre-Hispanic Western Hemisphere (Covey 2006:1). Through "alliances, diplomacy and armed conquest," the Incas were able to conquer and assimilate hundreds of smaller polities into their state (Moseley 1992:7). This group represented governing nobility that ruled over 10 million people and spanned a geographical region that stretched from Ecuador to northern Chile (Moseley 1992:9; Morris 2008:299). However, it must be noted that Inca impacts were probably quite minimal, or at least very indirect, on the northern coast of Peru. This is attributed to the fact that Inca hegemony was only around for less than a century, the coast was not as centralized as the Inca heartland, and the north coast cultural customs and traditions were not affected by "imperial mandate" (Klaus 2008:165). Furthermore, according to Klaus (2008:100), even though food production was intensified and redistributed, the horizontal subsistence economies of the Lambayeque were minimally impacted by Inca conquest. The Inca economy was supported by tribute in labor and reciprocity. As elucidated by Morris (2011:18), the Inca centralized power was highly effective in its ability to manage its economy by "harnessing human energy on a large scale." This was achieved through systems of land assignments and labor taxes in which people were transferred from small communities and into different regions, where they provided the physical infrastructure of the empire by producing more food and goods and contributed to projects such as building roads (Morris 2011:18). One 
example of labor tribute, or labor tax, is the mit'a system. This was a system of "rotational corvee" in which able-bodied men, typically heads of households, travelled long distances throughout the year to fulfill various labor tributes, such as architectural or road construction and agricultural engineering (Covey 2006; Morris 2011:60).

The curaca and ayllu systems were key components of pre-Hispanic Andean economies. As defined by Kolata (2013:52), ayllus were groups of related families, or kin collectives, that shared land and natural resources through economic reciprocity. Thus, the ownership of lands and natural resources rest in the hands of a local chief ayllu. In Inca controlled pre-Hispanic Peru, paramount lords, or curacas, governed ayllus (Turner 2008). According to Turner (2008), ayllu members formed the foundation for the mit'a system by providing labor to work the communal lands. The curacas redistributed the surplus of the ayllus' labor throughout the community through ritual festivals and ceremonies (Turner 2008). Furthermore, the products of ayllu labor were also redistributed to regional centers in return for food and goods. According to Kolata (2013:54), the ayllu system "empowered, structured and regulated" Andean social structures.

Curacas were paramount lords and leaders of pre-Hispanic indigenous societies, and were held accountable for the collective well-being of their subjects. Curacas headed ayllu groups, held power over the life and death of thousands of subjects by acting as arbitrators of local justice, managed lands, and distributed natural resources and goods (Klaus 2008:313; Ramirez 1996:7, 13). On the northern coast of Peru, rank, position and thus power correlated with the number of subjects that a lord had under his or her control (Ramirez 1996:15). The organization of curacas rested on the principle of the parcialidad system, or "part of a whole" (Klaus 2008:314). Under this system, a curaca would entrust their lands to a second-in- 
command, or conozeque, and other lesser lords (Klaus 2008:315; Ramirez 1996:15). Lands would continue to be entrusted down the hierarchical ladder, eventually making their way into the hands of individual heads of households (Ramirez 1996:18). Each household would in turn pay rent for land and access to natural resources by providing labor to the curaca (Klaus 2008:315). This system was flexible, effective and self-sufficient in that large bureaucratic oversight was not needed (Klaus 2008:314). When the northern coast was incorporated into the Tawantinsuyu Empire in the 1460s, the Inca divided, delegated and assigned land and resources to a curaca (Ramirez 1996:16). Land was farmed on a communal level and the curaca determined how much farmland was allocated to each household. Communal ownership of land, water, and natural resources was an important characteristic of life in pre-Hispanic Peru. This system helped maintain an "ecological equilibrium in the fragile Andean environment" (Kolata 2013:53). Because land was not in the hands of wealthy private owners, the community efficiently controlled cultivation and surplus by ensuring that there was always enough arable land and natural resources to survive (Kolata 2013:53). The curacas also controlled how much tax would be collected from each household, organized local labor forces and redistributed goods and resources (Andrien 2001:23). As Klaus (2008:316) states, the obligations between lords and their subjects were "mutually reinforcing and interdependent." The curacas provided festivals, feasts, chicha (corn beer), goods and natural resources to their subjects. The more goods that a curaca provided, the more his or her subjects were obligated to reciprocate with labor service and the easier it was to "request aide, manipulate coax and cajole" people into obedience (Ramirez 1996:22).

In sum, as Andrien (2001:23) asserts, the foundation of the indigenous Andean economy was based upon reciprocal rights and obligations controlled by curacas on the behalf of the 
ayllu. For example, at the Inca site of Huanuco Pampa, archaeological materials, such as thousands of jars of beer in the plaza center and eating and drinking vessels excavated in the plaza surrounding kallankas, indicate that the plaza was an area used for ritual feasting and public ceremony that created a relationship between the Inca lords and the state's constituents (Moore 1996:793). In other words, it most likely functioned as an area in which the Inca rulers reciprocated labor tributes through the generosity of feasts and gifts. In regards to the Lambayeque Valley region, impacts of the Inca conquest are minimally understood (Klaus 2008:166). This is partially due to the fact that the Inca adopted many aspects of the Chimu state, such as the delegation of land management to local lords (Klaus 2008:166).

\subsection{The Spanish Colonization of Peru}

In November of 1532, Francisco Pizarro and his Castilian mercenaries invaded Peru and within thirteen months the Inca capital city of Cuzco was besieged and overthrown by the Spanish (Klaus 2008:283). The Spanish invasion and domination of the Tawantinsuyu Empire represented the apogee of Spanish colonization in the Americas (Klaus 2008:283). However, during this time, a series of biological and cultural transformations began to unfold, forever altering the lives of indigenous Andean populations (Klaus 2008:1; Klaus and Tam 2009:356). Spanish contact and the subsequent transformations were disastrous, leading to the demographic and socio-economic collapse of many Andean populations (Cook 1981; Klaus 2008:1). The socio-economic collapse and political destabilization of Peru is often attributed to Spain's primary agendas of converting indigenous people into tax-paying Christians, manipulating and exploiting indigenous labor, and extracting natural resources (Klaus and Alvarez-Calderón - in press). As Deagan (2003:3) articulates, Spain's expansion into Peru was 
"simultaneously an invasion, a religious crusade, a social experiment, and a highly structured economic enterprise."

As elucidated in Chapter 1, Pre-Hispanic Andean populations never developed systems of writing and, therefore, left no written record to narrate human life experiences in pre-Hispanic and post-contact Peru. Therefore, the large corpus of work on European contact has been based upon archaeological investigations, European-based ethnohistorical accounts, and supplemental documents, such as census data, judicial records, treasury accounts and ecclesiastical sources (Andrien 2001:6). However, since most South American archaeologists devote their attention to pre-Hispanic Peru, few archaeological and bioarchaeological studies of Colonial Peru have been conducted. Therefore, until recently, most of our knowledge has rested upon ethnohistorical accounts and Spanish documents. Klaus (2008:282) asserts that this presents a "fundamental dichotomy" because each avenue of research is based on completely different methodologies and data sources.

Spanish chronicles of the Americas can provide valuable historical accounts of life in pre-contact and post-contact Peru; however, these sources are often biased and misleading. According to Turner (2008), analyses of Spanish chronicles, such as those conducted by R. Tom Zuidema (1964), reveal that these chronicles do not necessarily represent actual history. Instead, they may represent Inca mythical and symbolic accounts of history. Furthermore, the European conception of time and thus historical change differed greatly from the Inca (Andrien 2001:12). The Spanish viewed time in a linear progression, whereas the Inca viewed time in a cyclical progression (Andrien 2001:12). That said, Klaus argues that these historical chronicles do indeed provide "priceless windows into Andean life," but they must be viewed through a "double filter" that takes into consideration the limited 
understandings and biases of Spanish observers in Colonial Peru (Andrien 2001:5; Klaus 2008:282). Archaeological and bioarchaeological analyses can provide a filter to help balance these limited and often biased chronicles, thus providing an alternative perspective on Spanish colonization. The objective of this section is to explore ethnohistorical accounts and archaeological investigations in order to elucidate Spanish colonialism in Peru and provide a portrayal of how Andean life was affected by Spanish social, political, and environmental transformations. This in turn provides a framework to help interpret any biological stresses revealed in skeletal remains of individuals interred at CSMME and CSMME-CNS in the Spanish dominated Lambayeque region of northern Peru.

\subsubsection{Spanish Arrival and the Early Contact Period}

The biological impacts of Spanish contact were felt in Peru prior to Pizarro and his Castilian mercenaries landed on the western coast of South America in 1530. As early as the 1520s, European infectious diseases, such as smallpox and measles, had swept through South America, most likely spreading along trading routes from Panama (Klaus 2008:283). By the time Francisco Pizarro encountered the Sapa Inca in 1532, these epidemics had eradicated upwards of one million people, including the previous Sapa Inca, Wayna Capac (Klaus 2008:283; Moseley 1992:11). In November of 1532, Pizarro and his men first encountered the Inca army in the northern highlands of Cajamarca (Klaus 2008:283). During the following November, the Spanish conquered the Inca capital of Cuzco, subsequently leading to the permanent colonization of Peru and the end of the Tawantinsuyu empire. In the subsequent years, the Spanish appointed Inca emperor, Manco Inca, united surviving Inca factions and revolted against the Spanish, attacking Cuzco and Lima in 1536 (Andrien 2001:41; Klaus 
2008:283). Unable to overthrow the Spanish, the Inca eventually fled to Vilcabamba and maintained a reduced but effective state until 1572 (Kaus 2003:283; Kolata 2013:2).

Despite their suppression of the Inca rebels, the Spanish faced many difficulties trying to maintain order in the Peruvian Andes during the Early Contact period (Andrien 2001:43). The years following the siege of Cuzco were disorganized, turbulent and volatile, which Klaus (2008:282) contributes to greed, competition and internal divisions among the Spanish. Ramirez (1996:156) asserts that one of the first "assaults" on the organization of indigenous populations was the development of the encomienda system. This system helped the Spanish establish domination in Peru by collecting taxes and granting Spaniards stewardships of curacas and their subjects (Ramirez 1996:156). This system initially supported the colonial Peruvian economy through tax remittance and the exploitation of indigenous labor for the extraction of natural resources. The Spanish built on the already existing curacas system in order to collect taxes and meet labor quotas (Andrien 2001:45).

According to Ramirez (1996:156), the granting of stewardship of a lord was a "convenient means" of establishing domination because the Spanish knew relatively little about Andean geography and ecology, and did not speak the native languages or understand Andean cultures. Andrien (2001:45) states that by 1542, there were 467 encomenderos in Peru, collecting over 1.2 million pesos annually from rents and labor. The indigenous people supported their encomendero in return for protection and instruction in the Catholic faith. Due to the encomienda system, the balance of power began to shift to the Europeans. The Spanish took advantage of this shift by confiscating indigenous land and increasing their demands for labor and tax (Andrien 2001:46). However, this system began to break down in the 1550s because indigenous slave labor proved to be unreliable and sparse. Not only did the Spanish have 
difficulties in maintaining indigenous labor, but infectious diseases were ravaging indigenous populations and reducing the already weak labor pool (Andrien 2001:46; Klaus 2008:284).

Despite these turbulent times, Spain's power in Colonial Peru steadily grew during the mid-1500s. However, by the late 1560s the weakening of the encomienda system had created a political and economic crisis, and Spanish order in Colonial Peru was in danger of collapsing. In 1569, King Philip II sent Don Francisco de Toledo to resolve the crisis in Colonial Peru (Andrien 2001:49). According to Andrien (2001:49), Toledo's reform set out to forcefully move indigenous people into strategic colonial towns, impose a "regularized" system of taxation, and force Andean people to work in silver mines. Following an extensive inspection tour, or visita general, of Andean South America, Toledo implemented the first part of his reform by ordering over 1.5 million Andeans to be resettled into colonial towns, called reducciónes (Andrien 2001:50; Klaus 2008:284). Reducciónes were imperative for the Spanish to assert social, political, and economic control in Peru (Deagan 2003:7). These colonial towns were then organized into 614 administrative districts, or repartimientos, each headed by a local Andean curaca (Andrien 2001:50; Klaus 2008:285). Repartimientos were subsequently grouped into eight larger provinces, each under the control of a Spanish magistrate, or corregidor de indios (Andrien 2001:50). Spanish corregidor de indios gained control of the Peruvian countryside from the encomenderos (Klaus 2008:285). Even though an Andean lord headed the repartimientos, "political concepts, balances and interactions" were transformed to serve the Spanish Crown (Klaus 2008:285). The movement of indigenous peoples into nucleated towns facilitated the expansion of Spanish economic ventures, religious conversion, tax collection and control (Ramirez 1996:30). 


\subsubsection{Political, Socioeconomic and Ecological Transformations in the Lambayeque Valley}

Region

During the months of September and October of 1532, Francisco Pizarro worked his way through the Lambayeque Valley region, most likely encountering the Muchik as he passed through Olmos, Motupe, Jayanca, Tucume, Lambayeque and Zana on his way to Cajamarca (Klaus and Alvarez-Calderón - in press). After colonization, the Lambayeque Valley region became a "vital center" of agricultural production for the Spanish due to its suitable climatic conditions, large amounts of arable land, and potential for seaports (Klaus and Alvarez-Calderón - in press). However, as previously elucidated, the Lambayeque Valley of northern Peru lacked a Spanish chronicler and until recently most of what we know about the region rests on local lore and oral history. Therefore, adding a bioarchaeological perspective can help lend a voice to indigenous populations that inhabited this region during the Spanish Contact Period. According to Ramirez (1996), socioeconomic transformations in the Lambayeque Valley region were very minimal during the first few decades; however, by the 1590 s everything began to unravel. This section aims to elucidate political, socioeconomic and ecological transformations that ensued after Spanish colonization, emphasizing how these transformations led to socioeconomic disarticulation, political destabilization and environmental degradation in the Lambayeque Valley region of northern Peru.

The introduction of European pathogens was one of the first factors contributing to indigenous demographic collapse and socioeconomic disarticulation in the Lambayeque Valley region. As described by vistador Sebasitián de la Gama in 1540, just eight years after Spanish Contact, many previously thriving villages in the Lambayeque Valley region were demolished, ruined and/or abandoned (Klaus 2008:307). Extreme depopulation in Lambayeque is attributed 
to the introduction of European pathogens, such as typhus, measles and smallpox. The demographic collapse of many indigenous populations was compounded by pre-Hispanic indigenous civil wars and migration (Cook 1981; Klaus 2008:308). On the northern coast of Peru, an outbreak of typhus hit in 1546, followed by deadly epidemics of measles and smallpox from 1558-1561. In some instances, such as the encomienda of Jayanca, populations decreased by as much as 80 percent (Klaus 2008:307). According to Cook (1981), population on the northern coast of Peru dropped from 320,668 to 23,575 between 1520 and 1630. Lambayeque, in particular, witnessed a $40 \%$ reduction in its indigenous populations before rebounding around 1630 (Klaus and Alvarez-Calderón - in press).

One of the most significant socioeconomic transformations in post-contact Lambayeque, and in Peru in general, involved the transformation of curacas from high-ranking lords to tribute and tax collectors (Ramirez 1996:26; Klaus 2008:313). According to Ramirez (1996:26), the Spanish transformed the nature and function of the curaca and in doing so "destroyed the basic premise on which the curaca's power rested." The curacas subsequently became "accomplices and functionaries" of the colonial state, which destroyed the balance between curacas and their subjects (Ramirez 1996:26). The transformation of the curaca in the Lambayeque Valley region was, according to Klaus (2008:316), "swift and beyond their control." This transformation disassembled the existing socioeconomic system that promoted reciprocity and collective wellbeing, and in turn pushed many indigenous populations, such as the Muchik, into poverty. Separating curacas from their seconds-in-command and lesser lords dismantled the parcialidade system. As Ramirez (1996:156) states, this transformation "robbed lords of their subjects, their labor, and the ability to exploit enough ecological niches to guarantee selfsufficiency." Furthermore, this transformation disrupted Andean hierarchy and fragmented local 
political organization (Klaus 2008:316; Ramirez 1996:157). The dismantling of the parcialidade system led to 'rank inflation' in which lesser lords subsequently gained equal status with their curaca (Klaus 2008:316; Ramirez 1996:157). Depopulation also led to competition among curacas in order to maintain status and power (Ramirez 1996:157). Eventually, the Spanish began removing disobliging curacas and replacing them with lords who would carry out their orders and serve them best (Ramirez 1996:33). In order to serve the Spanish administration and maintain their positions, curacas began sacrificing the collective well-being of their subjects and their community, often reducing their legitimacy and resulting in mistrust, mistreatment, and abuse (Klaus 2008:316; Ramirez 1996:40).

As previously stated, Don Francisco de Toledo arrived in Peru in 1569 to manage the developing colonial crisis. The first implementation of his reform resulted in the forced resettlement of 1.5 million Andeans into colonial towns, or reducciónes. However, reducciónes were "informally" established in the Lambayeque Valley region as early as 1534 , long before the arrival of Toledo (Ramirez 1996:158). In the Lambayeque region, reducciónes concentrated scattered Muchik hamlets into nucleated colonial towns. For the Spanish, the resettlement of indigenous populations into nucleated towns facilitated the expansion of Spanish agribusiness, religious conversion, tax collection and control (Ramirez 1996:30). The Spanish justified the resettlement, reassuring indigenous people that it would be mutually beneficial. However, the resettlements came at a high price for indigenous Andean populations. Not only did reducciónes weaken the curaca's control over his jurisdiction, but the lands into which households were resettled into were far inferior to the lands from which they were taken. The new farmlands, generally in lower valley areas close to the sea had high water tables, salination problems and high fog and cloud cover. These factors thus contributed to a reduced growing season (Klaus 
2008:319; Ramirez 1996:30). It also meant the loss of access to the diverse ecological niches that the Andes had to offer. Furthermore, some populations were resettled into "sickly terrains," such as a reducciónes in Lambayeque where as many as 200 indigenous people died (Ramirez 1996:31). Ramirez (1996:31) asserts that this presents a hidden agenda behind Spanish reducciónes programs. The need to control land was crucial for Spanish economic expansion. Resettling indigenous populations opened up valuable land that was "coveted" by Spaniards (Ramirez 1996:31). Opening up valuable land gave Spain access to natural resources and raw materials. Furthermore, it gave the Spanish the ability to raise cattle and cultivate wheat, sugar cane and alfalfa, which were primary sources of economic wealth (Deagan 2003:6; Ramirez 1996:31).

Spanish contact and the subsequent political and socioeconomic transformations also resulted in environmental degradation in the Lambayeque region. Spanish policies, such as mono-crop agriculture, exhausted and depleted the soil after just one or two planting cycles (Klaus 2008:326). In the Lambayeque region, specifically, the Spanish created haciendas that concentrated on the production of sugar cane and alfalfa. These crops were so "water-hungry" that they left little for Muchik subsistence farming and drinking water (Klaus 2008:326). Furthermore, the processing of sugar required large quantities of firewood that in turn contributed to more deforestation and erosion (Klaus 2008:326). Irrigation canals could not be maintained due to the forced resettlement of people into colonial towns. Many of the canal networks subsequently filled with silt and debris and were eventually abandoned (Klaus 2008:326). Damage to irrigation canals often led to fertile land being reclaimed by the desert (Klaus 2008:326). Additionally, the introduction of European livestock, such as cattle and pigs, lead to overgrazing and further degradation of the environment. 
In conclusion, the political, economic and environmental transformations that unfolded during the Spanish colonization of the Lambayeque Valley region of Peru were wide-ranging and dramatic. The "old style" curaca filled a redistributive function and looked out for the collective well-being of his subject, whereas the "new style" curaca's primary role was to “siphon off surplus for the Spaniards" (Ramirez 1996:40). In other words, under Spanish domination, the curacas role became less and less beneficial to the community. They were no longer able to build a labor force strong enough to maintain their infrastructure, procure local natural resources and produce a surplus. Reducciónes further weakened the authority of the curaca and severed access to ancestral lands and microenvironments that were critical to indigenous economies (Klaus 2008:316). Reducciónes also led to epidemic outbreaks and to the breakdown of indigenous cultural patterns (Deagan 2003:5). This resulted in the dismantling of indigenous redistributive and subsistence systems. Furthermore, these transformations led to environmental degradation in Lambayeque and possible negative dietary outcomes. As Ramirez (1996:160) states, “institutional generosity” was replaced by Spanish extraction and exploitation that were based on "greed, self-interest, and individual gain." The turbulent centuries, spanning from the late Inca until Peru's independence from Spain in the early 1800s, resulted in the altering of indigenous socioeconomic structures and patterns of diet and disease. These transformations most likely put a tremendous amount of stress on indigenous populations, ultimately resulting in negative health outcomes, which are subjects of this research. 


\section{CHAPTER 5: RESEARCH DESIGN}

\subsection{Objective}

The objective of this study is to employ a bioarchaeological approach to examine dental indicators of early life stress. These indicators in turn will be used to infer indigenous health outcomes as a result of the Spanish colonization of Peru. More specifically, this study will utilize dental histological methods to analyze internal enamel micro-defects (Wilson Bands) in ethnically distinct Muchik individuals interred at two sites: the La Capilla Santa María Magdalena De Eten (CSMME) and the La Capilla Del Niño Serranito (CNS), both located in the coastal town of Eten in the Lambayeque Valley region of northern Peru. Stratigraphic and archaeological evidences indicate that individuals interred at CNS date to the Early Colonial Period (A.D. 1533-1620) and individuals interred at the CSMME site date to the Middle/Late Colonial Period (A.D. 1620-1760) (Klaus and Alvarez-Calderón - in press). Broadly, it is hypothesized that the Muchik population at Eten suffered negative health outcomes as a result of Spanish political and economic policies. As revealed in chapter 4, these policies ultimately lead to inequality amongst indigenous populations and the Spanish colonizers and alterations in indigenous subsistence patterns and access to natural resources. Though social inequality existed in pre-Hispanic Peru, it may not have existed to the extent it did after Spanish colonization.

\subsection{Site Background and Archaeological Excavations at CSMME and CNS}

According to local lore, in 1533, a Franciscan missionary settled in the demographically and economically stable Muchik fishing village of Atim (Klaus and Alvarez-Calderón - in press). Aiming to indoctrinate the Muchik people into the Catholic faith, the priest constructed a mission church, or ramada, and soon after renamed the village to Santa Maria de Magdalena de 
Eten, more simply referred to as "Eten." Eten eventually outgrew the mission church and the larger and more elaborate La Capilla Santa María Magdalena De Eten (CSMME) was constructed between 1620 and 1640. Due to the sighting of an apparition of the Christ child in 1649, Eten became a pilgrimage site, which is still visited to this day (Klaus and AlvarezCalderón - in press). Eten was abandoned between 1740 and 1760 and Puerto de Eten and Ciudad de Eten were established to the south and northeast, respectively. However, in 1776, another apparition of the Christ Child, or Divino Niño, occurred off the beach involving a distressed vessel. Following the sighting, Miguel Castillo, the vessel's captain, constructed a secondary chapel, which was named the La Capilla Del Niño Serranito (CSMME-CNS) (Klaus and Alvarez-Calderón - in press).

Haagen D. Klaus of Utah University and Peruvian archaeologist Jorge Alberto Centurion conducted excavations of CSMME and CNS in 2009 and 2012. Excavations at the CNS were originally intended to document a Late Colonial era sample; however, buried underneath the chapel was the first original mission church built by the Franciscan friar in 1533 (Klaus and Alvarez-Calderón - in press). Therefore, even though the CNS was constructed during the Late Colonial Period, all of the individuals interred there are from the 1533 church and represent the Early Colonial occupational phase. The CNS burial sample includes 253 burials representing 450 individuals from the Early Colonial Period and the CSSME burial sample includes 256 burials representing 308 individuals from the Middle/Late Colonial Period (Klaus and AlvarezCalderón - in press). 


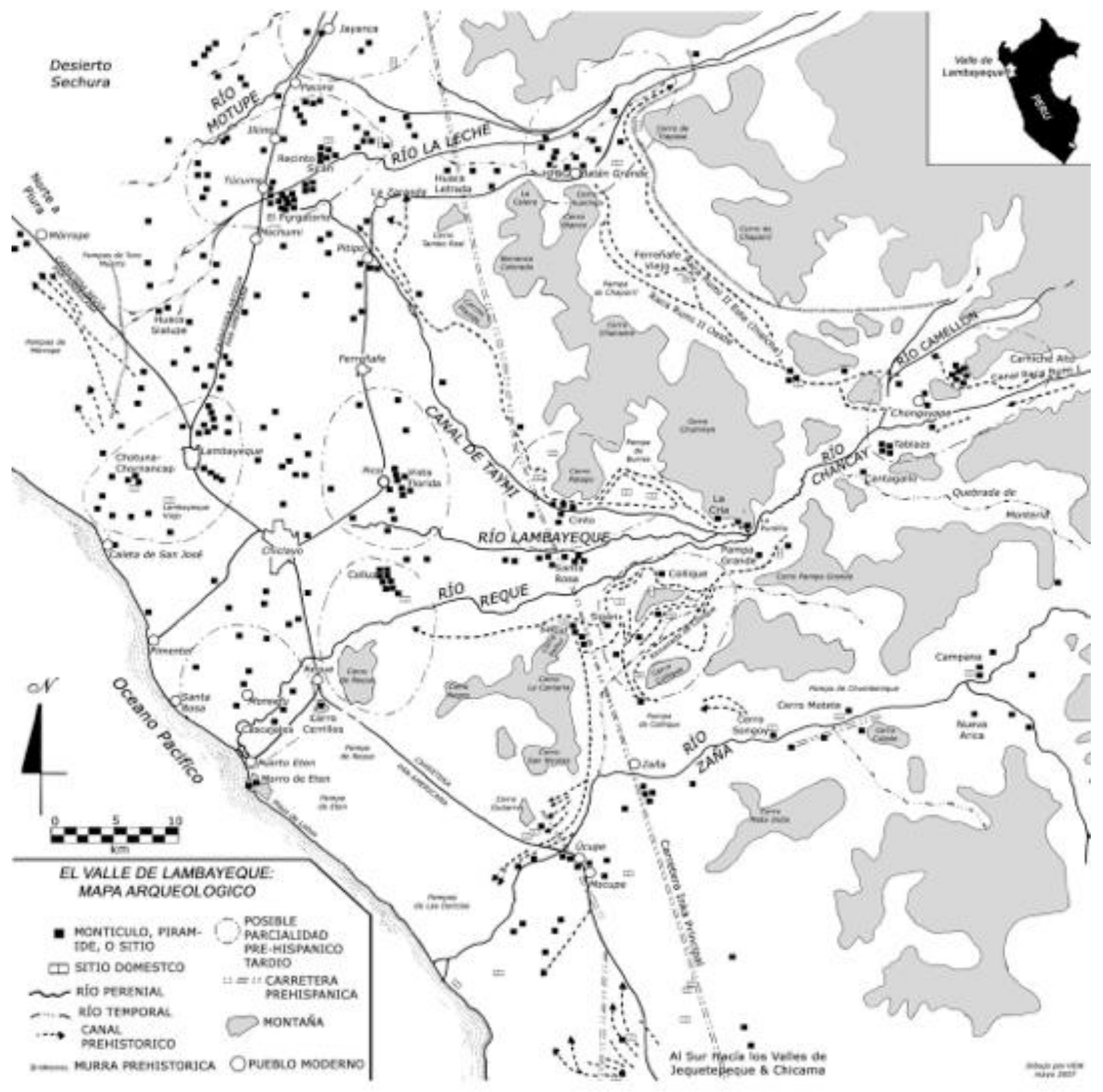

Figure 2: Map of the Lambayeque Valley region. Note the town of Eten on the coast directly above the legend (Map credit: Haagen Klaus). 


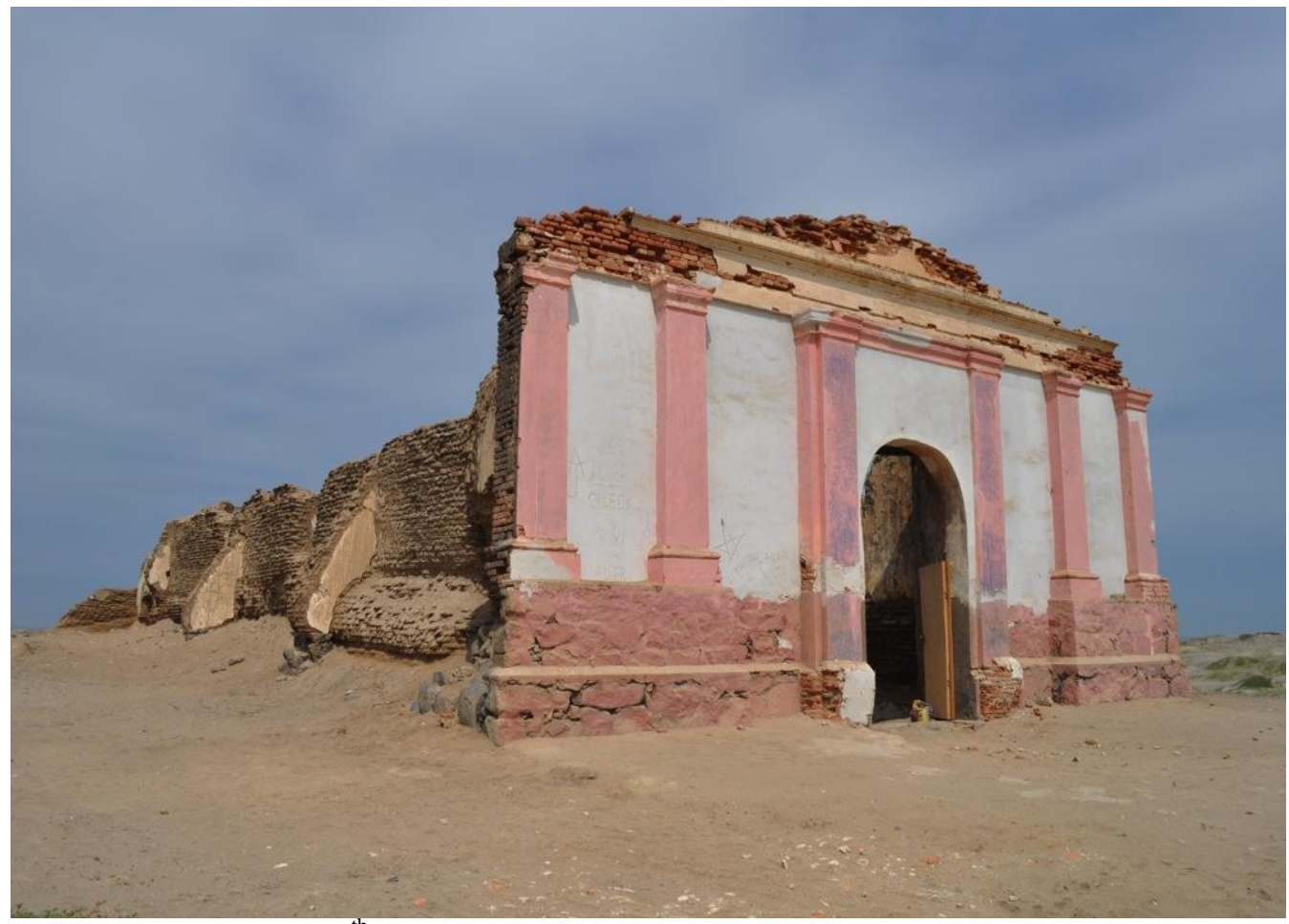

Figure 3: Ruins of the $18^{\text {th }}$ century CNS (Photo credit: Haagen Klaus).

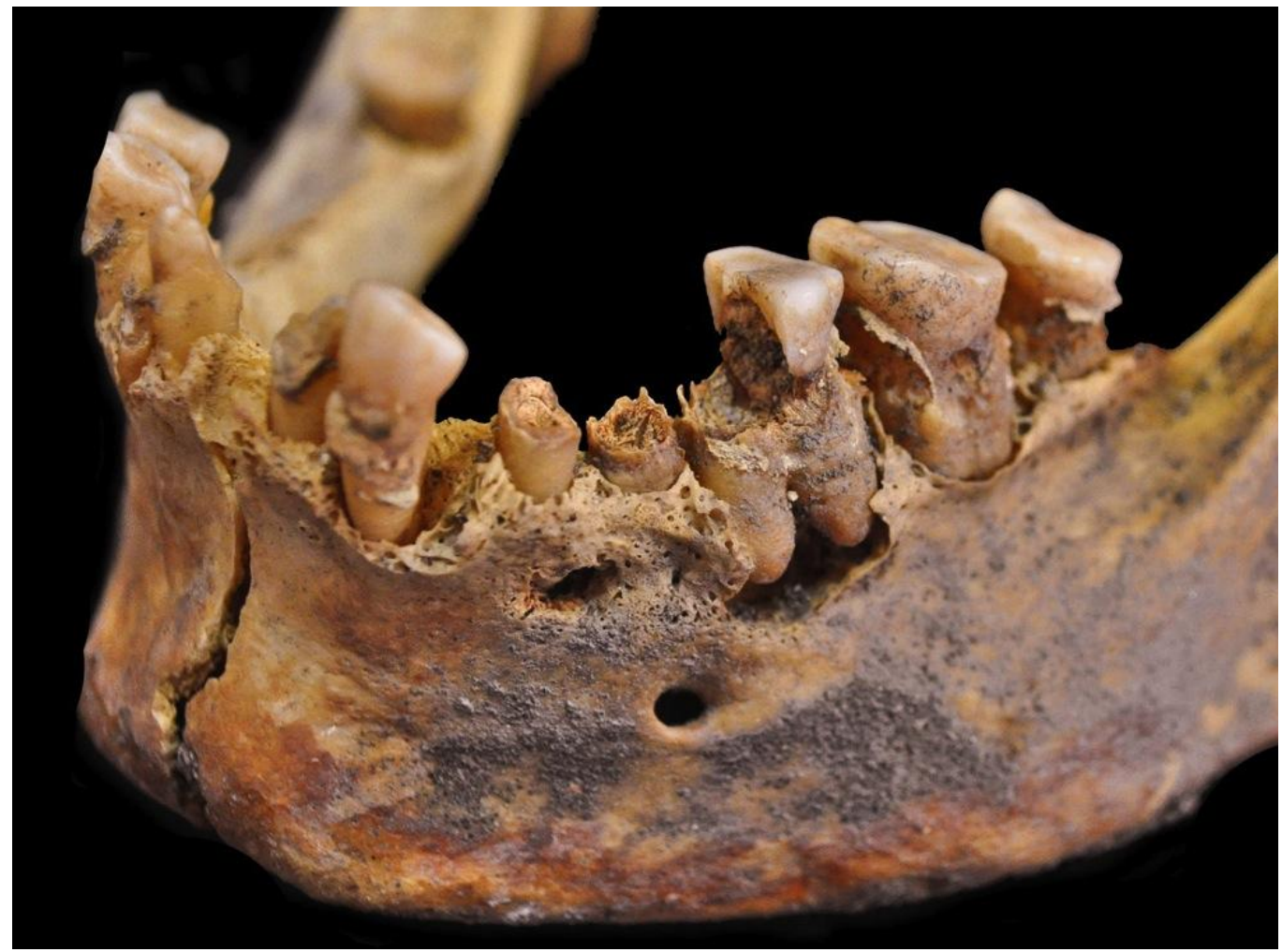

Figure 4: Mandible with marked pathologies from Burial Number U3-50 (CNS) (Photo credit: Haagen Klaus). 


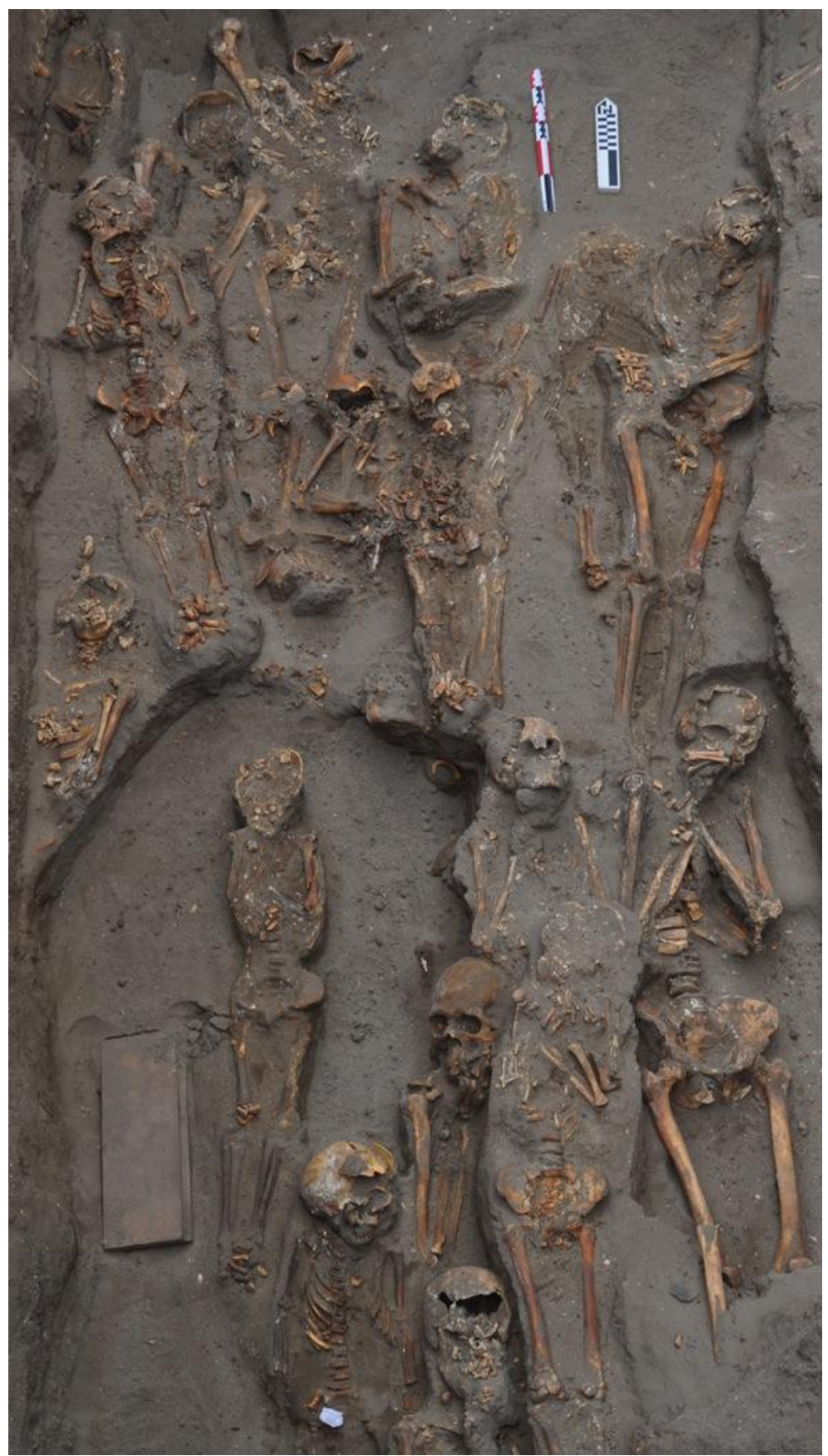

Figure 5: Twenty-two individuals interred in Unit 4 of CNS (Photo credit: Haagen Klaus). 


\subsection{Research Questions and Hypotheses}

The present study investigates indigenous physiological stress resulting from the Spanish colonization of Peru. More specifically, it characterizes post-contact Muchik life in the Lambayeque Valley, addressing two principal, multi-level questions. First, how did Spanish political, economic and agricultural policies transform life in the post-contact Lambayeque Valley region of northern Peru? Did early life physiological stress increase from the Early to Late Colonial Periods as a result of these transformations? If so, what were the possible stressors that contributed to an increase in early life stress, and, based on the circadian rhythm of enamel apposition, at what age did the stresses occur? Second, if physiological stress did increase in subadults, how did it impact adult health and longevity? In other words, is there a correlation between the presence of enamel defects and lower age at mortality? If so, is this correlation found at each site? The next section puts forth my research questions and hypotheses. Each question and hypothesis is discussed in more detail in the subsequent sections. This is followed by a methodological section, elucidating the methods that were used to investigate these questions.

\subsubsection{Research Question 1}

As previously stated, my primary research objective is to investigate how social, political, economic, and ecological transformations that ensued after the Spanish colonization of Peru impacted indigenous health outcomes. More specifically, how much stress was placed on individuals during infancy and early childhood life stages at CNS in comparison to CSMME? It must be noted that biocultural responses to European contact did not occur uniformly across the Americas (Baker and Kealhofer 1996:1; Klaus and Tam 2009:356). According to Klaus and 
Tam (2009:356), health was a dependent on the duration and intensity of European interaction. This is apparent in the high variability of biological and cultural responses to European contact as revealed through bioarchaeological investigations. Some populations experienced a rapid "cultural and demographic collapse" while other populations were more resilient (Baker and Kealhofer 1996:1). Were Muchik individuals living in the demographically and economically stable village of Eten negatively impacted by Spanish transformations or were they resilient and well adaptive? With that being said, it is hypothesized that Muchik subadults at Eten did indeed suffer negative health outcomes as a result of Spanish political and economic policies that ultimately lead to social inequality and thus alterations in subsistence patterns and access to natural resources. If this hypothesis is incorrect, however, what factors could contribute to the resilience of Muchik individuals to the impacts of Spanish colonization? Is it possible that Eten's diverse and resource-dense microenvironments buffered them from the negative impacts of colonial transformations? This hypothesis is based on four primary contexts: changing epidemiological patterns associated with Spanish contact, the transformation of social and political structures such as the altering of curacas, the forced resettlement of indigenous populations into dense nucleated colonial towns, and Spanish agricultural and economic policies that subsequently resulted in environmental degradation in the Lambayeque region.

As discussed in Chapter 4, the alteration of curacas disassembled the existing socioeconomic system that promoted reciprocity and collective well-being, and in turn pushed many indigenous populations, such as the Muchik, into poverty (Klaus and Alvarez-Calderón in press). The curacas were no longer able to build a labor force strong enough to maintain their infrastructure and efficiently procure local natural resources and produce a surplus. Furthermore, the implementation of reducciónes forcefully separated indigenous populations from diverse 
ecological zones and placed them into population-dense and resource-restricted colonial towns (Klaus 2008:319). Additionally, the movement of indigenous people into nucleated colonial towns left no one to maintain irrigation canals that supplied water for plant cultivation. These factors, compounded by Spanish agricultural policies such as monocropping, also lead to environmental degradation in the Lambayeque region (Klaus and Alvarez-Calderón - in press). As elucidated in Chapter 2, social inequality and poverty are highly correlated with developmental stress and worsened health outcomes (Brunner 1997; Goodman 1998; Klaus 2008; Nguyen and Preschard 2003). Social, political and economic transformations in Peru that subsequently led to socioeconomic inequality and poverty most likely put a tremendous amount of stress on indigenous populations, especially in regards to subadults who need adequate nutrition for growth and development. As revealed in Chapter 2, various bioarchaeological methods can be employed to reconstruct patterns of stress associated with ecological and socioeconomic factors.

The presence of Wilson bands is used as an indicator of non-specific stress with an unknown etiology. Although the exact source of stress cannot be pinpointed, enamel defects have been linked to an array of conditions including the negative effects of weaning (Larsen 1997:48), nutritional status and poor living conditions (Goodman and Rose 1991:281), infantile diarrhea and dehydration (Larsen 2000; Simpson 1999), and/or intrauterine malnutrition and maternal diabetes (FitzGerald and Saunders 2005:278). Therefore, an increase in biological stress, possibly due to poverty and indigenous malnutrition in the Lambayeque region, should be revealed by a higher prevalence of Wilson bands in individuals interred at the later CSMME site in comparison to the earlier CNS site. 


\subsubsection{Research Question 2}

The fetal programming hypothesis, first proposed by epidemiologist David Barker (1982), asserts that early life intrauterine stressors have negative health consequences later in adulthood. Armelagos et al. (2009) provide compelling bioarchaeological evidence in support of the fetal programming, or Barker hypothesis. More specifically, the authors examine how physiological perturbations in the form of enamel hypoplasias are associated with decreases in longevity. Armelagos et al. (2009:271) conclude that individuals with enamel defects that develop in utero or in infancy tend to have an increased chance of earlier adolescent or adult mortality. This is most likely contributed to social, cultural and behavioral exposure to stress as infants and children (Armelagos et al. 2009:271). Furthermore, the physiological stress that resulted in the enamel defect may in turn decrease one's ability to respond to future stressors (Armelagos et al. 2009:271). This study will, in part, apply the Barker hypothesis to the CNS and CSMME human remains, investigating if an increased prevalence of enamel hypoplasias and Wilson bands are associated with a younger age at death. It was originally intended to solely examine the relationship between Wilson bands and age at death; however, in the selection of samples for thin-sectioning, samples with the least occlusal wear were chosen, thus skewing the sample to be primarily represented by subadults. Data on enamel hypoplasias were available for a large portion of individuals interred at CNS and CSMME, thus providing a larger sample set and an additional test of the Barker Hypothesis. As previously stated, it is hypothesized that Muchik individuals in the Middle/Late Colonial Period were subject to an increased amount of physiological stress. This should be revealed through an increased prevalence of enamel hypoplasias and Wilson bands when comparing the Early Colonial Period CNS site to the Middle/Late Colonial Period CSMME site. If there is an increased prevalence of enamel defects 
in the form of enamel hypoplasias, is it associated with decreased longevity? Furthermore, what early life history stages are associated with the highest risk of death for individuals with enamel defects and why?

\subsection{Methodological Approach: Thin-section Procedures}

To investigate indicators of physiological stress in Muchik individuals, enamel thinsections of first mandibular or maxillary molars from CSMME $(n=15)$ and CNS $(n=15)$ were examined for the prevalence of Wilson bands (i.e. one tooth per individual from a total of 30 individuals). Enamel defects are most common in the middle and cervical two-thirds of anterior teeth (Goodman and Armelagos 1985:479). In other words, anterior teeth are more hypoplastic than posterior teeth. However, to remain as minimally invasive as possible, only molars that have been sampled for isotopic analysis and DNA extraction have been selected for histological investigation. Furthermore, selection was also based on the degree of occlusal wear. Molars with heavy occlusal wear and, thus, little remaining enamel were omitted from the study. These samples include both males and females, and subadults and adults from each site; however, since samples were chosen based on the preservation of enamel, the majority of the samples were subadults of indeterminate sex. The crown of the first molar begins to develop at birth and is complete around 3 years of age. Therefore, enamel growth defects in the first molars will capture stress events that occurred in in the first three years of life.

Various methods have been employed to prepare dental thin-sections for histological examination (see Marks and Rose 1996). Marks and Rose (1996:493) state that methodological confusion has hampered the use of dental histology, arguing that a standardized enamel thinsection method that is inexpensive and expedient will "encourage collection, synthesis and 
collaboration." In response to this, Mark and Rose (1996:478) offer an expedient and replicable method based on traditional dental histological methods. The dental thin-sectioning procedures used in this research project were adapted from Marks and Rose's (1996) methodological approach. As the authors note, dental thin-section procedures destroy teeth, thus ending any possible future research on the samples. Therefore, prior to dental thin-sectioning, all other avenues of research were completed on the samples, including casting and molding, macroscopic observations, and photographs. Furthermore, dental enamel was also sampled for multi-isotopic analysis and the roots were sectioned and saved for future DNA analysis.

The first step in Marks and Rose's (1996) refined procedure for dental thin-sectioning is to dehydrate and clean the samples with an effective solvent, such as ethyl alcohol, followed by air drying in a laboratory oven at 50 degrees Celsius. Following this approach, the teeth were suspended in an $85 \%$ ethyl alcohol solution for 24 hours, followed by a $95 \%$ solution for 24 hours and then a 100\% solution for 24 hours. This procedure removed any dirt, glue, and/or grease. The samples were then dehydrated in oven for 2 hours at 50 degrees Celsius. Next, the teeth were stabilized by embedding them in Buehler ${ }^{\mathrm{TM}}$ epoxy resin/hardener using aluminum foil "boats." This step ensures that the teeth did not chip or break during thin-sectioning. Before curing the resin in the oven, the resin embedded samples were placed in a vacuum desiccator for approximately 30 minutes, or until all air bubbles ceased to form in the resin. This ensured the greatest adhesion of the resin to the tooth surface and helped reduce the amount of air bubbles that often form during heat curing. The epoxy-covered teeth were then placed into a convection oven between 57 and 64 degrees Celsius for 90 minutes. Once cured, longitudinal buccal-lingual slices ( 1 $\mathrm{mm}$ in thickness) through the apex of both cusps (paracone and protocone of maxillary molars and protoconid and metaconid of mandibular molars) were cut from each tooth using a 
Buehler $^{\mathrm{TM}}$ Isomer 1000 diamond-blade microtome saw. If possible, two sections were cut from each tooth in the event that one slice was subsequently damaged. Immediately following sectioning, the thin-sections were cleaned with ethyl alcohol and an aerosol spray to remove any oil residue and/or other debris. Once the thin-sections were cleaned, they were mounted to frosted petroglyph slides using epoxy resin. The thin-sections were subsequently ground down on a Buehler ${ }^{\mathrm{TM}}$ EcoMet 3 variable speed grinder and polisher using 320 grit and 600 grit pads and then polished with a micro-cloth. After grinding and polishing, the thin-sections had been reduced to a thickness of approximately $200-400 \mu \mathrm{m}$. Finally, acid etching is required to not only observe and differentiate enamel prism orientation, but also to remove any remaining scratches caused by the saw or grinding machine (Marks and Rose 1996:497). This was accomplished by etching the thin-sections with a $1 \mathrm{M}$ solution of hydrochloric acid for fifteen-seconds (applying moderate agitation), rinsing them in water, dipping them in $95 \%$ alcohol and then allowing them to air dry. Typically, thin-sections are ground and polished using multiple abrasive pads of different grits, followed by a micro cloth (FitzGerald and Saunders 2005:280). However, according to Marks and Rose (1996:496), grinding and polishing of thin sections to remove scratches by the saw blade is tedious and error-laden. They argue that the required acid etching sufficiently removes enamel scratches. Since the samples used in this study were fragile, using a saw to cut sections less than $\sim 0.8-\mathrm{mm}-1-\mathrm{mm}$ was next to impossible, thus making it necessary to complete the tedious task of grinding and polishing them. 


\section{CHAPTER 6: RESULTS AND DISCUSSION}

\subsection{Thin-sectioning Results: Prevalence and Chronology of Wilson Bands}

The initial observation of neonatal lines, striae of Retzius and Wilson bands (WB) was accomplished by examining the samples under a bright field light microscope at $40 \mathrm{X}$ magnification. Individuals were scored by the absence (1) or presence (2) of both a neonatal line and observable Wilson bands. Wilson bands were then counted and totaled for each tooth/individual (see Table 1). Based on the criteria discussed by FitzGerald (2006), striae of Retzius were defined as Wilson bands if they were accentuated and observable for at least $75 \%$ of the distance between the EDJ and the occlusal surface in the imbricational area, or if visible for a least $75 \%$ of the distance around the dentine horns in the cuspal area. The prevalence of Wilson bands was determined by simply dividing the number of individuals with observed Wilson bands by the total number of samples in each subset (see Table 2). Furthermore, the number of Wilson bands per each tooth was recorded (which in this case is also the number of Wilson bands per each individual, since the sample only includes one tooth per individual). Statistical methods were used to determine if there are any significant differences in the frequency of Wilson bands between the two sites.

Based on the circadian rhythm of enamel apposition, age at stress events were determined by counting the number of regular striae of Retzius between the neonatal line and the observed Wilson bands. These results were analyzed to determine if there are any consistent patterns in the age at which stress events occurred. Based on the maximum prevalence graph by FitzGerald et al. (2006:185), the distribution of Wilson band prevalence shows ages associated with an increased risk of experiencing a stress event. This can, in turn, be used to infer possible stressors that caused the enamel growth disruptions. 


\subsubsection{Prevalence of Wilson Bands and Number of Wilson Bands per Individual}

Table 1: Wilson band and hypoplasia data for CSMME (Middle/Late Contact Period) and CNS (Early/Middle

Contact Period) $(\mathrm{EH}=$ enamel hypoplasias, $\mathrm{NNL}=$ neonatal line, $\mathrm{WB}=\mathrm{Wilson}$ bands) $(0=$ no data, $1=$ not present, $2=$ present)

\begin{tabular}{|c|c|c|c|c|c|c|c|}
\hline Site & Ent \# & Lab Code & Age & EH & NNL & WB & No. WB \\
\hline CSMME & E60-R2 & KGSU 94 & 6 & 1 & 2 & 1 & 0 \\
\hline CSMME & $5 \mathrm{D}-2$ & KGSU 61 & 4.5 & 1 & 2 & 1 & 0 \\
\hline CSMME & 5D-9 & KGSU 90 & 7.5 & 2 & 2 & 2 & 2 \\
\hline CSMME & 5D-11 & KGSU 84 & 0.75 & 2 & 2 & 2 & 1 \\
\hline CSMME & 5D-12 & KGSU 69 & 12 & 1 & 2 & 1 & 0 \\
\hline CSMME & $5 \mathrm{D}-21$ & KGSU 56 & 2.15 & 1 & 2 & 2 & 1 \\
\hline CSMME & $5 \mathrm{D}-26$ & KGSU 123 & 1 & 1 & 2 & 2 & 4 \\
\hline CSMME & 5D-61 & KGSU 132 & 5 & 1 & 2 & 2 & 2 \\
\hline CSMME & 5E.10 & KGSU 70 & 9.5 & 1 & 2 & 2 & 4 \\
\hline CSMME & 5E.12 & KGSU 107 & 10.5 & 2 & 1 & 1 & 0 \\
\hline CSMME & 5E.15 & KGSU 57 & 7 & 2 & 2 & 2 & 2 \\
\hline CSMME & 5E.28 & KGSU 103 & 14 & 2 & 2 & 1 & 0 \\
\hline CSMME & 5E. 38 & KGSU 122 & 0.75 & 2 & 2 & 2 & 3 \\
\hline CSMME & 5E.39 & KGSU 121 & 9 & 2 & 1 & 1 & 0 \\
\hline CSMME & $5 \mathrm{D}-16$ & KGSU 79 & 5 & 1 & 2 & 1 & 0 \\
\hline CNS & U4-AE24 & KGSU 253 & 11 & 2 & 2 & 2 & 5 \\
\hline $\mathrm{CNS}$ & U4-AE12 & KGSU 245 & 11 & 1 & 2 & 2 & 5 \\
\hline $\mathrm{CNS}$ & U4-AE7 & KGSU 240 & 14 & 2 & 2 & 1 & 0 \\
\hline CNS & U4-AE20 & KGSU 251 & 1 & 1 & 2 & 2 & 2 \\
\hline CNS & U2-11 & KGSU 152 & 9 & 2 & 2 & 2 & 1 \\
\hline $\mathrm{CNS}$ & U3-32 & KGSU 181 & 7 & 2 & 2 & 2 & 3 \\
\hline $\mathrm{CNS}$ & U3-84 & KGSU 193 & 35 & 2 & 2 & 1 & 0 \\
\hline $\mathrm{CNS}$ & U3-59 & KGSU 186 & 2.5 & 1 & 2 & 2 & 2 \\
\hline CNS & U4-AE22 & KGSU 252 & 9 & 2 & 2 & 2 & 3 \\
\hline CNS & U2-35 & KGSU 162 & 10 & 2 & 2 & 1 & 0 \\
\hline $\mathrm{CNS}$ & U4-44 & KGSU 220 & 22 & 1 & 2 & 2 & 2 \\
\hline CNS & $\mathrm{U} 2-44$ & KGSU 165 & 2 & 2 & 2 & 2 & 6 \\
\hline $\mathrm{CNS}$ & U3-89 & KGSU 194 & 20 & 2 & 2 & 1 & 0 \\
\hline CNS & U3-70 & KGSU 179 & 20 & 2 & 2 & 2 & 1 \\
\hline $\mathrm{CNS}$ & U4-28 & KGSU 211 & 12 & 1 & 2 & 2 & 1 \\
\hline
\end{tabular}


Table 2: Prevalence of Number of Wilson bands per Individual for CSMME and CNS

\begin{tabular}{|c|c|c|}
\hline Calculation & CNS & CSMME \\
\hline Number of Samples & 15.00 & 15.00 \\
\hline Number with WB & 11.00 & 8.00 \\
\hline Percentage of Individuals with WB & $73 \%$ & $53 \%$ \\
\hline Total Number if WB & 31 & 19 \\
\hline Mean Number of WB/Tooth & 2.81 & 2.375 \\
\hline
\end{tabular}

Enamel thin-sections of first mandibular or maxillary molars from CSMME $(n=15)$ and CSMME-CNS $(\mathrm{n}=15)$ were examined for the prevalence of Wilson bands. Eight individuals (53\%) from the later CSMME site were identified as having one or more Wilson bands, whereas 11 individuals (73\%) from the earlier CNS site were identified as having at least one Wilson band. Furthermore, the mean number of Wilson bands per individual was slightly higher in the earlier CNS site (2.81/individual) in comparison to the later CSMME site (2.375/individual). A t-test reveals that the frequency of Wilson bands is not statistically significant between the two sites $(\mathrm{p}=.398)$. However, this could be a result of high variation in each group, thus creating standard deviations greater than the means. A summary of these results is shown in Table 2 and in the Appendix.

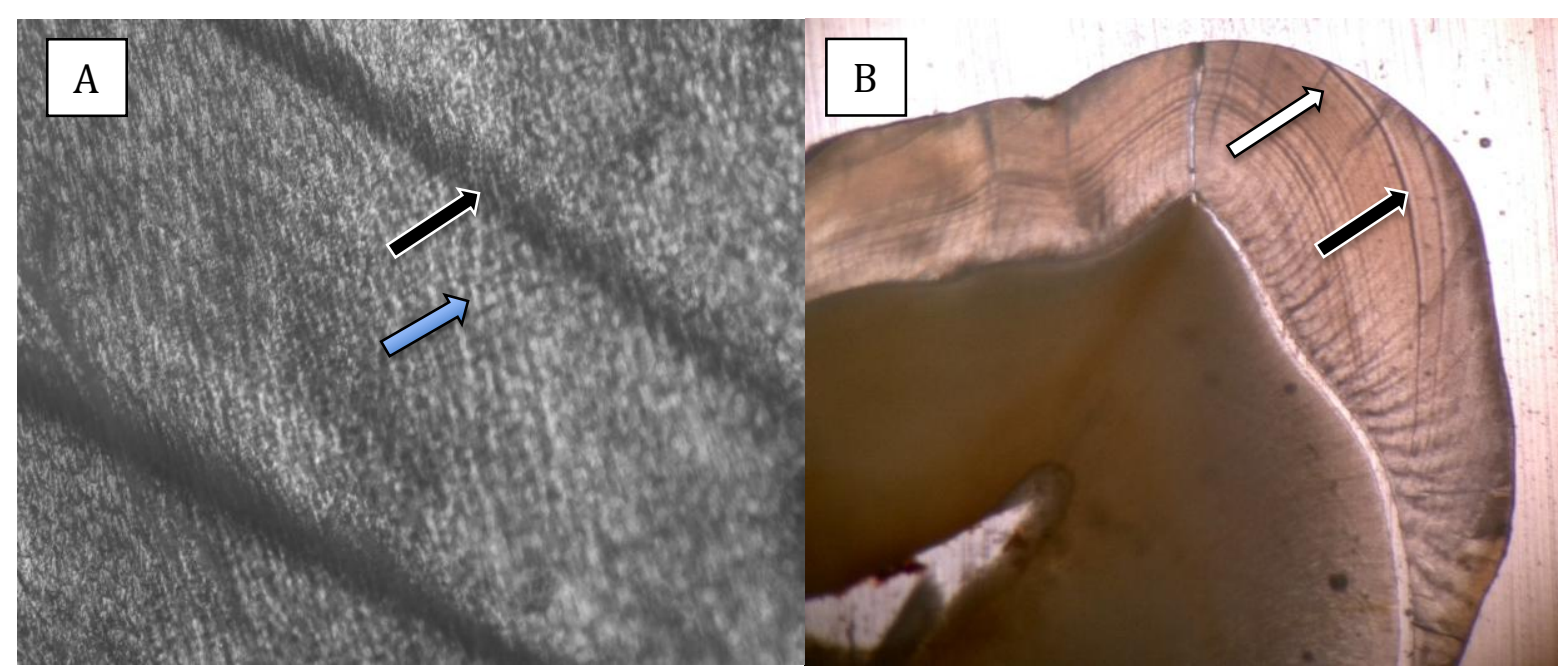

Figure 6: KGSU 245 (A) shows prism rods and well-defined Wilson bands. KGSU 245 (B) shows well-defined Wilson bands and striae of Retzius. The black arrow points to Wilson bands, the white arrow to striae of Retzius and the blue arrow to prism rods (running transverse to the Wilson band (Photo credit: Garland 2014). 


\subsubsection{Chronology of Early Life Stress Events}

In order to develop chronologies of early life stress based on the position of Wilson bands within the enamel matrix, the neonatal line was first identified in each tooth, along with prism rods and striae of Retzius. This was accomplished by examining the samples under a polarized light microscope at 40X magnification. Photographs were taken of samples with easily distinguishable neonatal lines, striae of Retzius and Wilson bands. As discussed in chapter 2, enamel forms in a rhythmical layering, beginning over the molar cusps and continuing down to the cervix. Striae of Retzius are incremental bands that are marked by discontinuity in enamel matrix, causing light to be scattered when viewed under a light microscope (Hillson 1992:157). Striae of Retzius representing 8-10 days (with a mean of 9 days) of enamel apposition were counted along the prism between the neonatal line and observed Wilson band. In areas difficult to see all striae of Retzius, the average width of each stria of Retzius was determined by calculating the mean width of striae in a measured group. This allowed for an estimation of the number of striae of Retzius in areas where they were difficult to discern.

Counting and measuring in this fashion formed chronologies of Wilson band formation and, thus, stress events. The number of striae of Retzius between the neonatal line and an observed Wilson band was multiplied by nine (mean days between striae of Retzius in human populations), providing the chronology (in days) of the given Wilson band. A distribution of Wilson band frequencies across different age groups shows the ages that were associated with an increased risk of experiencing a stress event. This can, in turn, be used to infer possible stressors causing the enamel growth disruptions. Figure 7 graphs the Wilson band frequency by age (at one month intervals) for each site separately and for both sites together (total). As depicted, the number of stress events increased and peaked between the ages of 4 and 5 months and again 
between the ages of 8 and 10 months. Both sites show the same pattern, albeit with a lower frequency of Wilson bands at CSMME. The results of Wilson band chronology will be further discussed in section 6.4 .

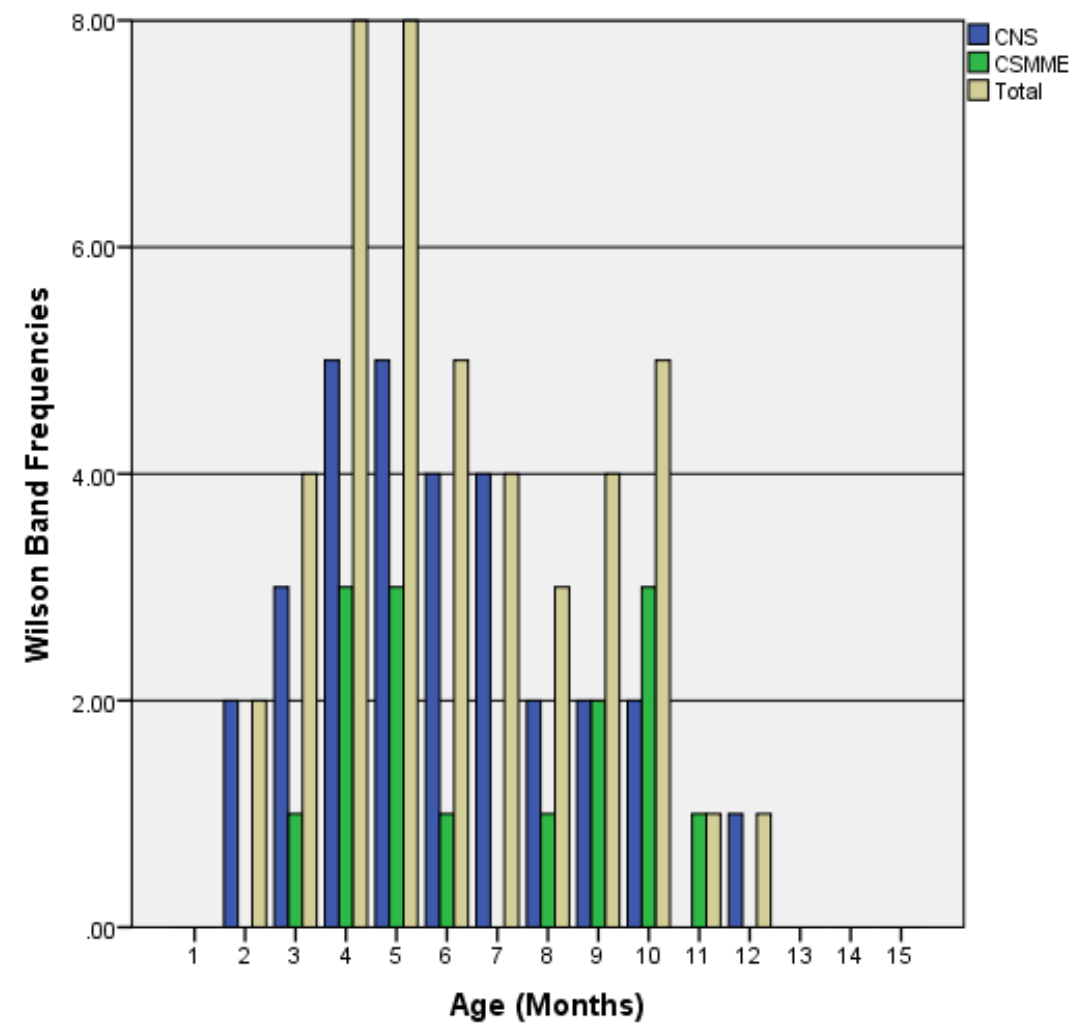

Figure 7: Distribution of age at Wilson band occurrence.

\subsection{Testing the Barker Hypothesis - Wilson Bands as Indicators of Early Mortality}

In order to examine any correlation between early life stress and early mortality, dental remains were examined for the presence or absence of Wilson bands and were subsequently compared to age at death values for each individual. Age at death estimations were provided by Haagen D. Klaus (unpublished). Individuals were scored by the absence (1) or presence (2) of Wilson bands on maxillary and mandibular first molars. Bias-corrected summary age values 
were previously computed by Klaus using SAS 9.1 and subsequently categorized here into four standardized age classes capturing major early life history stages: (1) infancy (ages 0-2.5); (2) early childhood (ages 2.5-5.9 years); (3) juvenile (ages 6-11.9 years); and (4) sub adult (ages 12+ years). These age classes capture age at eruption of deciduous teeth, weaning, first molar eruption, and second molar eruption, respectively. As will be discussed below, this allows one to investigate whether or not early life mortality as a result of physiological stress is associated with various life history periods. Counts were made for the number of individuals with Wilson bands and the number of individuals without Wilson bands, and percentage of deaths per each age class were calculated for both groups (see Figures 12 and 13). Another way to test the Barker hypothesis is to compare the frequency of Wilson bands for each age at death class. An age at death distribution was constructed to show which age at death classes were associated with the highest frequency of Wilson bands (see Figures 10 and 11).

Table 3: Site dates, sample size and number and percentage of individuals with Wilson bands (WB) and without Wilson bands at each site.

\begin{tabular}{|c|c|c|c|c|c|}
\hline Site & Date Range & Sample Size (n) & WB & No WB & \% with WB \\
\hline CSMME & A.D. $1625-1775$ & 15 & 8 & 7 & $53 \%$ \\
\hline CNS & A.D. $1533-1624$ & 15 & 11 & 4 & $73 \%$ \\
\hline
\end{tabular}

Table 4: Age demographics of subsamples from CNS and CSMME, 2 year intervals represent age classes 1-9

\begin{tabular}{|c|c|c|c|c|}
\hline Site & Age Class 1: 0-2.5 & Age Class 2: 2.6-5.9 & Age Class 3: 6-11.9 & Age Class 4: 12+ \\
\hline CSMME & 3 & 1 & 3 & 3 \\
\hline CNS & 1 & 2 & 0 & 2 \\
\hline
\end{tabular}

Table 5: Average age at death for individuals with Wilson bands (WB) and those without WB for each site.

\begin{tabular}{|c|c|c|}
\hline WB Observation & CSMME & CNS \\
\hline WB & 4.05 & 9.6 \\
\hline No WB & 8.8 & 19.75 \\
\hline All individuals & 6.9 & 12.3 \\
\hline
\end{tabular}




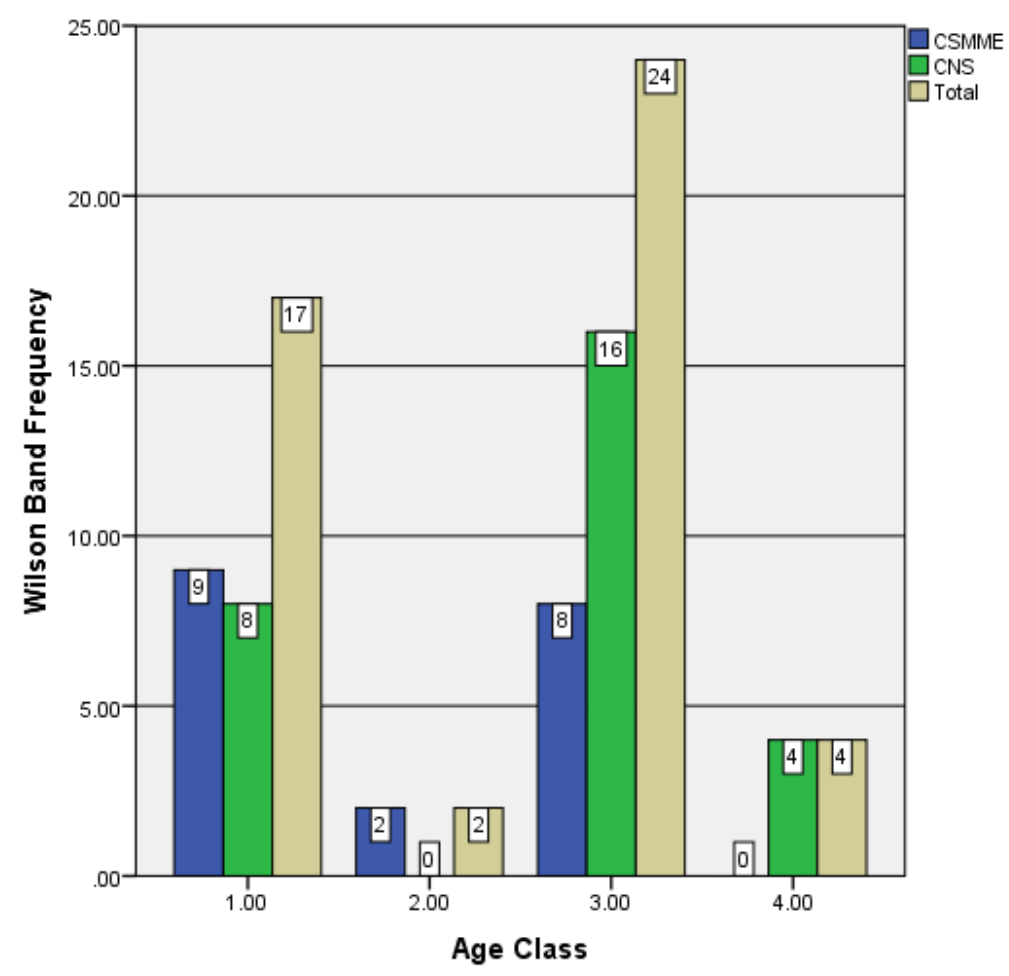

Figure 8: Age at Death distributions for individuals with observed Wilson Bands at each site.

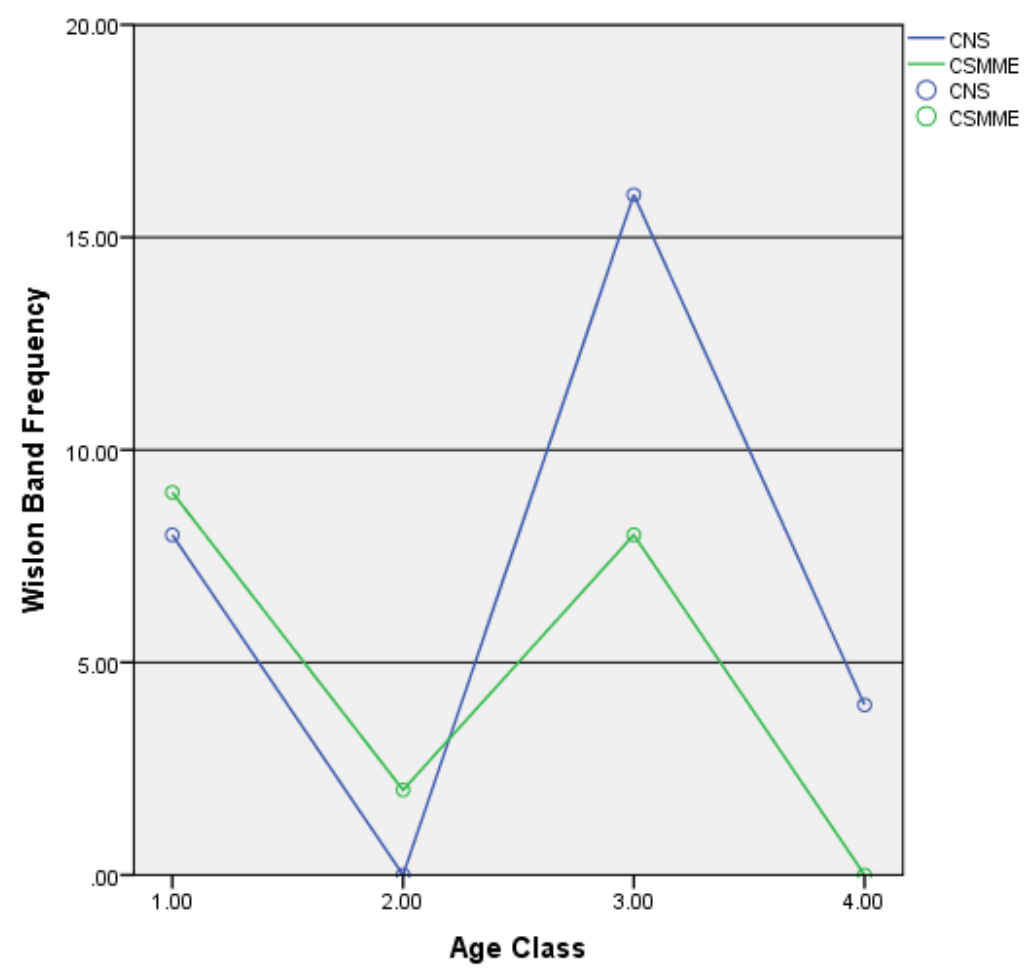

Figure 9: Age at Death distribution with highest frequencies of Wilson bands. 


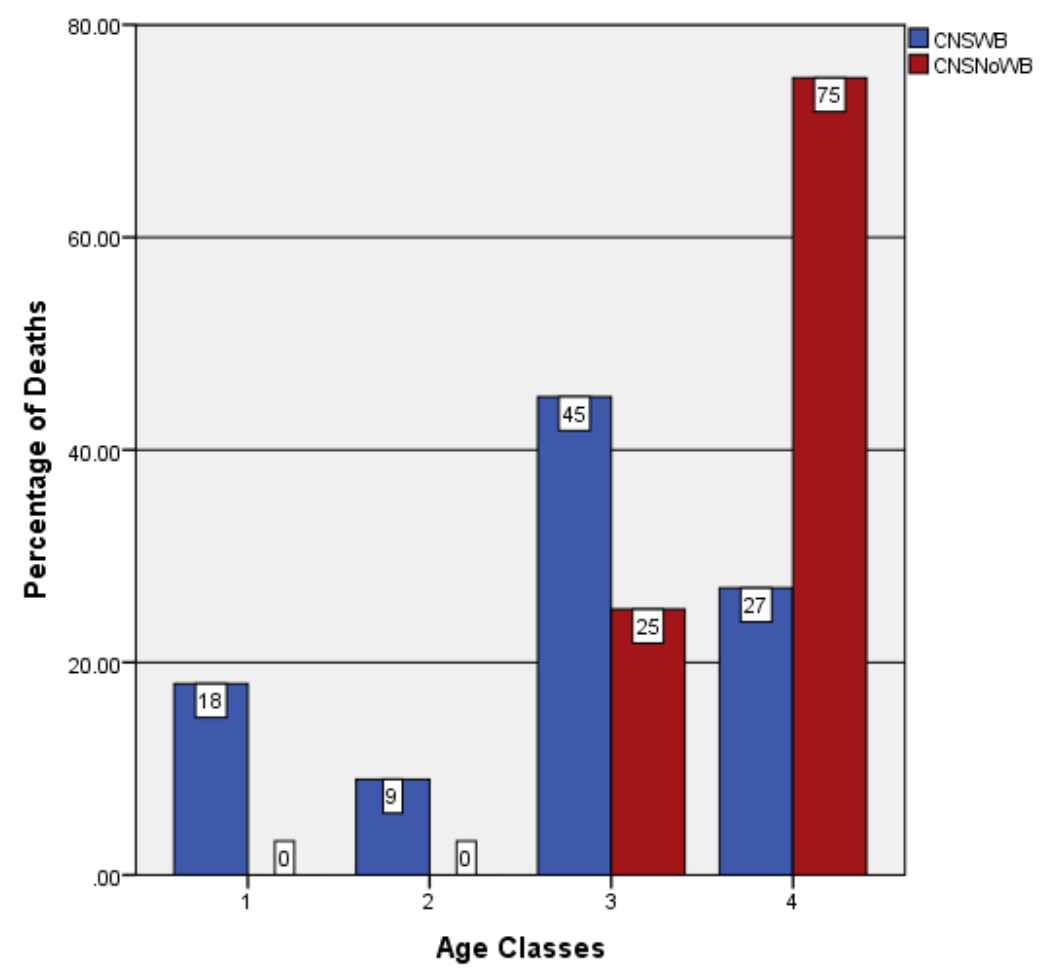

Figure 10: CNS - Percentage of deaths per age classes for individuals with observed WB and individuals without observed WB

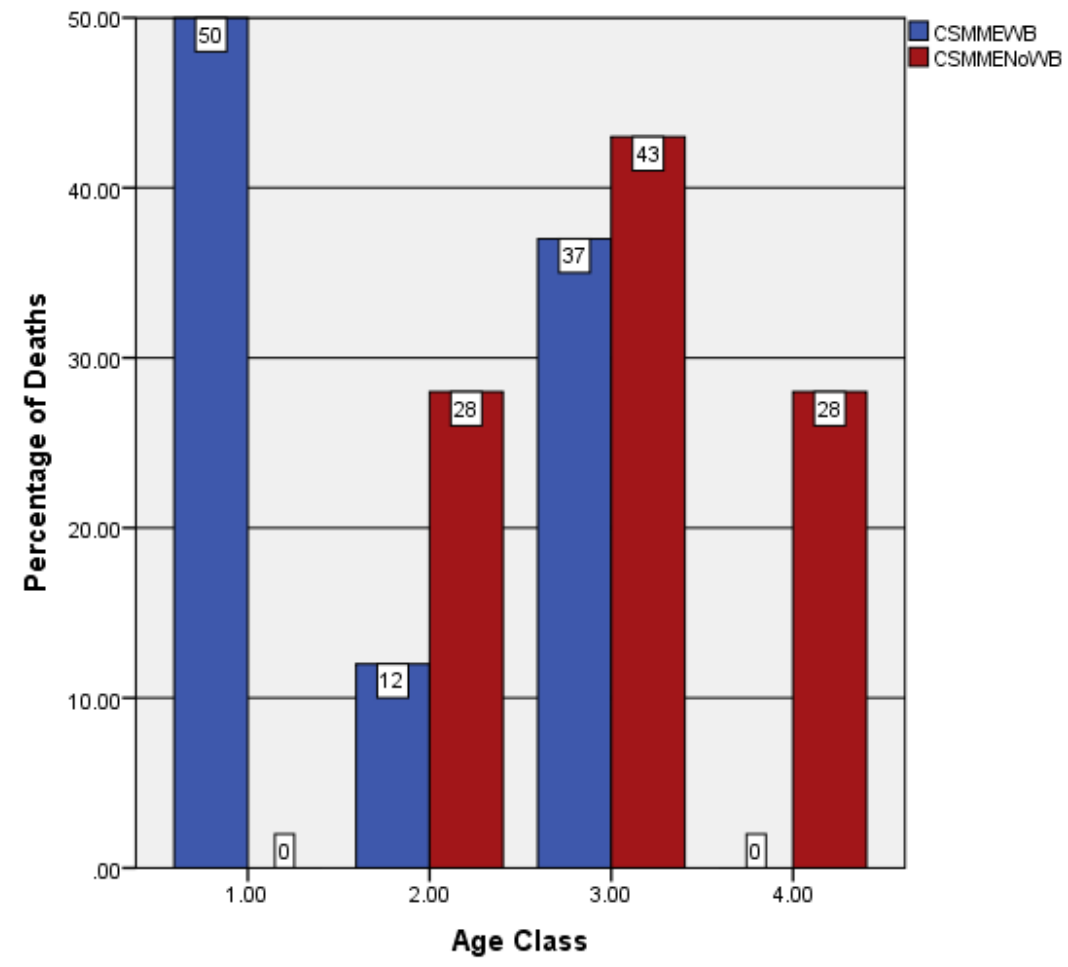

Figure 11: CSMME - Percentage of deaths per age class for individuals with observed WB and individuals without observed WB 
Figures 8 and 9 show which age at death intervals are associated with the highest frequency of Wilson bands. Individuals that died between the ages of 0-2.5 years and 6-12 years had the highest frequency of Wilson bands. Furthermore, individuals that lived past the age of 12 show fairly low frequencies of Wilson bands. Ages 0-2.5 years represents a time of supplemental feeding, possibly the initiation of weaning, and the eruption of deciduous teeth, whereas ages 6-12 capture $2^{\text {nd }}$ molar eruption and the beginning of puberty, suggesting that individuals with high frequencies of Wilson bands had greater difficulty surviving these life history periods. In regards to frequencies of Wilson bands per age class, ANOVA and Tukey's test reveals more variation between groups than within suggesting that the age classes are real groups; however, none of these groups are not statistically significant $(\mathrm{CNS} f=1.319$ and $p=$ $.318 ;$ CSMME $\mathrm{f}=3.462$ and $\mathrm{p}=.065)$. Figure 10 reveals that $72 \%$ of individuals interred at CNS with observed Wilson bands perished within 12 years of birth. Conversely, $75 \%$ of individuals without observed Wilson bands at CNS died after the age of 12. These results are similar to those among the individuals studied from CSMME. There are higher percentages of deaths in the first two age classes at CSMME in comparison to CNS, with no individuals exhibiting Wilson bands making it into adulthood. In fact, $100 \%$ of individuals with observed Wilson bands at CSMME died before the age of 12. Furthermore, results from CSMME reveal a high rate of infant mortality, with $50 \%$ of individuals with observed Wilson bands perishing in infancy before the age of 2.5 years. The mean ages at death are shown in Table 5. At both sites, individuals with observed Wilson bands have a lower mean age at death, 9.6 years for CNS and 4.05 years at CSMME, than individuals without observed Wilson bands, 19.75 years at CNS and 8.8 years at CSMME. Table 5 also reveals that individuals interred at CSMME, overall, had 
lower ages at death, with an average age of death at 6.9 years, in comparison to CNS, which reveals an average age of death at 12.3 years.

\subsection{Testing the Barker Hypothesis - Enamel Hypoplasias as Indicators of Early Mortality}

Data on enamel hypoplasias were available for a large portion of individuals interred at CNS $(\mathrm{n}=184)$ and CSMME $(\mathrm{n}=172)$, thus providing a larger sample set encompassing a wider range of age at deaths with which to test the Barker Hypothesis among the two sites. All dental remains with hypoplasias data were compared to age at death values for each individual. Haagen D. Klaus of George Mason University provided documentation of enamel hypoplasias and age at death estimations (unpublished). For the purpose of this specific research question, biological stress is characterized solely by the presence of enamel hypoplasias. Individuals were scored by the absence (1) or presence (2) of enamel surface hypoplasias on maxillary and mandibular anterior teeth.

Haagen Klaus using SAS 9.1 previously computed bias-corrected summary age values. These age values were subsequently categorized in the same fashion as the Wilson band data. However, since these data sets contained a larger proportion of adults, a fifth age class composed of individuals 18 years and older was included. This captures another life history period - the eruption of the third molar and the transition into adulthood. The number of individuals representing each age class is shown in Table 7. Counts were made for the number of individuals with enamel hypoplasias and the number of individuals without hypoplasias, and percentage of deaths per each age class were calculated for both groups (see Tables 8 and 9). Statistical methods were used to compare the presence of hypoplasias to age at death. An age at death distribution was constructed, showing the percentage of deaths per age class for individuals with 
and without observed enamel hypoplasias. The age at death distribution for each group at each site are represented as graphs in Figures 12 and 13.

Table 6: Site dates, sample size and number of individuals with hypoplasias (EH) and without hypoplasias at each site.

\begin{tabular}{|c|c|c|c|c|c|}
\hline Site & Date Range & Sample Size (n) & EH & No EH & \% with EH \\
\hline CSMME & A.D. 1625-1775 & 172 & 31 & 141 & $18 \%$ \\
\hline CNS & A.D. 1533-1624 & 184 & 64 & 120 & $35 \%$ \\
\hline
\end{tabular}

Table 7: Age demographics of CSMME and CNS. Data provided by Haagen Klaus of George Mason

\begin{tabular}{|c|c|c|c|c|c|c|}
\hline Age Class & $\mathbf{0 - 2 . 5}$ & $\mathbf{2 . 6 - 5 . 9}$ & $\mathbf{6 - 1 1 . 9}$ & $\mathbf{1 2 - 1 7 . 9}$ & $\mathbf{1 8 +}$ & Total \\
\hline CSMME & 125 & 28 & 5 & 4 & 9 & 1 \\
\hline CNS & 69 & 40 & 17 & 26 & 13 & 19 \\
\hline
\end{tabular}

Table 8: CNS - Percentage of total deaths in each age class of individuals with enamel hypoplasias (EH) vs. individuals without observed hypoplasias.

\begin{tabular}{|c|c|c|}
\hline Age Class & \% EH & \% No EH \\
\hline $1=0-2.5$ & $0 \%$ & $49 \%$ \\
\hline $2=2.6-5.9$ & $5 \%$ & $14 \%$ \\
\hline $3=6-11.9$ & $27 \%$ & $4 \%$ \\
\hline $4=12-17.9$ & $14 \%$ & $7 \%$ \\
\hline $5=18+$ & $54 \%$ & $25 \%$ \\
\hline
\end{tabular}

Table 9: CSMME - Percentage of total deaths in each age class of individuals with enamel hypoplasias (EH) vs. individuals without observed hypoplasias

\begin{tabular}{|c|c|c|}
\hline Age Class & \% EH & \% No EH \\
\hline $1=0-2.5$ & $19 \%$ & $57 \%$ \\
\hline $2=2.6-2.9$ & $10 \%$ & $31 \%$ \\
\hline $3=6-11.9$ & $29 \%$ & $4 \%$ \\
\hline $4=12-17.9$ & $10 \%$ & $1 \%$ \\
\hline $5=18+$ & $32 \%$ & $6 \%$ \\
\hline
\end{tabular}




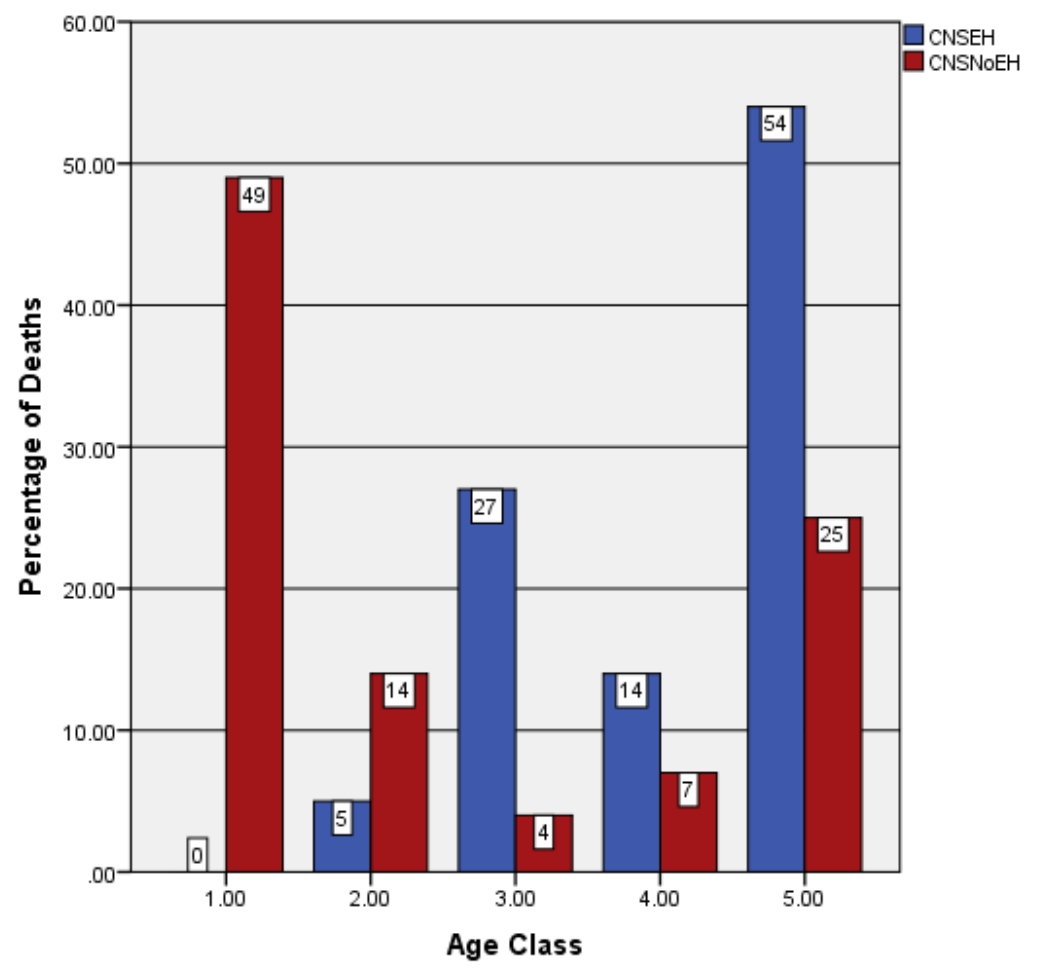

Figure 12. Percentage of total deaths per each age class for CNS. EH = observed hypoplasias and No EH $=$ no observed hypoplasias.

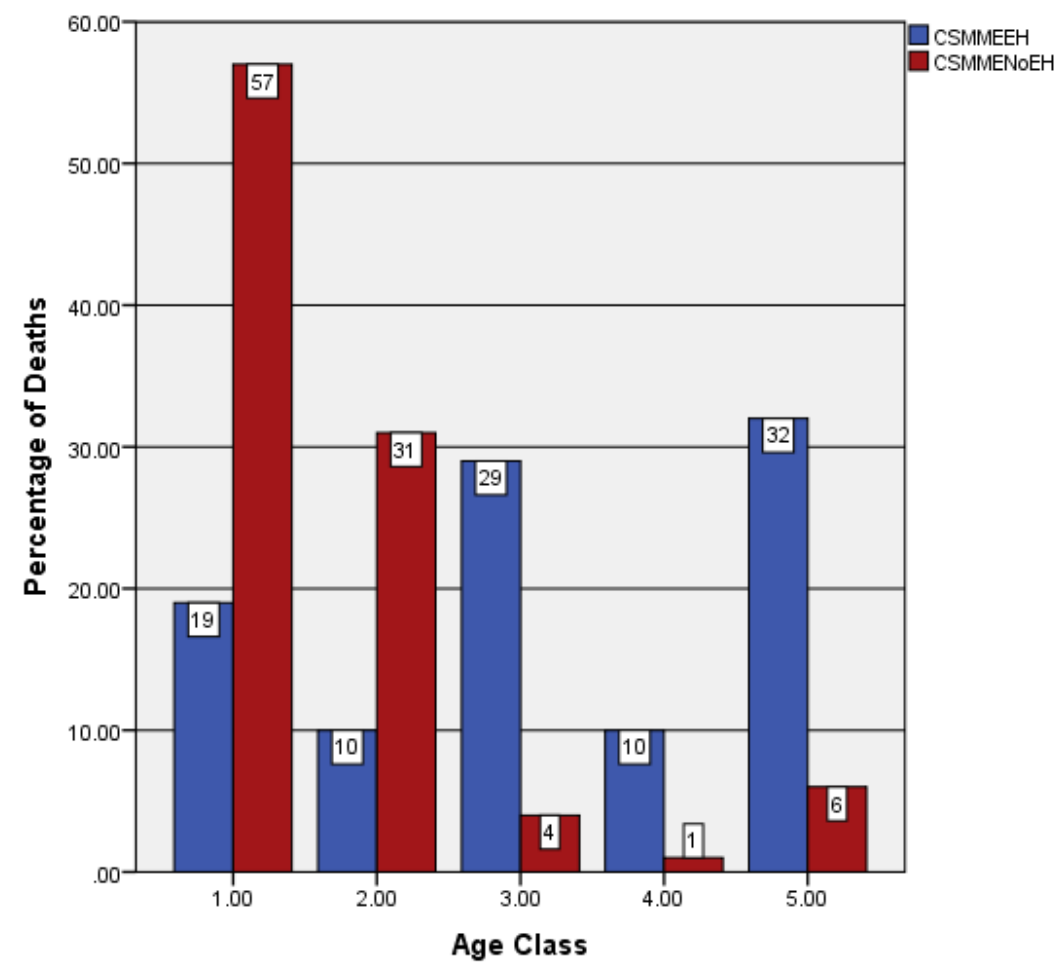

Figure 13. Percentage of total deaths per each age class for CSMME. 
Table 10: Age at death (years) for individuals with observed EH and without observed EH

\begin{tabular}{|c|c|c|}
\hline EH Observation & CSMME & CNS \\
\hline EH & 13.2 & 21.52 \\
\hline No EH & 4.5 & 12.25 \\
\hline All individuals & 6.09 & 15.49 \\
\hline
\end{tabular}

Figures 12 and 13 plot the percentage of deaths in each age class, divided into individuals with observed enamel hypoplasias and individuals without observed enamel hypoplasias. These data reveal that the highest percentage of deaths of individuals without observed enamel hypoplasias at both CNS and CSMME falls within the first age class (49\% and 57\%, respectively. Interestingly, the highest percentage of deaths for individuals with observed enamel hypoplasias at both CNS and CSMME falls within the last age class (54\% and 32\%, respectively). Furthermore, there are a higher percentage of deaths in the first two age classes at CSMME in comparison to CNS, with very few individuals without observed enamel hypoplasias making it to adulthood. Thus, results from CSMME reveal a high rate of infant mortality, with $57 \%$ of individuals without observed enamel hypoplasias perishing before the age of 2.5 and $88 \%$ perishing before the age of 6 . The mean ages at death are shown in Table 10 and statistical significances are shown in the appendix. At both sites, individuals without observed enamel hypoplasias have a lower age at death, at 12.2 years for CNS and 4.5 years at CSMME, than individuals with observed enamel hypoplasias, whose average age at death are 21.5 years at CNS and 13.2 years at CSMME. Figure 9 reveals that individuals interred at CSMME, overall, had lower ages at death, with an average age of death at 6.04 years, in comparison to CNS, which reveals an average age of death of 15.5 years. A Mann-Whitney test reveals that the mean ages of death for individuals with and without enamel hypoplasias at both sites is significantly different $(\mathrm{CNS} \mathrm{z}=-5.526$ and $\mathrm{p}=.000 ;$ CSMME $\mathrm{z}=-5.2$ and $\mathrm{p}=.000)$; however, only age 
classes 1 and 2 and 2 and 3 are significantly different at CNS, and only age classes 1 and 2 are significantly different at CSMME (see Appendix J and K).

\subsection{Discussion}

\subsubsection{Early Life Stress in the Lambayeque Valley Region of Northern Peru}

Indigenous individuals living in post-contact Peru faced a variety of challenges in relation to social, political, environmental and epidemiological transformations that ensued after Spanish colonization. As Crook (1998) succinctly articulates, "child growth has been an effective monitor of economic and social conditions that limit resources and erode adaptive strategies of those living on the margins." These economic and social conditions often arise from political and economic agendas and policies that limit access to natural resources (Crook 1998:339). Limited access to natural resources, in return, can lead to a diet that lacks quantity, quality and diversity. Therefore, childhood growth is a widely accepted indicator of a child's nutritional status and quality of living (Crook 1998:339). Did Spanish policies and transformations, such as the implementation of reducciónes and the alteration of the curaca, lead to social inequality and poverty and, thus, increased early life physiological stress? Were Muchik individuals living in the demographically and economically stable village of Eten negatively impacted by Spanish contact or were the able to find ways to circumvent the negative impacts of these transformations?

To recap, my hypothesis was based on four primary contexts: changing epidemiological patterns associated with Spanish contact, the transformation of social and political structures such as the altering of curacas, the forced resettlement of indigenous populations into dense nucleated colonial towns, and Spanish agricultural and economic policies that subsequently 
resulted in environmental degradation in the Lambayeque region. As revealed in Chapter 4, during the Early Contact period, European infectious diseases, such as smallpox, typhus, and measles, were sweeping through South America. The Lambayeque Valley region did not escape from these epidemics; these diseases were among the first factors contributing to indigenous demographic collapse and socioeconomic disarticulation in the Lambayeque Valley region. By 1540, just eight years after Spanish Contact, many previously thriving villages in the Lambayeque Valley region were demolished, ruined and/or abandoned (Klaus 2008:307). Furthermore, the alteration of curacas disassembled the existing socioeconomic system that promoted reciprocity and collective well-being, and in turn pushed many indigenous populations, such as the Muchik, into poverty (Klaus and Alvarez-Calderón - in press). The curacas were no longer able to build a labor force strong enough to maintain their infrastructure and efficiently procure local natural resources and produce a surplus. The implementation of reducciónes forcefully separated indigenous populations from diverse ecological zones and placed them into population dense and resource restricted colonial towns (Klaus 2008:319). Additionally, the movement of indigenous people into nucleated colonial towns left no one to maintain irrigation canals that supplied drinking water and water for plant cultivation. These factors, compounded by Spanish agricultural policies such as mono-crop agriculture, also lead to environmental degradation in the Lambayeque region (Klaus and Alvarez-Calderón - in press). As elucidated in Chapter 2, social inequality and poverty are highly correlated with developmental stress and worsened health outcomes (Brunner 1997; Goodman 1998; Klaus 2008; Nguyen and Preschard 2003). This begs the question - how did these factors impact infant and early childhood mortality and morbidity in the Lambayeque Valley region of Peru and what information can be gleaned from the observation of Wilson bands? Major stressors in infancy, the stage a life 
lasting from birth until age 3, generally revolve around infant feeding practices and disease. Were nutritionally dense and pathogen free foods readily accessible for infant supplemental feeding and weaning after Spanish Contact?

Dental enamel preserves the early life history of individuals and associated physiological stresses. Enamel defects are indicators of non-specific stresses that are often associated with disease and malnutrition. Their prevalence along with early life mortality rates provides wellaccepted demographic markers of a population's adaptation to its living conditions; however, high childhood mortality rates are common in most nonindustrial countries (FitzGerald et al 2006:180). Nonetheless, as Fitzgerald et al (2006:185) note, high infant mortality rates and increased prevalence of enamel defects are "barometers" of social, political, economic and ecological factors, especially in regards to infant feeding and care. The process of supplementation feeding and weaning are often associated with increased physiological stress, infant mortality and morbidity; contaminated water and unhygenically prepared foods that are supplemented at an early age and infants' loss of passive immunity from their mothers are two possible contributing factors (Katzenberg et al 1996:177). As Katzenberg et al. (1996:177) assert, skeletal evidence, such as enamel defects, and nitrogen isotopic analysis can be used to reconstruct infant feeding practices in past populations. Furthermore, these analyses can be used to infer relationships between associated social, political, and ecological factors that impact infant feeding practices and early life mortality and morbidity.

The beginning of supplemental feeding marks a time during which foods and water are first introduced to an infant. According to Sellen (2006:185), after 6 months of age and until weaning, breast milk remains as a primary source of nutrients and immune protection; however, supplemental feeding becomes necessary in order to support increased dietary demands. Cross- 
cultural comparisons reveal that supplemental feeding patterns are highly variable, however, on average it typically begins around 6 months of age (Sellen 2006:185). Infant mortality and morbidity tends to be higher in populations where sanitation, safe water access and social conditions are poor and where infants are either not breastfed at all or are supplemented or weaned at an early age onto nutritionally poor or contaminated food and water (Herring et al. 1998:427; McGarvey 2009:235). Furthermore, early transition from breast milk to supplemental foods tends to be associated with weanling diarrhea and food allergies (Herring et al. 1998:427). For example, Arifeen et al. (2001) found the exclusively breastfeed infants in contemporary Dhaka slums were less likely to die from diarrheal disease or respiratory infection. According to McGarvey (2009:235), in contemporary settings, insufficient or a lack of breastfeeding is strongly correlated with infant mortality and morbidity, especially in the first six months of life.

Developed chronologies of Wilson band occurrence varies from study to study. Similar to the present study, Fitzgerald et al. (2006:185) reveal that frequencies of Wilson bands in deciduous teeth from an imperial Roman skeletal sample begin to increase at two months and peak around 6 months. Based on historical documents, FitzGerald et al. (2006:185) note that in ancient Rome, supplemental foods were introduced around 3 months of age, arguing that this represents a time of vulnerability for infants in that nutritionally-suspect or unhygenically prepared foods were often supplemented. In another study, Karhu (1991) also found peak Wilson band frequency from birth to 6 months of age, though gives no inference on the possible stressor. Unfortunately, limited data are available in regards to infant feeding practices in postcontact Peru, with modern analogs being the primary point of comparison. With that said, can the chronology of Wilson bands provide any insight into infant feeding practices and quality/quantity of available food? If so, what does it tell us about life in post-contact Peru? As 
will be discussed, results of the present study are similar to those of FitzGerald et al. (2006) and Karhu (1991), thus providing a cross-cultural comparison to strengthen the argument that Wilson bands forming in the first 6 months of life may be attributed to quality of supplemental food and water.

Patterns of early life stress were examined using Wilson band data collected from a total of 30 individuals. As hypothesized, Wilson bands are prevalent in samples from both CNS and CSMME, with 19 of the 30 teeth examined exhibiting at least one Wilson band. In contrast to the original hypothesis, results reveal a higher prevalence of both Wilson bands and enamel hypoplasias at the earlier CNS site (73\% and 35\%, respectively) in comparison to the later CSMME site (53\% and 18\%, respectively). Analysis of Wilson band frequencies in the samples indicates that CNS had a slightly greater mean frequency of bands per individual (2.8) in comparison to CSMME (2.375). However, overall, Wilson band frequencies between the two sites are not significantly different $(\mathrm{p}=.398)$. As previously stated, this may be a result of high variation in each group resulting in a standard deviation that is as large as, if not larger than, the mean. Similar bioarchaeological studies of internal enamel micro-defects also reveal a high prevalence of Wilson bands in post-contact populations. As discussed in Chapter 2, Simpson (1999) and Wright (1990) both reveal not only a high prevalence of Wilson bands, but also increased numbers of Wilson bands per tooth in mission samples from La Florida and Belize, respectively. For instance, Simpson (1999) revealed a prevalence rate of $83 \%$ in Mission era samples in comparison to $36 \%$ in pre-contact samples. Similarly, Wright (1990) revealed a Wilson bands prevalence of $97 \%$, with an average of 2.4 per tooth in Mission samples in comparison to .88 Wilson bands per tooth in pre-contact samples. At first glance, these results suggest higher prevalence rates in comparison to the present study; however, Simpson (1999) 
and Wright's (1990) research examined canines, which are more hypoplastic than molars and generally reveal higher frequencies of enamel defects. Taking this into consideration, one would hypothesize that higher prevalence rates would have been produced in this study if canines were examined instead of first molars. It also must be noted that the Wilson band frequencies in this study should be recognized as being understated; inherent difficulties in distinguishing some Wilson bands from striae of Retzius most likely resulted in a lower estimated prevalence of Wilson bands. Moreover, poor preservation of enamel close to the cervical margin during thinsectioning may also have resulted in lowering the estimated prevalence of Wilson bands. In sum, even though results indicate a temporal decrease in the prevalence of Wilson bands in individuals who lived in Eten suggests acclimation, it is argued that there were still substantial levels of early life stress. Enamel defect results, along with high infant mortality rates, indicate high levels of early life stress at both sites. However, this is limited since the present study does not include a pre-contact population for comparative purposes. The decrease in prevalence rates may indicate that long-term, the Muchik population at Eten was behaviorally and culturally adaptive to Spanish colonization and the subsequent social, political and economic transformations.

Identifying periods associated with stress events during early childhood provides further information about a population's stress. The developed chronology of Wilson band occurrence reveals two peaks in frequencies: between the ages of 4 to 5 months and between the ages of 8 to 10 months (see Figure 7). This pattern is consistent at both sites, with $48 \%$ of all Wilson bands occurring between the ages of 4 to 6 months and $25 \%$ occurring between the ages of 8 to 10 months. An increased frequency of Wilson bands during the first few months of life may mark the onset of infant supplemental feeding. According to Simpson (1999:257), water is crucial in 
the formation of enamel matrix and any external factor that may disrupt normal fluid and electrolyte balance could lead to the development of Wilson bands. The results generated here suggests that acute diarrhea from a number of stress events, such as bacterial infections or early supplementation/weaning effects, may have led to dehydration and the formation of Wilson bands.

Based on the chronologies of Wilson bands, it is suggested that early supplementation with contaminated or nutritionally void food may have resulted in the high prevalence of Wilson bands in the first 6 months of life. This may have been compounded by changing epidemiological patterns associated with early Spanish contact, affecting both children and breastfeeding mothers. Even though lactation performance is typically resilient to maternal malnutrition, it is possible that early supplementation occurred with the onset of illness in a breast-feeding mother (Sellen 2006:162). Additionally, given the cultural context discussed in Chapter 5, political and economic factors associated with Spanish colonization may have resulted in not only contaminated and/or limited water supplies, but also unequal access to water resources and or nutritionally dense food. Spanish mono-crop policies focusing on maize and sugar cane may have resulted in a less nutritious and diversified diet. Moreover, these crops were so "water-hungry" that they left little water for Muchik subsistence farming and drinking water (Klaus 2008:326). This could have been compounded by unhygenically prepared food due to insalubrious living conditions associated with poverty-stricken reducciónes, thus resulting in less than desirable food and water quality for early supplemental feeding. As discussed below, preliminary carbon and oxygen isotopic analysis of bone and tooth enamel carbonate from CNS and CSMME are consistent with these arguments. FitzGerald et al. (2006:186) note that infant vulnerability can increase if the supply of breast milk or supplemental food is inadequate during 
times of acceleration in the velocity of growth. One such growth spurt often occurs around 9 months of age (FitzGerald et al. 2006:186). Enamel micro-defect results are consistent with this assertion; at both sites, the second peak in Wilson band frequency occurs around 9 and 10 months of age. However, most individuals exhibiting Wilson bands in the 4-6 month age range also exhibit Wilson bands in the subsequent 8 to 10 month peak. Therefore, the second peak in Wilson band occurrence could merely reflect one's frailty and exposure to continuous stress assaults.

\subsubsection{Barker Hypothesis - Enamel Defects as Indicators of Early Mortality}

Based on the Barker hypothesis, since early life stress is associated with decreased health and longevity, individuals with observed enamel hypoplasias and Wilson bands should reveal lower ages at death. At first glance, ages-at-mortality rates are consistent with the overall hypothesis that indigenous Andean populations experienced tremendous amounts of stress as a result of the Spanish colonization of Peru. Average age at death for all individuals interred at the later CSMME site (6.05 years) is more than half that of the average age at death for individuals interred at the earlier CNS site (15.5 years). Average age at death for the subsamples selected for internal micro-defect analysis is consistent with this overall pattern; the selected samples from CSMME reveal an average age at death at 6.9 years, whereas the selected samples from CNS have an average age at death at 12.3 years. This is expected taking into consideration the previously discussed cultural context. However, as will be discussed, high levels of infant mortality may also indicate high fertility and birthrates within a population. The results comparing age a death of individuals with and without observed enamel hypoplasias seem to contradict the Barker hypothesis; individuals at both sites without indicators of physiological perturbations in the form of enamel hypoplasias were overall dying at a younger age in 
comparison to those with observed enamel hypoplasias. However, this is not the case for Wilson bands; at both sites the majority of individuals exhibiting Wilson bands perished before the age of 12 (73\% at CNS and 100\% at CSMME). Conversely, $75 \%$ of individuals without observed Wilson bands at CNS survived past the age a 12 , whereas $71 \%$ of individuals at CSMME survived past the age of 6 , with $28 \%$ of surviving past the age of 12 .

According to Robson et al. (2006:35), dental development and eruption is often used as a marker of early life history events. For instance, the emergence of the first permanent tooth marks the transition to the juvenile period, the eruption of the second molar marks the transition to adolescence, and the eruption of the last permanent tooth marks the transition to adulthood (Robson et al 2006:35). As previously stated, age classes were categorized based on major early life history periods, each associated with different developmental stages and dental eruptions. Infancy (ages 0-2.5 years) represents a time of deciduous incisor and canine eruption, breastfeeding and supplemental feeding, rapid growth velocity and many developmental milestones in physiology, behavior and cognition (Bogin 2006:206). The childhood period (ages 2.5-5.9 years) is characterized by moderate growth rate, a continuation of deciduous teeth eruptions and possibly first molar eruption, a cessation in the consumption of breast milk, and near completion of brain growth towards the end of the period (Bogin 2006:206). The juvenile period (ages 6-11.9 years) is marked by first molar eruption, a slower growth rate, self-feeding capability and an increase in economic and social skills (Bogin 2006:206). This period also captures the onset of puberty. The subadult, or adolescence, stage (ages 12-17.9 years) begins after the onset of puberty and represents a time of second molar eruption and a growth spurt in height and weight. 
Is there a relationship between the presence of enamel micro-defects and death within specific life history periods? Overall, and especially at CSMME, the infancy and juvenile periods are associated with the highest percentage of deaths for individuals exhibiting Wilson bands (see figures 10 and 11). Comparing the actual frequencies of Wilson bands to age at death classes provides another interesting analysis; instead of comparing age at death to solely the presence or absence of Wilson bands, this analysis looks at which age at death classes are associated with the highest frequency of Wilson bands. In other words, are individuals with high Wilson band frequencies, possibly indicating repeated stress assaults, dying during specific life history periods? Similar to age classes associated with the highest percentages of deaths, a distribution of the frequency of Wilson bands at different age at death intervals reveals that ages at death between the infancy and juvenile periods are associated with the highest frequency of Wilson bands. As previously discussed, Wilson bands in this study are possibly associated with infant feeding practices in which nutritionally void or contaminated food and water were supplemented at an early age. During the juvenile period, the first molar and incisors erupt, allowing for sufficient capabilities to eat foodstuff similar to that of adults (Bogin 2006:210). In other words, the juvenile stage is associated with "feeding semi-independence," something younger children are not able to do. Furthermore, this time period represents the slowest growth rate since birth. Bogin (2006:211) asserts that this is a trade of between growth and learning; the learning and practice of food procurement and social behavior takes place during the juvenile period. In sum, individuals experiencing early life physiological stress in the form of malnutrition and infection due to contaminated food and water had difficulties surviving through the infancy and juvenile life history periods. Individuals with observed Wilson bands who perished during infancy were most likely malnourished and did not receive the proper nutrition 
needed for the rapid growth velocity, especially that of the brain, and associated developmental milestones. If an individual with observed Wilson bands survived through the infancy period, they most likely did not survive through the juvenile period. Only $27 \%$ of individuals at CNS and $0 \%$ individuals at CSMME survived past the juvenile stage.

Interestingly, the earlier CNS site had a higher prevalence of both observed enamel hypoplasias and observed Wilson bands. However, it must be noted that the observed Wilson bands and enamel hypoplasias in this study likely arose from different etiologies. The developmental sequence of enamel of anterior teeth is much different than that of molars; for instance, enamel forms on the canines between the ages of 1.5 to 6 years in comparison to 1 to 3 years on first molars. Furthermore, the frequency of Wilson bands in this study peak around 5 months of age, much early than the peak frequency of enamel hypoplasias on the anterior teeth. As previously discussed, research has shown that anterior teeth have peak hypoplasia frequencies of approximately 2 to 2.5 years in most populations (Goodman and Armelagos 1985). However, other research has revealed peak frequencies of enamel hypoplasias in anterior teeth as high as 3 years of age (Katzenberg et al. 1996:177). These peak frequencies are often contributed to the onset of weaning (Katzenberg et al. 1996; Herring et al. 1998). Individuals interred at CSMME reveal a very low age at death, with an overall $61 \%$ dying before the age of 2.5 . Therefore, one possibility to explain the contradiction with the Barker hypothesis in regards to enamel hypoplasias is that many individuals may have died before or while enamel apposition on the anterior teeth was occurring, thus, if at the right time, leaving no hypoplastic defects embedded in the enamel. It must also be noted that the inconsistency with the Barker hypothesis in regards to enamel hypoplasias may, in part, be explained by the concept of "hidden heterogeneity in risk," a fundamental aspect of the osteological paradox. The selected sample is made up of 
individuals that may have variations in underlying "frailty," or susceptibility to disease and death, due to genetic and/or environmental factors (Wood et al. 1992:345). According to Wood et al (1992), this could confound aggregate-level mortality analyses, such as the present study.

\subsubsection{Concluding Remarks}

In conclusion, I revisit my original hypothesis that an increase in biological stress, possibly due to poverty and early life malnutrition in the Lambayeque region associated with Spanish colonialism, should be revealed by a higher prevalence of Wilson bands in individuals interred at the CSMME site in comparison to individuals interred at the CNS site. However, as discussed, results reveal a higher prevalence of Wilson bands at the earlier CNS in comparison to the later CSMME site. At this juncture, two different perspectives may explain the differences in the prevalence of both Wilson bands and enamel hypoplasias between CNS and CSMME. First, it can be suggested that the high prevalence and number of Wilson bands per individual at the two sites may reflect changing epidemiological patterns and differential access to natural resources. However, a lower prevalence of Wilson bands and enamel hypoplasias at the later CSMME site in comparison to the earlier CNS site may indicate that, long-term, the Muchik population may have begun to adapt to Spanish transformations, especially in regards to accessing quality food and water for infant supplemental feeding and weaning. This is plausible given the fact that Eten was located on an ecotone, surrounded by multiple, resource-dense microenvironments. As elucidated in chapter 4, the Muchik persisted throughout multiple cultural developments, each with associated changes in social, political and economic structures. Furthermore, demographic data suggests that, following waves of epidemic diseases, the Lambayeque region began to rebound in the mid-1600s (Cook 1981). It is, therefore, reasonable 
to assume that Muchik individuals at Eten, after an initial disruption to life in the Early Contact period, continued to persist, independently cultivating crops and exploiting the abundant natural resources the surrounding microenvironments had to offer.

Preliminary isotopic results are consistent with the perspective that during the Middle/Late Colonial Period, Muchik individuals began to acclimate to Spanish social, political and economic transformations. Delta ${ }^{13} \mathrm{C}_{\text {diet }}$ values at both CSMME (ranging from -12.9 to 18.7) and CNS (-10.0 to -16.4) are indicative of a diet likely rich in $\mathrm{C}_{4}$ plant sources, such as sugar cane and maize. Though it must be noted that the isotopic signature of marine fish parallels that of $\mathrm{C}_{4}$ plants; therefore, $\delta^{13} \mathrm{C}_{\mathrm{diet}}$ values could also reflect a diet rich in marine based resources (Finucane et al., 2006). However, mean $\delta^{13} \mathrm{C}_{\text {diet }}$ values for bone carbonate are slightly more negative for CSMME in comparison to CNS (-14.7 and -12.6, respectively), suggesting that Muchik individuals living in the Middle/Late Colonial Period may have had a more varied diet that incorporated more $\mathrm{C}_{3}$ plant sources, such as beans and squash. Furthermore, $\delta^{18} \mathrm{O}_{\mathrm{dw}}(\mathrm{V}$ SMOw) values from CSMME bone and enamel carbonate align with $\delta^{18} \mathrm{O}$ values from higher altitude yunga zones (Knudson 2009). Since $\delta^{13} \mathrm{C}_{\text {diet }}$ values do not correspond to values associated with $\mathrm{C}_{3}$ rich yunga zones, these results suggest that individuals interred at CSMME did not originate from a yunga zone, but may have been exploiting riverine and underground aquifer water sources for drinking water, or utilizing irrigation waters that originated from higher elevations. Mean $\delta^{18} \mathrm{O}_{\mathrm{dw}(\mathrm{V}-\mathrm{S} M O w)}$ values for CSMME bone carbonate differ from Mean $\delta^{18} \mathrm{O}_{\mathrm{dw}(\mathrm{V} \text { - }}$ SMOw) values for CNS bone carbonate (-6.9 and -5.0 , respectively), possibly suggesting differential access to natural water resources during the Early Colonial Period. Future nitrogen isotopic analysis will not only allow for further explication of $\mathrm{C} 4$ signatures reflecting the 
exploitation of terrestrial plant or marine resources, but also help determine infant supplementation and/or weaning age.

A second perspective emerges when interpreting the lower prevalence and number of Wilson bands and enamel hypoplasias at the later CSMME site within the context of age at death data. Individuals interred at the later CSMME site, overall, had lower ages at death, with an average age of death of 6.04 years, in comparison to the earlier CNS site, which reveals an average age of death of 15.5 years (59\% of CSMME individuals died before the age of 5 and a high percentage of those died before age of one or two while molar crowns were still forming). It is, therefore, possible that many individuals died from episodes of stress or disease before enamel hypoplasias and Wilson bands had a chance to form. The crown of the first molar begins to develop at birth and is complete around 3 years of age. Enamel growth defects in the first molars will, therefore, capture stress events that occurred in infancy from approximately birth to 3 years of age. If an individual died prematurely, especially if they died very quickly in the first year of life or during weaning, they may not reveal any enamel defects. Within this perspective, it could be argued that early contact children had more survivable stress and disease events that most likely shifted to high mortality stress and disease events at the later CSMME site. This is reflected by a lower prevalence of both Wilson Bands and enamel hypoplasias and lower ages at mortality at CSMME in comparison to CNS. However, a skeletal sample with a high number of infants may be a result of high birthrates and female fertility. Therefore, calculating female fertility may help tease out which of the previously discussed perspectives are more plausible.

In terms of paleodemography, the increase in early life death may actually indicate an increase in fertility and birth rates. In other words, age at death distributions in a skeletal population may tell more about fertility than mortality. Female fertility is estimated as the 
inverse of the proportion of individuals older than 30 years of age $\left(D_{30+}\right)$ over the number of individuals older than 5 years of age $\left(\mathrm{D}_{5+}\right)\left(\right.$ Fertility $\left.=\mathrm{D}_{30+} / \mathrm{D}_{5+}\right)($ Buikstra 1985 ; Klaus and Tam 2009; Larsen 2002). Here, results reveal an increase in fertility from the Early Colonial Period (0.39 at CNS) to the Middle/Late Colonial Period (0.27 at CSMME). Interestingly, female fertility is much higher in both CNS and CSMME in comparison to published data on the nearby post-contact site of Mórrope (.602) (Klaus and Tam 2009:363). However, similar to this study, fertility rates increased at Mórrope from the Early to Late Colonial Periods. Demographic data reveals that around 1640, following the initial wave of European epidemics, the Lambayeque region began to stabilize and repopulate (Cook 1981:143). Thus, an increase in fertility and birthrates, along with a decrease in physiological stress associated with disease and malnutrition, may indicate that during the Middle/Late Colonial Periods, Muchik individuals adjusted and acclimated to Spanish contact and oppression.

The present study sought to characterize early life stress on the coast of northern Peru during the Spanish Contact periods. This was in an effort to not only add a bioarchaeological perspective from South America to help create a more hemispheric-level understanding of the biological consequences of European contact in the New World, but to also lend a voice to the Muchik individuals that inhabited the Lambayeque Valley whose lives, most likely insignificant in the eyes of the Spanish rulers, may otherwise have been lost to history. Further analysis, such as comparison to multiple health/stress data, pre-Hispanic fertility and birthrates, isotopic results, and future histological examination of not only a larger post-contact subsample, but also precontact samples, is needed to tease out which of the previously discussed perspectives is the most plausible. However, at this juncture the first perspective is more plausible. Overall, the results reveal fairly high levels of short-term early life stress in the individuals interred at both $\mathrm{La}$ 
Capilla Santa María Magdalena De Eten (CSMME) and the La Capilla Del Nino Serranito (CNS). These stresses are contributed to social, political and environmental transformations associated with Spanish colonization, likely resulting in not only changes in epidemiological patterns, but also alterations in subsistence patterns and access to natural resources, ultimately leading to a reduction in the quality and quantity of resources available for early infant supplementation. However, the temporal decrease in the prevalence of Wilson bands, along with higher birthrates and female fertility at the later CSMME site, suggests that during the Middle/Late Colonial Period the Muchik began to adjust to these transformations. 


\section{REFERENCES}

Arifeen, $\mathrm{S}$.

2001 Exclusive breastfeeding reduces acute respiratory infection and diarrhea deaths among infants in Dhaka slums. In Pediatrics 108:1-8.

Andrien, K.J.

2001 Andean Worlds: Indigenous History, Culture, and Consciousness Under Spanish Rule, 1532-1825. University of New Mexico Press: Albuquerque, NM.

Agarwal, S.C. and Glencross, B.A 2011 Building a Social Bioarchaeology. In Social Bioarchaeology, Agarwal, S.C. and Glencross, B.A. (editors). Wiley-Blackwell Press: West Sussex, United Kingdom.

Armelagos, G.J., Goodman, A.H., Harper, K.N., and Blakey, M.L. 2009 Enamel hypoplasias and early mortality: Bioarchaeological support for the Barker hypothesis. In Evolutionary Anthropology, 18:261-271

Baker, B.J. and Kealhofer, L. 1996 Bioarchaeology of Native American Adaptation in the Spanish Borderlands. Baker, B.J. and Kealhofer (editors). University Press of Florida: Gainesville, Florida

Blakely, M.L and Armelagos, G.J.

1985 Deciduous enamel defects in prehistoric Americans from Dickson Mounds: Prenatal and Postnatal Stress. In American Journal of Physical Anthropology, 66:371-380

Borgin, B. 2006 modern human life history: The evolution of human childhood and fertility. In The Evolution of Human Life History. Hawkes, Kristen, and Paine, Richard (Editors), School of American Research Press: Santa Fe, NM. Pp. 197-230

Boyde, A. 1997 Microstructure of enamel. In CIBA FOUNDATION SYMPOSIA, 205:18-31

Brunner, E.

1997 Socioeconomic determinants of health: Stress and the biology of inequality. In British Medical Journal, 314:1472-1476.

Cabo, B. 1653 (1990) Inca Religion and Customs. University of Texas Press: Austin, Texas

Clement, A.J.

1963 Variations in the Microstructure and Biochemistry of Human Teeth. In Dental: Anthropology. Brothwell, D.R. (editor), Pergamon Press: New York, New York. 
Cook, N.D.

1981 Demographic Collapse: Indian Peru, 1520-1620. Cambridge University Press:

Cambridge, U.K.

Covey, A.

2006 How the Incas Built their Heartland. University of Michigan Press: Ann Arbor Michigan.

Crook, D.

1999 Child Growth and Nutritional Status in a High-Poverty Community in

Eastern Kentucky. In American Journal of Physical Anthropology, 109:129-142

Deagan, K.

2003 Colonial origins and colonial transformations in Spanish America. Historical Archaeology, 37:3-13

Donohoe, $\mathrm{M}$.

2003 Causes and health consequences of environmental degradation and social justice.

In Social Science and Medicine, 56:573-587.

Finucane, B., Agurto, P.M.., and Isbell, W.H.

2006 Human and animal diet Conchopata Peru: Stable isotope evidence for maize and animal management practices during the Middle Horizon. In Journal of Archaeological Science 33:1766-1776

Fitzgerald, C.M.

1998 Do Enamel microstructures have regular time dependency?

Conclusions from the literature and a large-scale study. In Journal of

Human Evolution, 35:371-386

FitzGerald, CM. and Saunders, S.

2005 Test of histological methods of determining chronology of

accentuated striae in deciduous teeth. In American Journal of Physical

Anthropology, 127:270-290

FitzGerald, CM., et al.

2006 Health of infants in a Imperial Roman skeletal sample: Perspectives from dental

microstructures. In American Journal of Physical Anthropology. 130:179-189

Goodman, A.H.

1984 Health Changes at Dickson Mound, Illinois (A.D. 950-1300). In Paleopathology at the Origins of Agriculture, Cohen M.N. and Armelagos, G.J., pp. 271-305 
Goodman, A.H.

1998 The Biological Consequence of Inequality in Antiquity. In Building a New

Biocultural Synthesis. Goodman, A.H. and Leatherman, T.L (editors), The University of Michigan Press: Ann Arbor, Michigan.

Goodman, A.H and Rose, J.

1990 Assessment of systemic physiological perturbations from dental enamel hypoplasias and associated histological structures. In American Journal of Physical Anthropology, 33:59-110

Goodman, A.H and Rose, J.

1991 Dental Enamel Hypoplasias as Indicators of Nutritional Status. In: Advances in Dental Anthropology. Kelly and Larsen (editors). Wiley-Less, Inc. New York, New York. Pp 279-293.

Goodman, A.H. and Armelagos, G.

1985 Factors affecting the distribution of enamel hypoplasias within the human permanent dentition. In American Journal of Physical Anthropology, 68:479-493.

Hagen, A.V. and Morris, C. 1998 The Cities of the Ancient Andes. Thames and Hudson Ltd: London, U.K.

Herring, D.A., Saunders, S.R. and Katzenberg, M.A.

1998 Investigating the weaning process in past populations. In American Journal of Physical Anthropology, 105:425-439.

Hillson, S.W.

1979 Diet and dental disease. In World Archaeology, 11:147-162.

Hillson, S.W.

1992 Dental enamel growth, perikymata and hypoplasia in ancient tooth crowns. In J.R. Soc Med, 85:460-466.

Hillson, S.W. and Bond, S.

1997 Dental enamel growth, perikymata and hypoplasia in ancient tooth crowns. $J . R$. Soc Med, 85:460-466

Hillson, S.W. and Dean M.C. 1999 The periodicity of enamel cross-striations based on the developing permanent dentition of known-age children from Spitalfields. In American Journal of Physical Anthropology, Abstract. 
Huda, T.F.J. and Bowman, J.E.

1994 Variation in cross-section number between striae in an archaeological population. In International Journal of Osteoarchaeology, 4:49-52.

Huda, T.F.J. and Bowman, J.E.

1995 Age determination from dental microstructures in juveniles. In

American Journal of Physical Anthropology, 97:135-150.

Katzenberg, M.A., Herring, D.A., and Saunders, S.R.

1996 Weaning and infant mortality: Evaluating the skeletal evidence. In Yearbook of Physical Anthropology, 39:177-199.

Keatinge, R.

1988 Peruvian Prehistory. Cambridge University Press: New York, New York

Kelly, M.A. and Larsen, C.S

1991 Advances in Dental Anthropology. Wiley-Less, Inc. New York, New York.

King S.E. and Ulijaszek, S.J.

1999 Invisible Insults During Growth and Development: Contemporary Theories and Past Populations. In Human Growth in the Past: Studies from Bones and Teeth. Hoppa R.D. and FitzGErald C.M. (editors). Cambridge University Press: Cambridge, United Kingdom.

Klaus, H.D.

2008 Out of the Light Came Darkness: Bioarchaeology of Mortuary Ritual, Health, and Ethnogenesis in the Lambayeque Valley Complex, North Coast Peru, A.D. 900-1750. Unpublished Ph.D. dissertation: Ohio State University.

Klaus, H.D. and Rosabella, A.C.

In Press-Need permission to site: Escaping Conquest: Initial Perspectives on the Diversity of Biocultural Responses. Book Chapter prepared for: Bioarchaeology of Contact, Colonial Encounters and Colonialism: Global Visions and New Approaches from Studies of Human Skeleton. Murphy, M.S. and Klaus, H.D. (editors). University of Florida Press.

Klaus, H.D. and Tam, M.E.

2009 Contact in the Andes: Bioarchaeology of systemic stress in Colonial Morrope, Peru. American journal of Physical Anthropology, 138:356-368

Knudson, K.J 2009 Oxygen isotope analysis in a land of environmental extremes: The complexities of isotopic work in the Andes. In International Journal of Osteoarchaeology 19:171-191

Kolata, A.L.

2013 Ancient Inca. Cambridge University Press: New York, New York 
Larsen, C.S.

1997 Bioarchaeology: Interpreting behavior from the human skeleton. Cambridge University Press: Cambridge, U.K.

Larsen, C.S.

2000 Reading the Bones of La Florida. Scientific American 282:80-85.

Larsen, C.S.

2001a Bioarchaeology of Spanish Florida: The Impact of Colonialism. Gainesville: University Press of Florida.

Larsen, C.S.

2001b Frontiers of contact: Bioarchaeology of Spanish Florida. Journal of World Prehistory, 15:69-123.

Larsen, C.S.

2002 Bioarchaeology: The lives and lifestyles of past people. Journal of Archaeological Research, 10:119-148

Marks, M.K. and Rose, J.C. 1996 Thin section procedure for enamel histology. In American Journal of Physical Anthropology, 99:493-498.

McGarvey, S.T.

2009 Interdisciplinary Transitional Research in Anthropology, Nutrition and public Health. In Annual Review of Anthropology 38:233-249

Moore, J.D.

1996 The archaeology of plazas and the proxemics of ritual. American Anthropologist, 98:789-802

Morris, C.

2008 Links and chain of Inca cities: Communication, alliance, and the cultural production of status, Value and Power. In The Ancient City: New Perspectives on Urbanism in the Old and New World. pp 299- 319.

Moseley, M.E.

1992 The Incas and Their Ancestors: The Archaeology of Peru. London: Thames and Hudson.

Murra, J.V.

1980 The Economic Organization of The Inka State. Greenwich, CT: JAI Press.

Nguyen, Vinh-Kim, and Peschard, K 2003. Anthropology: Inequality, and disease: A review. Annual Review of Anthropology, 32: 447-474. 
Price, D. J.

2012 An Introduction to Archaeological Chemistry. Springer.

Quilter, J.

2002 Moche politics, religion and warfare. In Journal of World History, 16:145-187.

Ramirez, S.E.

1996 The World Upside Down: Cross-Cultural Contact and Conflict in Sixteenth-

Century Peru. Stanford University Press: Stanford California

Reid, D. and Ferrell, R.

2006 The relationship between number of striae of retzius and their periodicity in imbricational enamel formation. In Journal of Human Evolution, 50:195-202

Reid, D.J., Beynon, A.D. and Ramirez-Rozzi, F.V. 1998 Histological reconstruction of dental development in four individuals from a medieval site in Picardie, France. In Journal of Human Evolution, 35:463-477.

Reitsema, L.J.

2013 Beyond dietary reconstruction: Stable isotope application to human physiology, health and nutrition. American Journal of Human Biology.

Reitsema, L., Crews, D., and Polcyn, M.

2010 Preliminary evidence for medieval Polish diet from carbon and nitrogen isotopes. Journal of Archaeological Science, 37:1413-1423

Robson, S.L., van Schaik, C.P. and Hawkes, Kristen 2006 The derived features of human life history. In The Evolution of Human Life History. Hawkes, Kristen, and Paine, Richard (Editors), School of American Research Press: Santa Fe, NM. Pp. 17-44

Rose, J.C.

1977 Defective enamel histology of prehistoric teeth from Illinois. In American Journal of Physical Anthropology, 46:439:446.

Sellen, D.W. 2008 Lactation, Complementary Feeding, and Human Life History. In The Evolution of Human Life History. Hawkes, Kristen, and Paine, Richard (Editors), School of American Research Press: Santa Fe, NM.

Simpson, Scott W.

1991 Reconstructing patterns of growth disruption from enamel microstructures. In Hoppa RD, FitzGerald CM (editors), Human Growth in the past: studies from bones and teeth. Cambridge University Press: Cambridge. Pp. 241-263. 
Shimada, I., Masuda, S. and Morris, C. 1985 Andean Ecology and Civilization. University of Tokyo Press: Tokyo, Japan.

Turner, B.

2008 The servants of Machu Picchu: Life histories of populations dynamics in Late Horizon Peru. Unpublished PhD dissertation, Emory University.

Von-Hagen, A. and Morris, C.

1998 The Cities of the Ancient Andes. Thames and Hudson Ltd: London, U.K.

Wilson, D.F. and Shroff, F.R.

1970 The nature of the striae Retzius as seen with the optical microscope. In Australian Dental Journal, abstract.

Wright, L.E.

1990 Stresses of conquest: A study of Wilson bands and enamel hypoplasias in the Maya of Lamanai, Belize. In American Journal of Human Biology, 2:25-35 


\section{APPENDICES}

Appendix A: Mean and T-Test for frequencies of Wilson bands at CSN and CSMME.

\begin{tabular}{|l|l|r|r|r|r|}
\hline & Site ID & N & Mean & \multicolumn{1}{c|}{ Std. Deviation } & \multicolumn{1}{c|}{ Std. Error Mean } \\
\hline \multirow{3}{*}{ No WB } & CSMME & 15 & 1.2667 & 1.48645 & .38380 \\
\cline { 2 - 6 } & CNS & 15 & 2.2667 & 2.01660 & .52068 \\
\hline
\end{tabular}

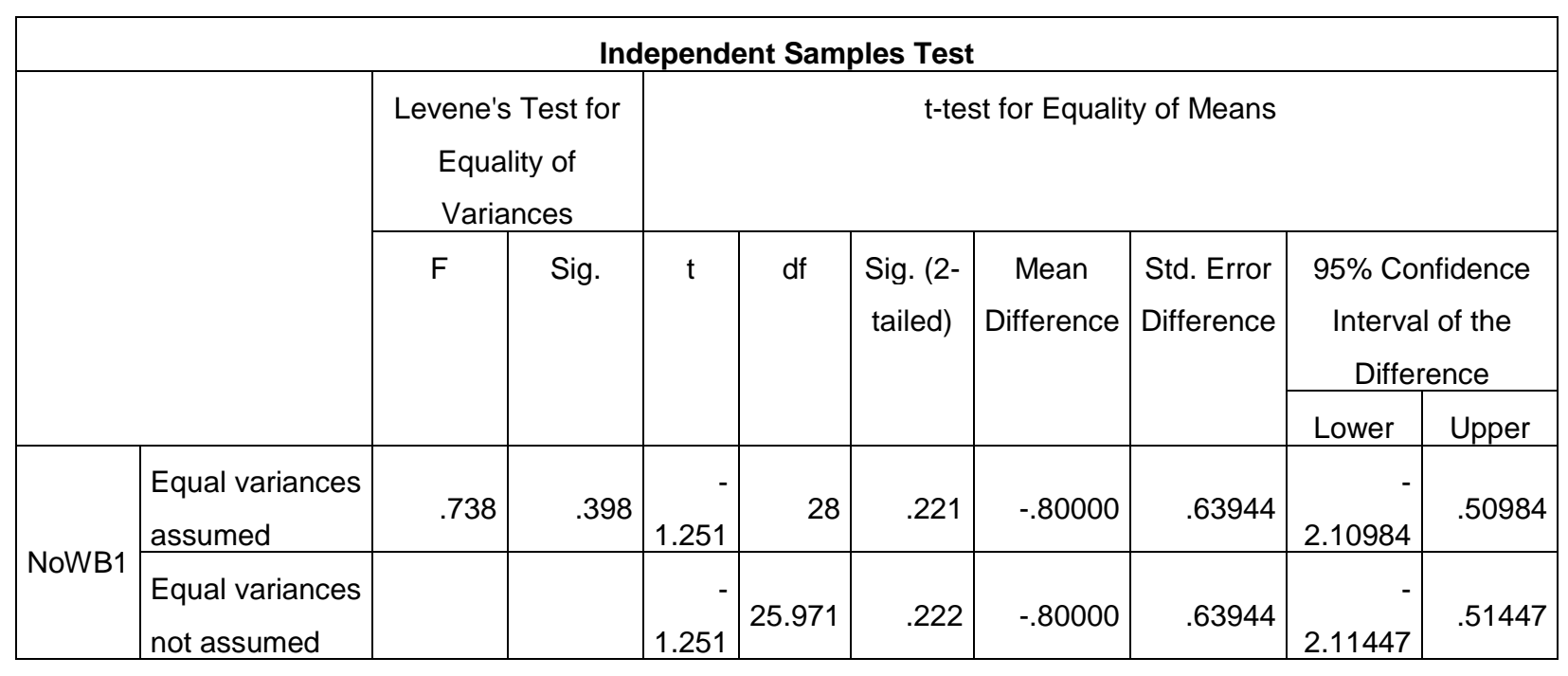

Appendix B: CSMME average age at death for individuals with and without observed hypoplasias

\begin{tabular}{|l|r|r|r|r|}
\hline & $\mathrm{N}$ & \multicolumn{1}{c|}{ Mean } & \multicolumn{1}{c|}{ Std. Deviation } & \multicolumn{1}{c|}{ Std. Error Mean } \\
\hline EH & 31 & 13.2233 & 11.92666 & 2.17750 \\
\hline No EH & 141 & 4.5121 & 8.91280 & .75327 \\
\hline
\end{tabular}

Appendix C: CSMME T-Test for age at death.

\begin{tabular}{|c|c|c|c|c|c|c|}
\hline & \multicolumn{6}{|c|}{ Test Value $=0$} \\
\hline & \multirow[t]{2}{*}{$\mathrm{t}$} & \multirow[t]{2}{*}{ df } & \multirow[t]{2}{*}{ Sig. (2-tailed) } & \multirow[t]{2}{*}{ Mean Difference } & \multicolumn{2}{|c|}{$\begin{array}{l}\text { 95\% Confidence Interval of the } \\
\text { Difference }\end{array}$} \\
\hline & & & & & Lower & Upper \\
\hline $\mathrm{EH}$ & 6.073 & 31 & .000 & 13.22333 & 8.7698 & 17.6768 \\
\hline No EH & 5.990 & 141 & .000 & 4.51214 & 3.0228 & 6.0015 \\
\hline
\end{tabular}


Appendix D: CNS average age at death for individuals with and without hypoplasias

\begin{tabular}{|l|r|r|r|r|}
\hline & $\mathrm{N}$ & Mean & Std. Deviation & \multicolumn{1}{c|}{ Std. Error Mean } \\
\hline EH & 64 & 21.5231 & 13.39876 & 1.66191 \\
\hline No EH & 120 & 12.2554 & 15.83277 & 1.43934 \\
\hline
\end{tabular}

Appendix E: CNS t-test for average age at death.

\begin{tabular}{|c|c|c|c|c|c|c|}
\hline & \multicolumn{6}{|c|}{ Test Value $=0$} \\
\hline & \multirow[t]{2}{*}{$\mathrm{T}$} & \multirow[t]{2}{*}{ df } & \multirow[t]{2}{*}{ Sig. (2-tailed) } & \multirow[t]{2}{*}{ Mean Difference } & \multicolumn{2}{|c|}{$\begin{array}{l}95 \% \text { Confidence Interval of the } \\
\text { Difference }\end{array}$} \\
\hline & & & & & Lower & Upper \\
\hline $\mathrm{EH}$ & 12.951 & 64 & .000 & 21.52308 & 18.2030 & 24.8431 \\
\hline No EH & 8.515 & 120 & .000 & 12.25537 & 9.4056 & 15.1052 \\
\hline
\end{tabular}

Appendix F: Average age at death for each site (EH and No EH combined)

\begin{tabular}{|l|r|r|r|r|}
\hline & N & \multicolumn{1}{|c|}{ Mean } & \multicolumn{1}{c|}{ Std. Deviation } & \multicolumn{1}{c|}{ Std. Error Mean } \\
\hline CSMME & 172 & 6.0494 & 10.04187 & .77018 \\
\hline CNS & 184 & 15.4941 & 15.63136 & 1.14615 \\
\hline
\end{tabular}

Appendix G: ANOVA and Post Hoc of CNS Ageclass and frequency of Wilson bands

CNSFreq

\begin{tabular}{|l|r|r|r|r|r|}
\hline & Sum of Squares & \multicolumn{1}{|c|}{ df } & Mean Square & F & \multicolumn{1}{c|}{ Sig. } \\
\hline Between Groups & 8.183 & 3 & 2.728 & 1.319 & .318 \\
\hline Within Groups & 22.750 & 11 & 2.068 & & \\
\hline Total & 30.933 & 14 & & & \\
\hline
\end{tabular}

Multiple Comparisons

Dependent Variable: CNSFreq

Tukey HSD

\begin{tabular}{|l|l|r|r|r|r|r|}
\hline (I) ID1 & (J) ID1 & $\begin{array}{r}\text { Mean Difference } \\
\text { (I-J) }\end{array}$ & Std. Error & \multicolumn{1}{c|}{ Sig. } & \multicolumn{2}{|c|}{$95 \%$ Confidence Interval } \\
\cline { 6 - 7 } & & 1.58333 & 1.09838 & .501 & -1.7223 & 4.8890 \\
\hline \multirow{2}{*}{1.00} & 2.00 & .91667 & .92830 & .759 & -1.8771 & 3.7104 \\
\cline { 2 - 7 } & 3.00 & & & & Lower Bound & Upper Bound \\
\hline
\end{tabular}




\begin{tabular}{|l|l|r|r|r|r|r|}
\hline & 4.00 & 2.25000 & 1.24545 & .321 & -1.4982 & 5.9982 \\
\hline \multirow{3}{*}{2.00} & 1.00 & -1.58333 & 1.09838 & .501 & -4.8890 & 1.7223 \\
\cline { 2 - 7 } & 3.00 & -.66667 & 1.01690 & .911 & -3.7271 & 2.3938 \\
\cline { 2 - 7 } & 4.00 & .66667 & 1.31282 & .956 & -3.2843 & 4.6176 \\
\hline \multirow{3}{*}{3.00} & 1.00 & -.91667 & .92830 & .759 & -3.7104 & 1.8771 \\
\cline { 2 - 7 } & 2.00 & .66667 & 1.01690 & .911 & -2.3938 & 3.7271 \\
\cline { 2 - 7 } & 4.00 & 1.33333 & 1.17422 & .677 & -2.2005 & 4.8672 \\
\hline \multirow{3}{*}{4.00} & 1.00 & -2.25000 & 1.24545 & .321 & -5.9982 & 1.4982 \\
\cline { 2 - 7 } & 2.00 & -.66667 & 1.31282 & .956 & -4.6176 & 3.2843 \\
\cline { 2 - 7 } & 3.00 & -1.33333 & 1.17422 & .677 & -4.8672 & 2.2005 \\
\hline
\end{tabular}

Appendix H: ANOVA and Post-Hoc test of CSMME age classes and frequency of Wilson bands

CSMMEFreq
\begin{tabular}{|l|r|r|r|r|r|}
\hline & Sum of Squares & df & Mean Square & F & Sig. \\
\hline Between Groups & 20.100 & 2 & 10.050 & 3.462 & .065 \\
\hline Within Groups & 34.833 & 12 & 2.903 & & \\
\hline Total & 54.933 & 14 & & & \\
\hline
\end{tabular}

\section{Multiple Comparisons}

Dependent Variable: CSMMEFreq

\begin{tabular}{|c|c|c|c|c|c|c|}
\hline \multirow[t]{2}{*}{ (I) ID2 } & \multirow[t]{2}{*}{ (J) ID2 } & \multirow{2}{*}{$\begin{array}{c}\text { Mean Difference } \\
(\mathrm{I}-\mathrm{J})\end{array}$} & \multirow[t]{2}{*}{ Std. Error } & \multirow[t]{2}{*}{ Sig. } & \multicolumn{2}{|c|}{ 95\% Confidence Interval } \\
\hline & & & & & Lower Bound & Upper Bound \\
\hline \multirow{2}{*}{1.00} & 3.00 & .50000 & 1.20474 & .910 & -2.7141 & 3.7141 \\
\hline & 4.00 & 2.66667 & 1.20474 & .109 & -.5474 & 5.8807 \\
\hline \multirow{2}{*}{3.00} & 1.00 & -.50000 & 1.20474 & .910 & -3.7141 & 2.7141 \\
\hline & 4.00 & 2.16667 & .98366 & .111 & -.4576 & 4.7909 \\
\hline \multirow{2}{*}{4.00} & 1.00 & -2.66667 & 1.20474 & .109 & -5.8807 & .5474 \\
\hline & 3.00 & -2.16667 & .98366 & .111 & -4.7909 & .4576 \\
\hline
\end{tabular}


Appendix I: Mann-Whitney Tests - CNS: Grouping Variable: EH

\begin{tabular}{|l|l|r|r|r|}
\multicolumn{5}{c|}{ Ranks } \\
\hline \multirow{3}{*}{ AGE } & EH & N & Mean Rank & Sum of Ranks \\
\cline { 2 - 6 } & 1.00 & 121 & 77.21 & 9342.00 \\
\cline { 2 - 6 } & 2.00 & 64 & 122.86 & 7863.00 \\
\cline { 2 - 6 } & Total & 185 & & \\
\hline
\end{tabular}

\begin{tabular}{|l|r|}
\multicolumn{2}{c}{ Test Statistics $^{\mathbf{a}}$} \\
\hline Mann-Whitney U & \multicolumn{1}{c|}{ AGE } \\
\hline Wilcoxon W & 1961.000 \\
\hline Z & 9342.000 \\
\hline Asymp. Sig. (2-tailed) & -5.526 \\
\hline
\end{tabular}

Appendix J: Mann-Whitney Test - CSMME: Grouping Variable: EH

\begin{tabular}{|r|l|r|r|r|}
\multicolumn{1}{|c|}{ Ranks } \\
\hline \multirow{3}{*}{ AGE } & EH & N & Mean Rank & Sum of Ranks \\
\cline { 2 - 5 } & 1.00 & 141 & 77.25 & 10892.50 \\
\cline { 2 - 5 } & 2.00 & 31 & 128.56 & 3985.50 \\
\cline { 2 - 5 } & Total & 172 & & \\
\hline
\end{tabular}

\section{Test Statistics $^{a}$}

\begin{tabular}{|l|r|}
\hline & \multicolumn{1}{|c|}{ AGE } \\
\hline Mann-Whitney U & 881.500 \\
\hline Wilcoxon W & 10892.500 \\
\hline Z & -5.200 \\
\hline Asymp. Sig. (2-tailed) & .000 \\
\hline
\end{tabular}


Appendix K: Mann-Whitney Test of EH and age at death: Grouping variable = Age Class

\begin{tabular}{|c|c|c|}
\hline Age Class Groupings & CNS p values & CSMME p values \\
\hline $1-2$ & .002 & .010 \\
\hline $2-3$ & .000 & .000 \\
\hline $3-4$ & .076 & .591 \\
\hline $4-5$ & .821 & .422 \\
\hline
\end{tabular}

